Aus der Klinik für Mund-, Kiefer- und Gesichtschirurgie

(Prof. Dr. med. Dr. med. dent. H. Schliephake)

im Zentrum Zahn-, Mund- und Kieferheilkunde

der Medizinischen Fakultät der Universität Göttingen

\title{
Bestimmung der relativen Kieferknochendichte mittels digitalen Messverfahrens nach Defektauffüllungen mit ß-TCP unter Berücksichtigung der klinischen Verläufe
}

\author{
INAUGURAL-DISSERTATION \\ zur Erlangung des Doktorgrades \\ für Zahnheilkunde \\ der Medizinischen Fakultät der \\ Georg-August-Universität zu Göttingen
}

vorgelegt von

Galina Blem

aus

Timirjazevo

Göttingen 2016 
Dekan:

Referent:

Ko-Referent:

Drittreferent:
Prof. Dr. rer. nat. H. K. Kroemer

Priv. Doz. Dr. Dr. A. Ludwig

Prof. Dr. J. Menke

Prof. Dr. M. Oppermann

Datum der mündlichen Prüfung: 07.03.2018 
Hiermit erkläre ich, die Dissertation mit dem Titel "Bestimmung der relativen Kieferknochendichte mittels digitalen Messverfahrens nach Defektauffüllungen mit ß-TCP unter Berücksichtigung der klinischen Verläufe" eigenständig angefertigt und keine anderen als die von mir angegebenen Quellen und Hilfsmittel verwendet zu haben.

Göttingen, den 28.11.2016 


\section{Inhaltsverzeichnis}

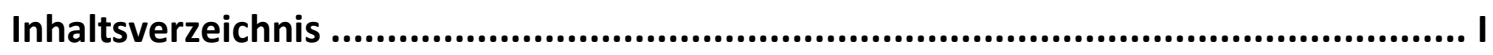

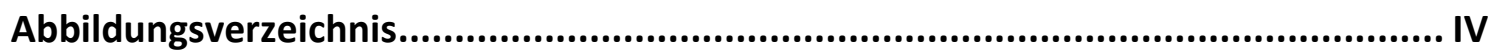

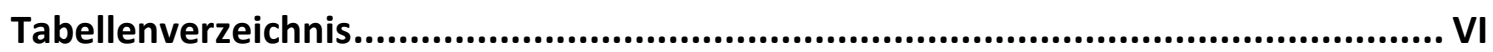

Abkürzungsverzeichnis .............................................................................. VII

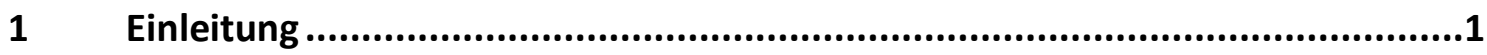

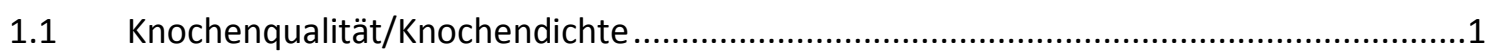

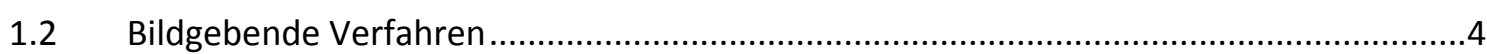

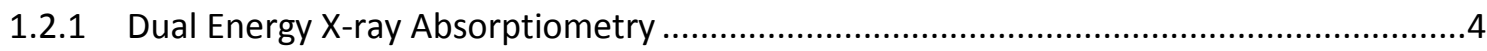

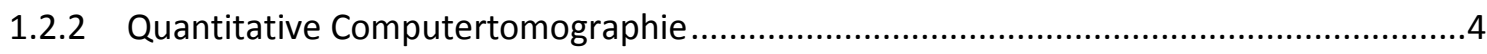

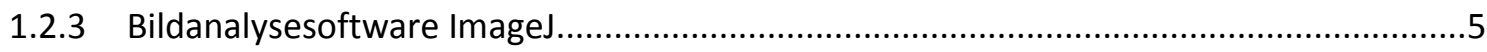

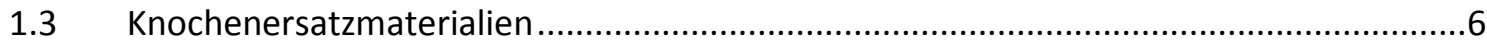

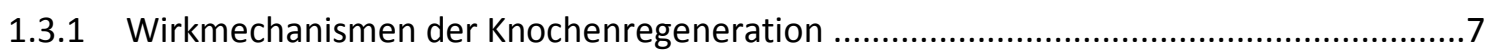

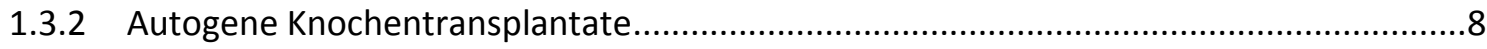

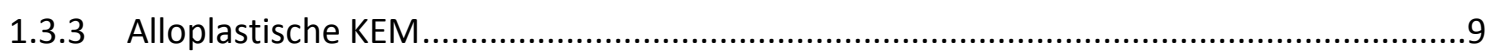

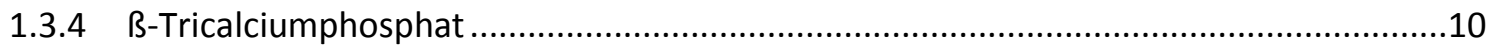

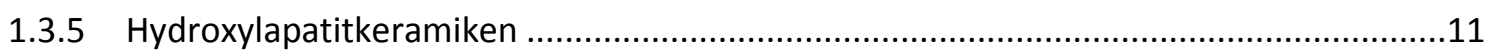

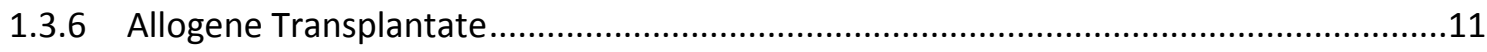

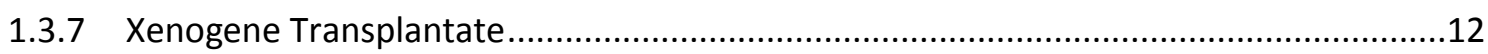

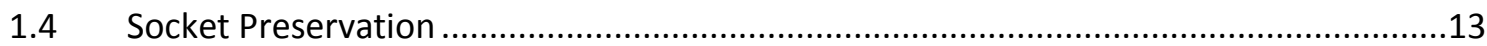

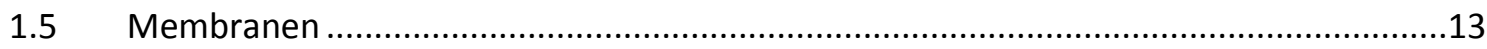

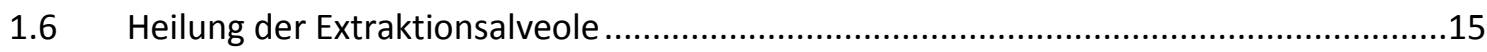

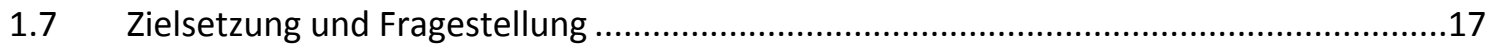

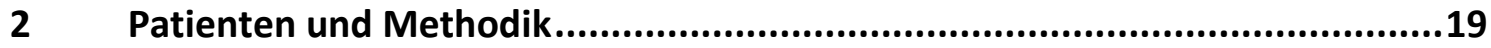

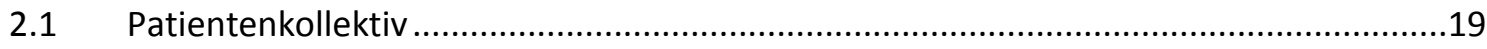

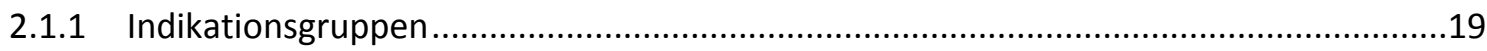

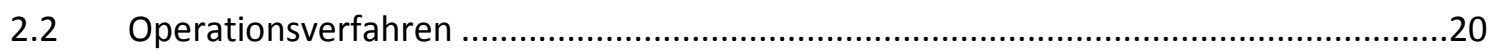

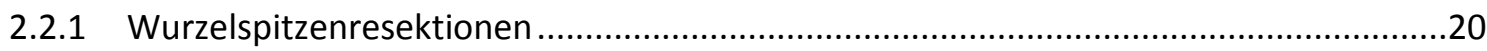

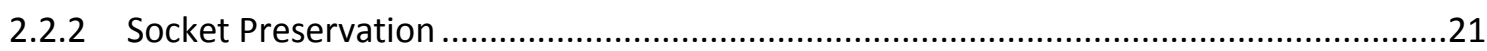

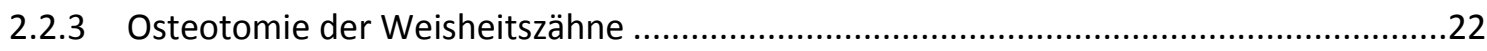

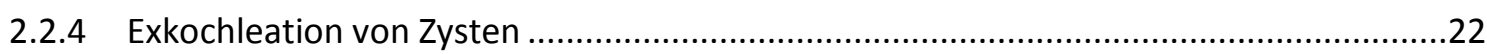

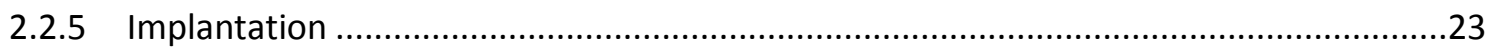

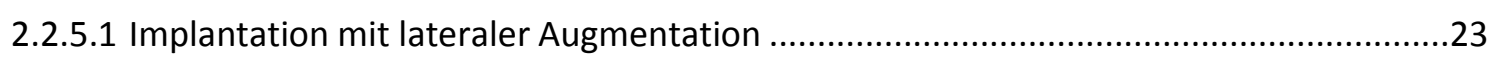

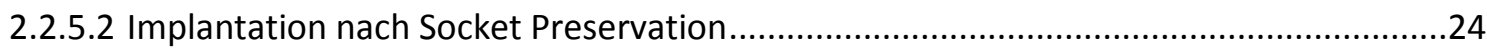

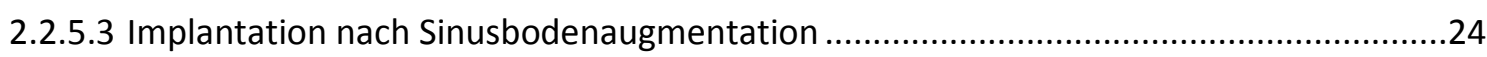




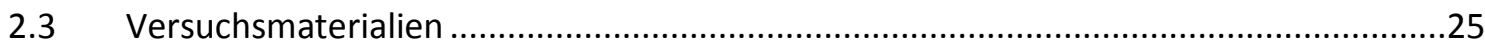

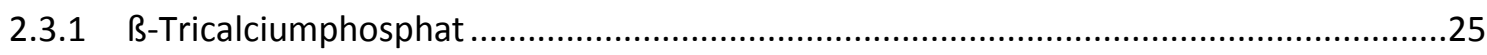

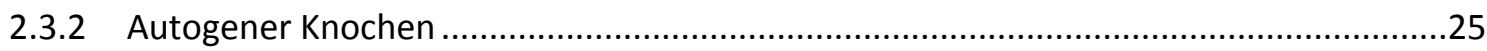

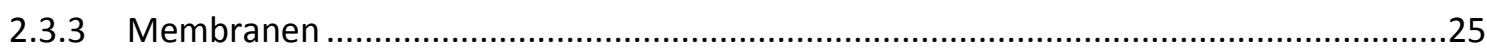

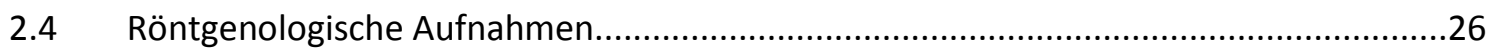

2.5 Klinische Nachuntersuchungen der Patienten .......................................................27

2.6 Messverfahren zur Berechnung der relativen Knochendichte ...................................27

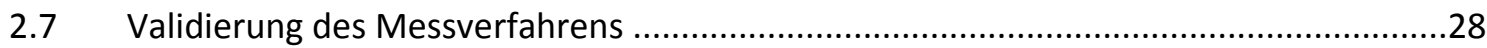

2.8 Anwendung der Bildanalyse auf einzelne Indikationsgruppen ..................................29

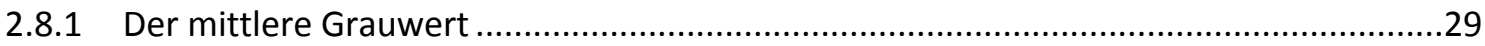

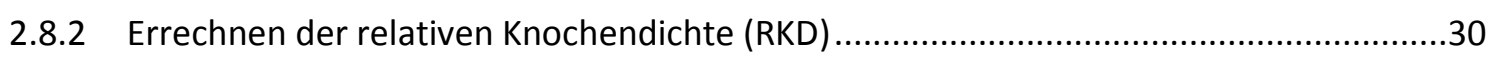

2.8.3 Anleitung zur Benutzung des Bildanalyseprogramms ImageJ ......................................30

2.9 Qualitative Beurteilung der Röntgenbilder ........................................................32

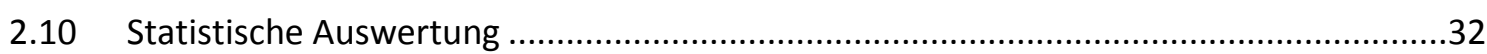

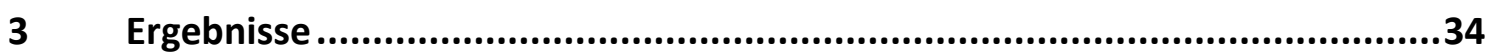

3.1 Ergebnisse der Anwenderkalibrierung zur Validierung der Messung ...........................34

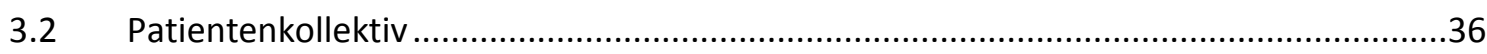

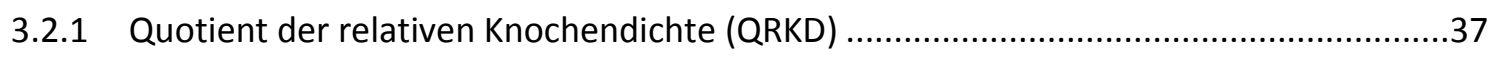

3.2.2 Quotient der relativen Knochendichte postoperativ (QRKD postoperativ) ...................39

3.2.3 Quotient der relativen Knochendichte Verlauf (QRKD Verlauf) ..................................41

3.3 Qualitative Bewertung der Röntgenbilder ...................................................43

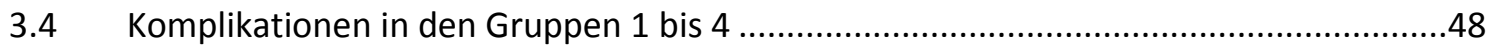

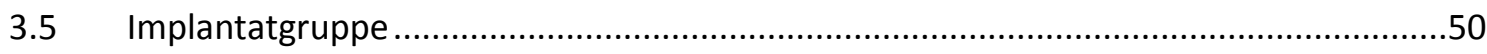

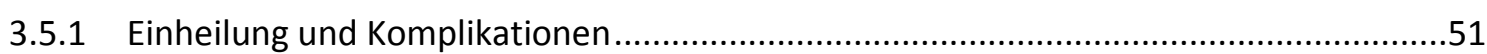

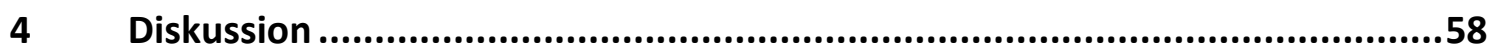

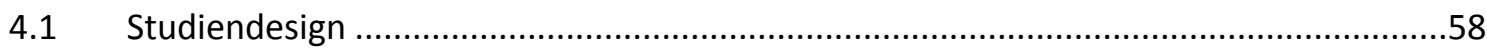

4.2 Anwenderkalibrierung zur Validierung des Messverfahrens .....................................59

4.3 Quotient der relativen Knochendichte (QRKD) .....................................................60

4.4 Kritik an der Messmethode mit Image ............................................................64

$4.5 \quad$

4.6 Betrachtung der einzelnen Indikationsgruppen ................................................65

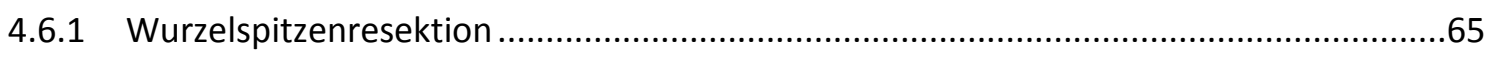

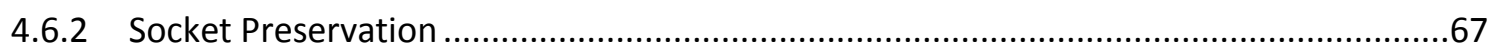

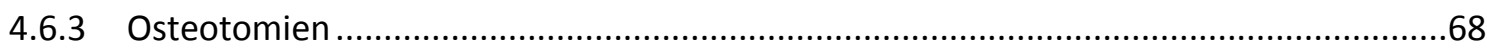

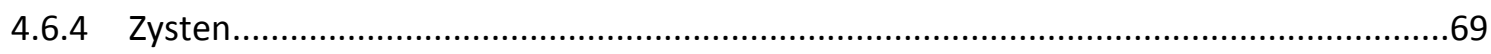

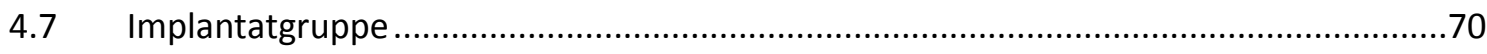

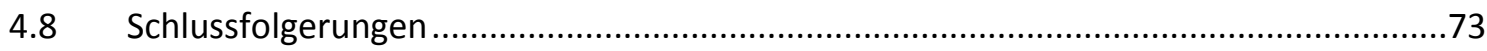

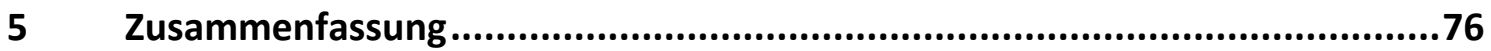




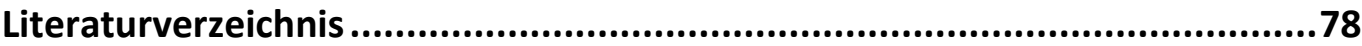




\section{Abbildungsverzeichnis}

Abbildung 1: Knochenqualitäten Klassifizierung nach Lekholm und Zarb (Spiekermann et al. 1995)

Abbildung 2: Anforderungen an Biomaterialien (Wagner und Nawas 2004)

Abbildung 3: WSR am Zahn 21 sowie Knochendefektauffüllung mit ß-TCP und postoperativem Zahnfilm

Abbildung 4: Zustand nach Zahnentfernung mit Defektaufbau zur Socket Preservation und Abdecken mit einer PRGF-Eigenblutmembran ....

Abbildung 5: Defektdarstellung, Exkochleation einer follikulären Zyste im ersten Quadranten und Knochendefektauffüllung mit ß-TCP

Abbildung 6: Implantatinsertion im ersten Quadranten mit lateralem Knochendefektaufbau mit ß-TCP, einer PLLA-Membran und PRFG-Membran zur Stabilisierung, Adaptation des Mukoperiostlappens mittels monofiler Naht

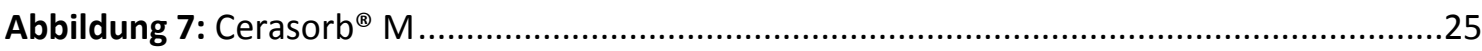

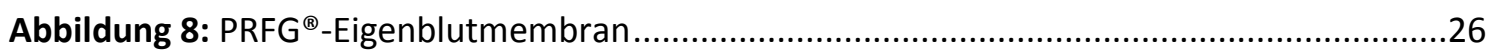

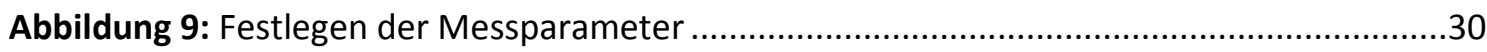

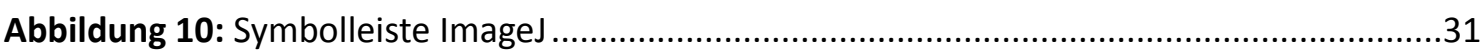

Abbildung 11: Ausgewählte ROls mit ß-TCP-augmetiertem Defekt und gesundem

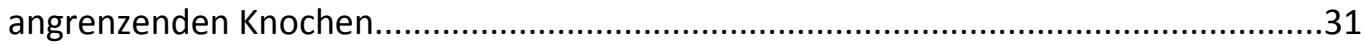

Abbildung 12: Mittelwerte der zehn gemessenen Fälle, die Punkte repräsentieren die einzelnen Untersucher

Abbildung 13: Indikationsgruppen mit Häufigkeitsverteilung der Parameter: Anzahl, Alter, Geschlecht, Ober- und Unterkiefer

Abbildung 14: Boxplot mit Median und Quartil (1. und 3. Quartil) innerhalb der Indikationsgruppen

Abbildung 15: Boxplot zur Darstellung der Knochendichtewerte postoperativ zwischen Ober- und Unterkiefer.

Abbildung 16: Scatterplot zur Darstellung des linearen Zusammenhangs zwischen QRKD postoperativ und QRKD Verlauf

Abbildung 17: Bewertungsskala für die qualitative Beurteilung der Degradation von ß-TCP auf den Röntgenaufnahmen

Abbildung 18: Augmentation mit ß-TCP bei Zustand nach Osteotomie und Zystektomie postoperativ und nach der Verlaufszeit mit dazugehörigem QRKD

Abbildung 19: Code 2 WSR postoperativ und nach der Verlaufszeit von 145 Tagen mit dem QRKD

Abbildung 20: Zustand nach Osteotomie und Zystektomie und der Verlaufszeit nach 99 Tagen

Abbildung 21: Code 4 nach WSR und im Verlauf nach 117 Tagen mit kleiner Aufhellung .........45

Abbildung 22: Zustand nach WSR und im Verlauf nach 1528 Tagen mit deutlich erkennbarer apikaler Aufhellung

Abbildung 23: Zustand nach WSR und nach 1512 Tagen mit Auftreten einer Rezidivostitis......45

Abbildung 24: Häufigkeitsverteilung der Bewertungscodes in den Gruppen eins bis vier nach röntgenologischer Beurteilung

Abbildung 25: Codierungsskala zur Beurteilung der Komplikationen 
Abbildung 26: Häufigkeitsverteilung der Bewertungscodes in den Gruppen eins bis vier zur klinischen Beurteilung von Komplikationen

Abbildung 27: Darstellung der Parameter: Anzahl, Alter, Geschlecht, Ober- und Unterkiefer mit der Häufigkeitsverteilung in den Implantatuntergruppen laterale Augmentation, Implantation nach Socket Preservation und Implantation nach Sinusbodenaugmentation

Abbildung 28: Codierungsskala zur Beurteilung von Implantateinheilung und Komplikationen

Abbildung 29: Postoperatives Röntgenbild, nach 144 Tagen und nach 279 Tagen ohne lateralen Knochenverlust

Abbildung 30: Inserierte Implantate 25-27 mit Sinuslift, Zustand nach 296 Tagen

Abbildung 31: Postoperatives Röntgenbild mit lateralem ß-TCP-Aufbau, nach 584 Tagen zeigt sich ein starker Knochenrückgang um die Implantatschulter

Abbildung 32: Zustand nach Sinuslift mit ß-TCP und Implantatinsertion regio 16 und 17, Verlust des Implantates 17 nach 69 Tagen, Verlust des Implantates 16 nach 405 Tagen

Abbildung 33: Postoperative Aufnahme nach Implantatinsertion, Periimplantitis an Implantaten 11 und 21, Aufnahmen nach 254 Tagen und nach 1250 Tagen

Abbildung 34: Tortendiagramm zeigt prozentuale Erfolgs- und Misserfolgsraten in der Gruppe der lateralen Augmentationen.

Abbildung 35: Tortendiagramm zeigt prozentuale Erfolgs- und Misserfolgsraten in der Gruppe der Implantation nach Socket Preservation

Abbildung 36: Tortendiagramm zeigt prozentuale Erfolgs- und Misserfolgsraten in der Gruppe der Implantation nach Sinusbodenaugmentation 


\section{Tabellenverzeichnis}

Tabelle 1: Kriterien der Knochenqualität nach Misch (1990) ....................................................

Tabelle 2: Materialien zum defizitären Knochenaufbau mit wichtigen Eigenschaften und Wirkungsweisen

Tabelle 3: Verwendete Implantatsysteme.

Tabelle 4: Mittelwert mit Standardabweichung der fünf Messwerte des QRKD für jeden Fall und Untersucher

Tabelle 5: Krippendorffs alpha als ein Maß für die Interrater-Reliabilität zwischen den drei Untersuchern in den Vorversuchen .....

Tabelle 6: Indikationsgruppen mit absoluten und relativen Häufigkeiten der nominalen Variablen und der metrischen Variable mit Mittelwert und Standardabweichung

Tabelle 7: Quotienten der relativen Knochendichte in den jeweiligen Indikationsgruppen mit Mittelwert, Standardabweichung und dem Zeitintervall in Tagen

Tabelle 8: Mediane der QRKD innerhalb jeder Indikationsgruppe mit dazugehöriger postoperativer Verlaufszeit in Tagen

Tabelle 9: Ergebnisse der multivariaten linearen Regression für QRKD postoperativ .39

Tabelle 10: Mittelwert mit Standardabweichung des QRKD postoperativ bei Frauen, Männern, Ober- und Unterkiefer, Komplikationsgruppe Ja/Nein sowie der p-Wert der univariaten Regressionsmodelle.

Tabelle 11: Korrelationskoeffizient nach Pearson für QRKD, das Alter und die Zeit zwischen OP und Verlauf in Tagen mit zugehörigem p-Wert

Tabelle 12: Ergebnisse der multivariaten Regression für QRKD Verlauf

Tabelle 13: Mittelwert mit Standardabweichung des QRKD Verlauf bei Frauen, Männern, Ober- und Unterkiefer, Komplikationsgruppe Ja/Nein sowie der p-Wert der univariaten Regressionsmodelle

Tabelle 14: Korrelationskoeffizient nach Pearson für QRKD Verlauf, das Alter und die Zeit zwischen OP und Verlauf in Tagen mit zugehörigem p-Wert

Tabelle 15: Absolute und relative Häufigkeiten der Bewertungscodes (Qualitative Bewertung) innerhalb jeder Indikationsgruppe

Tabelle 16: Absolute und relative Häufigkeiten der Bewertungscodes (Komplikationen) innerhalb jeder Indikationsgruppe.

Tabelle 17: Nachuntersuchungszeitraum in Tagen .50

Tabelle 18: Darstellung der absoluten und relativen Häufigkeiten bezüglich Einheilung und Komplikationen in der Implantatgruppe.

Tabelle 19: Ergebnisse der multivariaten logistischen Regression für Komplikationen $\mathrm{Ja} /$ Nein 


\section{Abkürzungsverzeichnis}

$\begin{array}{ll}\text { BMP } & \text { Bone morphogenetic protein } \\ \text { B-TCP } & \text { B-Tricalciumphosphat } \\ \text { CT } & \text { Computertomographie } \\ \text { CSD } & \text { Critical size defect } \\ \text { DFDB } & \text { Demineralized freeze-dried bone allograft } \\ \text { DGZMK } & \text { Deutsche Gesellschaft für Zahn-, Mund-, Kieferheilkunde } \\ \text { DVT } & \text { Dentale Volumentomographie } \\ \text { DXA } & \text { Dual Energy X-ray Absorptiometry } \\ \text { et al. } & \text { et alii } \\ \text { FDBA } & \text { Freeze dried bone allograft } \\ \text { GBR } & \text { Guided bone regeneration } \\ \text { GTR } & \text { Guided tissue regeneration } \\ \text { HU } & \text { Hounsfield unit/ Hounsfield-Einheiten } \\ \text { HA } & \text { Hydroxylapatit } \\ \text { IGF-I } & \text { Insulin-like-growth-factor-I } \\ \text { KEM } & \text { Knochenersatzmaterial } \\ \text { MAV } & \text { Mund-Antrum-Verbindung } \\ \text { MGK } & \text { Medizinische und Gesichtschirurgische Klinik } \\ \text { OK } & \text { Oberkiefer } \\ \text { OPG } & \text { Orthopantomogramm } \\ \text { PDGF } & \text { Platelet-derived growth factor } \\ \text { PLLA } & \text { Poly-L-lactide acid } \\ \text { PRGF } & \text { Plasma rich in growth factors } \\ \text { QRKD } & \text { Quotient relative Knochendichte } \\ \text { RKD } & \text { Relative Knochendichte } \\ \text { ROI } & \text { Region of interest } \\ \text { SZB } & \text { Seitenzahnbereich } \\ \text { TGF- } & \text { Transforming growth factor beta } \\ \text { UK } & \text { Unterkiefer } \\ \text { WKB } & \text { Wurzelkanalbehandlung } \\ \text { WF } & \text { Wurzelfüllung } \\ \text { WSR } & \text { WCT }\end{array}$




\section{$1 \quad$ Einleitung}

Bei umfangreichen implantat-prothetischen Versorgungen steht die korrekte präoperative Planung im Vordergrund. Enossale Implantate müssen primärstabil in den Knochen inseriert werden, um nach Abschluss der prothetischen Rehabilitation einwirkenden Kaukräften standhalten zu können. Einen der wichtigsten Aspekte für deren Belastungskapazität stellt die Knochenarchitektur und -struktur dar. Eine erhöhte Implantatverlustrate korreliert nach derzeitigem Erkenntnisstand mit mangelhafter Knochenqualität (Norton und Gamble 2001, Smolka et al. 2006). Unterschiede in der Knochendichte nach topografischer Lokalisation wurden bereits von verschiedenen Studiengruppen belegt (Devlin et al. 1998, Norton und Gamble 2001). Die dichteste Knochenstruktur ist demnach in der anterioren Mandibula, gefolgt von der anterioren Maxilla, der posterioren Mandibula und schließlich in der posterioren Maxilla vorzufinden (Shapurian et al. 2006). Nach Auffassung der Autoren seien diese regionalen Unterschiede in der Beschaffenheit des Kieferknochens für die unterschiedlichen Erfolgsraten bei der Implantattherapie verantwortlich (Shapurian et al. 2006, Anitua et al. 2006). Fest steht, dass die Osseointegration der Titanimplantate (Brånemark et al. 1985) speziell von Faktoren wie Knochenmineraldichte, Form, Volumen und Vaskularität des Kieferkamms abhängt, gefolgt von Faktoren wie Implantatdesign und patientenspezifischen Merkmalen (Devlin et al. 1998). Alveolarkammdefekte werden durch periradikuläre Prozesse, Traumata, pathologische Knochenläsionen, Parodontalerkrankungen sowie Zahnextraktionen ausgelöst und können zusätzlich ein unzureichendes Knochenvolumen mit ungünstigen Kammformen für die spätere Implantation hervorrufen (Nevins und Mellonig 1999). Präoperative Vorhersagbarkeit der Knochenqualität und -quantität besitzt insofern enorme klinische Relevanz in Bezug auf dentale Implantatinsertion und die nachfolgende prothetische Versorgung.

\subsection{Knochenqualität/Knochendichte}

In der Vergangenheit sind Klassifizierungen der Knochenqualität und der makroskopischen Struktur vorgenommen worden. Dazu gehören radiologische Untersuchungen am anterioren Kieferknochen von Lekholm und Zarb im Jahre 1985. Ihre Klassifizierung teilte die Knochenqualitäten - unter Zuhilfenahme von Hounsfield Einheiten (HU) aus der CT-Diagnostik - in vier Klassen ein (Abb. 1). Bezogen auf die Morphologiestruktur der spongiösen und kortikalen Anteile stellt sich die Differenzierung wie folgt dar: 
Typ 1: $\quad$ Homogener kompakter Knochen, wenig Spongiosa

Typ 2: $\quad$ Breite Kompaktaschicht umgibt dichte Spongiosa

Typ 3: Dünne Kompaktaschicht umgibt dichte Spongiosa

Typ 4: Dünne Kompaktaschicht umgibt weitmaschige, lockere Spongiosa

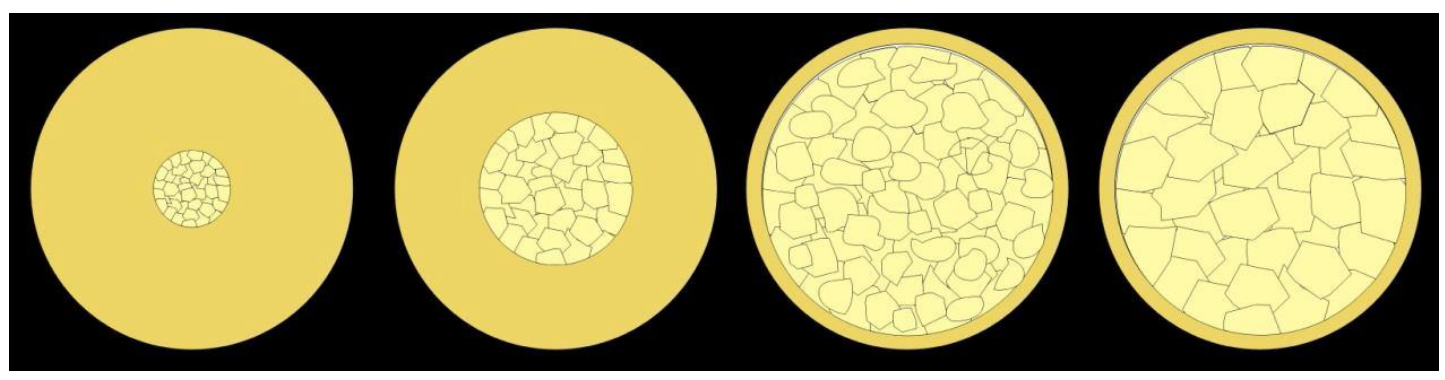

Typ 1

Typ 2

Typ 3

Typ 4

Abbildung 1: Knochenqualitäten Klassifizierung nach Lekholm und Zarb (Spiekermann et al. 1995)

In der humanen Mandibula sind hauptsächlich Knochenqualitäten vom Typ 1 oder Typ 2 mit einer hohen Dichte und in der Maxilla die Qualitäten vom Typ 3 oder Typ 4 mit einer weitmaschigen Knochenstruktur vertreten (Lekholm und Zarb 1985). Weiterführend entwickelten Misch und Judy (1987) die Klassifizierung der Knochenqualitäten D1 bis D4 nach klinisch-praktischen Kriterien im Hinblick auf die implantologische Wertigkeit (Tab.1). Die Klassen sind knöchernen Kieferstrukturen topografisch zugeordnet und weisen auf Problematiken in bestimmten Knochenklassen bei der Insertion von enossalen Implantaten hin (Spiekermann et al. 1995). 
Tabelle 1: Kriterien der Knochenqualität nach Misch (1990)

\begin{tabular}{|c|c|c|c|c|}
\hline Knochenqualität & D1 & D2 & D3 & D4 \\
\hline \multirow{3}{*}{$\begin{array}{l}\text { Kompakta } \\
\text { Spongiosa } \\
\text { Lokalisation }\end{array}$} & dicht & dicht-porös & dünn-porös & \\
\hline & & engmaschig & weitmaschig & weitmaschig \\
\hline & $\begin{array}{l}\text { UK-Front, } \\
\text { atrophiert, } \\
\text { zahnlos }\end{array}$ & $\begin{array}{l}\text { UK, OK-Front } \\
\text { palatinal }\end{array}$ & $\begin{array}{l}\text { UK und OK SZB, OK } \\
\text { fazial }\end{array}$ & Tuberbereich \\
\hline \multirow{2}{*}{$\begin{array}{l}\text { Blutversorgung } \\
\text { Implantation }\end{array}$} & reduziert & gut & gut & gut \\
\hline & $\begin{array}{l}\text { schwierig, } \\
\text { Gefahr der } \\
\text { Überhitzung }\end{array}$ & ideal & $\begin{array}{l}\text { Gefahr der } \\
\text { Erweiterung des } \\
\text { Bohrlochs }\end{array}$ & \\
\hline \multirow{2}{*}{$\begin{array}{l}\text { Primärstabilität } \\
\text { Klinik }\end{array}$} & gut & gut & gering & sehr gering \\
\hline & $\begin{array}{l}\text { geringe } \\
\text { vertikale } \\
\text { Höhe, } \\
\text { Einheilzeit } \\
\text { verlängert }\end{array}$ & $\begin{array}{l}\text { optimale } \\
\text { Bedingungen }\end{array}$ & \multicolumn{2}{|c|}{$\begin{array}{l}\text { Knochenkondensation erforderlich, } \\
\text { Vermehrung von Implantatpfeilern, } \\
\text { Knochenfläche max. ausnutzen }\end{array}$} \\
\hline
\end{tabular}

Diese Einteilungen wurden als Grundlage für Knochendichtemessungen genutzt (Norton und Gamble 2001, Smolka et al. 2006, Anitua et al. 2006), sie reichen jedoch nicht aus, um komplizierte regenerative Knochenstrukturen zu beschreiben, zumal sich bei nicht standardisierten Beurteilungskriterien eine breite Varianz in der interindividuellen Untersucherbeurteilung ergeben kann. Knochenqualität ist zudem ein breit gefächerter Begriff, der verschiedene Eigenschaften wie Knochengröße, geometrische Form, Makro- und Mikrostruktur beschreibt und sich nach Meinung von Felsenberg und Boonen (2005) nicht allein durch Messung der Knochenmineraldichte bestimmen lässt. Nichtsdestoweniger stehen dem Implantologen heutzutage einige bildgebende Verfahren zur Orientierung bezüglich präoperativer Knochendichte zur Verfügung. Dazu gehören radiologische Messungen mittels Dual Energy X-ray Absorptiometry (DXA) (Devlin et al. 1998, Klemetti und Vainio 1993), das Computertomogramm (CT) (Smolka et al. 2006, Norton und Gamble 2001), die Densitometrie (Devlin et al. 1998, Zhao et al. 2010) und die Bildanalyse der Röntgenbilder mit digitalen Programmen (Chiapasco et al. 2000, Saldanha et al. 2006, Ihan Hren und Miljavec 2008).

Der Vollständigkeit halber seien auch die histomorphometrische Beurteilung der Knochenstruktur, jedoch eher im Rahmen klinischer prospektiver Studien (Götz 2014), sowie die intraoperative Erfassung des Bohrwiderstandes durch den Operateur zum Rückschluss auf die Knochendichte und -struktur zu erwähnen. Letztere Methode ist ein rein subjektives Verfahren und ausschließlich auf die klinische Erfahrung und das Geschick des Implantologen zurückzuführen (Truhlar et al. 1997). 


\subsection{Bildgebende Verfahren}

Unterschiedliche wissenschaftliche Verfahren stehen für die Beobachtung des Heilungsverlaufs im Knochen zur Verfügung. Die klinische Begutachtung als Grundlage der Befunderhebung und engmaschiger Kontrollen wird meist durch bildgebende Diagnostik ergänzt. Ein Orthopantomogramm (OPG) liefert zweidimensionale Übersichtsaufnahmen der dentoalveolären Strukturen und angrenzender skelettaler Bereiche zur Abklärung kariologischer, endodontischer, parodontologischer und oralchirurgischer Fragestellungen (Bock 2011). Dreidimensionale Aufnahmen mittels dentaler Volumentomographie (DVT) oder Computertomographie (CT) generieren zusätzlich Daten zur Feststellung ossärer Ausdehnung in vertikaler, horizontaler und transversaler Richtung im Kopf-Hals-Bereich. Pathologische Befunde können durch Navigation in einzelnen Schichtebenen erfasst werden. Im Hinblick auf die Planung dentaler Implantate ermöglichen dreidimensionale Röntgenverfahren, anatomische Gegebenheiten besser beurteilen zu können. Die genaue Abbildung der Kieferhöhlen und des Canalis mandibulae minimiert die Gefahr einer iatrogenen Verletzung dieser Strukturen. Sie dienen des Weiteren zur Darstellung der Knochendichte, die wiederum zur präoperativen Einschätzung der Knochenqualität genutzt werden kann.

\subsubsection{Dual Energy X-ray Absorptiometry}

Die DXA ist ein zweidimensionales röntgenologisches Messverfahren zur Bestimmung der Knochenmineraldichte des skelettalen Knochens bezogen auf die Fläche in $\mathrm{cm}^{2}$. Das Prinzip beruht auf emittierten Photonenstrahlen zweier unterschiedlicher Energiegrade, die auf verschiedene Detektoren geleitet werden. Die Knochenmineraldichte wird aus der Menge der Strahlung errechnet, die durch den Knochen hindurchtritt und die Einheit Mineralgehalt pro Fläche $\left(\mathrm{g} / \mathrm{cm}^{2}\right)$ besitzt. Absorptionsbedingte Unterschiede zwischen Knochen und Weichgewebe werden computergestützt ermittelt. Unerwünschte Werte der Weichteilabsorption werden aus der Messung eliminiert. Gegenüber dem CT ist die Strahlenbelastung des Patienten reduziert (5-10 $\mu \mathrm{Sv}$ / Messung), nachteilig sind die hohen Kosten gegenüber Standardverfahren und die Durchführbarkeit in speziellen Zentren (Devlin et al. 1998).

\subsubsection{Quantitative Computertomographie}

Die beste radiologische Aussagekraft zur morphologischen und qualitativen Analyse des Knochens besitzt jedoch das CT (Smolka et al. 2006). Die quantitative Computertomographie (qCT) gilt bisher als das einzige nicht-invasive Verfahren, um trabekuläre Knochenmineralisation als Aspekt der Knochenqualität unabhängig von der kortikalen 
Begrenzung beurteilen zu können (Lindh et al. 1996). Die Knochendichte wird dabei in Hounsfield-Einheiten (HU) angegeben (Norton und Gamble 2001) und in einer Vergleichsmessung gegenüber Wasser mit dem Wert 0 (HU) festgelegt. Während der Aufnahme führt der Patient einen Eichstandard aus Hydroxylapatit mit sich, der zur Umrechnung ermittelter HU dient, um eine präzise Aussage über den Knochenmineralgehalt in $\mathrm{mg} / \mathrm{cm}^{3}$ zu erhalten (Cann und Genant 1980).

Der Informationsgehalt beschränkt sich bei allen Methoden dennoch nur auf den Mineralisationsgrad und nicht auf den trabekulären Zustand des Knochengerüsts (Schwenzer und Ehrenfeld 2000). Bei Vorhandensein von Metallrestaurationen im Mund können sich Verzeichnungen mit Metallartefaktdarstellung ergeben und die Bildqualität in diesen Bereichen herabsetzen. Der Untersuchte wird außerdem einer relativ hohen ionisierenden Strahlung ausgesetzt. Im Hinblick auf den Strahlenschutz wird nach der Röntgenverordnung (RöV §23) eine rechtfertigende Indikation gefordert, die erst nach gründlicher Abwägung zwischen gesundheitlichem Nutzen und Strahlenrisiko gestellt werden darf. Aufnahmetechniken mit geringerer Strahlenexposition und einem vergleichbaren gesundheitlichen Nutzen sind laut genannten Richtlinien Aufnahmen mit höheren Dosiswerten vorzuziehen.

\subsubsection{Bildanalysesoftware ImageJ}

In röntgenologischen Aufnahmen sichtbare Knochendichteabnahme ist das Resultat von Dekalzifikation und Reduktion trabekulären Knochens, deshalb kann eine direkte Korrelation zwischen Knochendichte und Knochenqualität angenommen werden (Norton und Gamble 2001). Allgemein bekannt ist die Tatsache, dass Weichteil- und Knochenstrukturen die einfallende Röntgenstrahlung unterschiedlich stark absorbieren. Dichte Strukturen wie Zahnschmelz und Knochen absorbieren stärker, sodass sich strahlenarme Bereiche im Röntgenbild heller darstellen lassen als anatomische Strukturen wie Kieferhöhlen, welche aufgrund geringer Absorption dunkel erscheinen. Diese Unterschiede des Schwärzungsgrades eines digitalen Röntgenbildes können unter Zuhilfenahme eines digitalen Bildanalyseprogramms in Grauwertstufen umgerechnet werden.

Das in dieser Studie angewendete Programm ImageJ (Wayne Rasband, National Institutes of Health, USA) besitzt eine Grauwertskala von 0-255. Jedem Bildpunkt (Pixel) ist ein Grauwert zugeordnet, dabei repräsentiert 0 den schwarzen Punkt und 255 den weißen. In einer ausgewählten region of interest (ROI) im digitalen Röntgenbild können auf diese Weise Pixel unterschiedlicher Grauwerttonalitäten zusammengerechnet werden und ergeben einen Wert. Bei besonders strahlenarmen Strukturen 
(Zahn, Knochen, KEM) ergeben sich höhere Werte als bei strahlenreichen Strukturen (Kieferhöhlen, apikale Aufhellungen, Zysten). Die Verwendung von Referenzwerten, die auf zu vergleichenden Röntgenbildern ihre Dimension beibehalten wie Messkugeln, Zähne oder definierte Knochenareale, dienen der Kontrolle. Auf diese Art lassen sich Knochendichtewerte auf unterschiedlichen Röntgenbildern vergleichen und Aussagen über die Knochenregeneration ableiten (Chiapasco et al. 2000).

Prospektive klinische Untersuchungen sind in der Vergangenheit vor allem in Leerdefekten nach Zystektomien durchgeführt worden (Chiapasco et al. 2000, Shokier und Khalifa 2009, Zhao et al. 2010). Diese Knochenkavitäten lassen sich röntgenologisch besonders gut darstellen und von dem umliegenden gesunden Knochen abgrenzen.

Eine systematische Evaluation zur Überprüfung der Zuverlässigkeit des Messverfahrens unter verschiedenen Untersuchern ist in veröffentlichten wissenschaftlichen Arbeiten bisher nicht beschrieben worden. Eine rein subjektive Beurteilung von Röntgenaufnahmen kann eine Verzerrung und ungenaue Bewertung des Heilungsverlaufs ergeben (Gelfand et al. 1983, Zakariasen et al. 1984). Aus diesem Grund ist die Überlegung ein objektivierbares und vom Untersucher unabhängiges Verfahren mithilfe digitaler Messtechnik zur Diagnosesicherung in den Praxisalltag zu integrieren sinnvoll.

\subsection{Knochenersatzmaterialien}

Knochenersatzmaterialien (KEM) sind zur Unterstützung der Regeneration eines defizitären Knochens entwickelt worden. Eine Vielzahl an biologischen und synthetischen Materialien mit ähnlicher klinischer Anwendbarkeit finden inzwischen einfach, sicher, kostengünstig und effizient in der Zahnmedizin und Chirurgie ihre Anwendung (Horowitz et al. 2009c). Mitte des 19. Jahrhunderts setzten sich Barth und Ollier zeitgleich mit dem Thema Knochenersatz in tierexperimentellen Untersuchungen auseinander (Barth 1893, Barth 1895). Daraus resultierten die noch heute gültigen Anforderungen an ein KEM, das zur Gruppe der Biomaterialien gehört und folgende biologische sowie mechanische Eigenschaften erfüllen sollte: 


\section{Biologische Eigenschaften}

•keine Toxizität, Kanzerogenität

-keine antigenen Reaktionen

-keine Infektiosität

-Sterilisierbarkeit

- biologische Stabilität

- Resorbierbarkeit
Mechanische Eigenschaften

-Formstabilität

- mechanische Belastbarkeit

-Radioopazität

Abbildung 2: Anforderungen an Biomaterialien (Wagner und Nawas 2004)

Augmentationsmaterialien können nach ihrer biologischen oder synthetischen Herkunft (autogen, allogen, xenogen, alloplastisch) eingeteilt werden (Misch und Dietsch 1993, Bauer und Muschler 2000). Der Ursprung des Materials bestimmt die Terminologie bei dessen Insertion. Kommt ein biologisches Material zum Einsatz, wird es als Transplantation bezeichnet, bei synthetischen Produkten spricht man von einer Implantation (Gernreich et al. 2003). Weitere Unterscheidungsmerkmale richten sich nach dem Einheilungsverhalten und dem Wirkmechanismus der Knochenregeneration (Osteogenese, Osteoinduktion, Osteokonduktion) (Schenk 1991, Horowitz et al. 2009c, Khoury und Hanser 2009).

\subsubsection{Wirkmechanismen der Knochenregeneration}

Zur Unterstützung der Knochenregeneration kommen unterschiedliche Augmentationstechniken zum Einsatz, die grundsätzlich drei Wirkmechanismen während der Einheilung unterliegen: Osteokonduktion, Osteoinduktion und Osteogenese.

Osteokonduktion bezeichnet die Funktion des porösen Materials als Leitschiene zur Defektüberbrückung, entlang welcher es zur Einsprossung von Gefäßen und knochenbildenden Zellen kommt und sich körpereigener Knochen formt (Schenk 1991). Dabei ist die Struktur und Porengröße des Augmentationsmaterials ausschlaggebend, sie sollten eine Penetration von Osteoprogenitorzellen zulassen sowie die Knochenapposition fördern. Schließlich ist auch die Resorptionsfähigkeit eine entscheidende Voraussetzung, um Platz für den neu gebildeten Knochen bereitzustellen (Khoury und Hanser 2009). Die Dynamik des Umbauvorgangs im Knochen sollte im besten Fall simultan zur Resorption des KEMs erfolgen. Eine zu schnell voranschreitende Degradation des aufgefüllten Materials würde nicht seine osteokonduktive Funktion als Leitgerüst und Platzhalter erfüllen, es käme zum Einwachsen des Weichgewebes in die Defekthöhle. Eine zu langsame Degradation andererseits könnte die Neuformierung des Knochens verlangsamen oder sogar 
behindern. Damit ist vor allem die Porosität des Augmentationsmaterials für dessen mechanische und biologische Eigenschaften entscheidend (Horowitz et al. 2009c).

Osteogenese bedingt das Überleben der Präosteoblasten und Osteoblasten im Transplantat, um neuen Knochen synthetisieren zu können. Dazu sind bisher nur autogene Knochentransplantate imstande, weil bei einer Augmentation mit KEM keine Zellen übertragen werden (Khoury und Hanser 2009). Die höchste osteogene Potenz weist bislang nur die gut revaskularisierte Spongiosa auf (Merten et al. 2003).

Bei der Osteoinduktion regen Mediatoren, zum Beispiel die bone morphogenetic proteins (BMPs), die ortsständigen Knochenzellen und Mesenchymzellen zur Teilung, Differenzierung und Sekretion an. Daraufhin wird neuer Knochen verstärkt synthetisiert (Zhang et al. 1997, Khoury und Hanser 2009).

Ein ideales knochenanaloges Defektmaterial sollte, wenn möglich, diese drei Kardialanforderungen erfüllen, was bisher nur dem autogenen Knochentransplantat gelingt, welches demzufolge als Bewertungsmaßstab zum Vergleich mit körperfremden Aufbaumaterialien definiert wird (Merten et al. 2003).

\subsubsection{Autogene Knochentransplantate}

Autogener Knochen wird bei einem Patienten an einer Donorstelle entnommen und in eine andere Empfängerregion im selben Körper transplantiert. Als Donorstelle kann der Kieferknochen der Retromolarregion, des Unterkieferwinkels oder der Kinnregion fungieren (Jensen und Sindet-Petersen 1991). Bei größeren oralen Knochendefekten können extraorale Entnahmestellen wie der Beckenkamm, Scapula, Fibula, Rippenbogen, Tibia oder die Schädelkalotte (Calvarium) verwendet werden (Donovan et al. 1994, Smolka et al. 2006, Khoury und Hanser 2009). Für kleinere augmentative Maßnahmen sind Kortikalis- und Spongiosachips, beispielsweise nach Entnahme aus dem Implantatbohrloch, mit bestätigter Wirksamkeit und einem kaum bestehenden Unterschied der biologischen Eigenschaften meist ausreichend (Merten et al. 2003).

Das oft als "Goldstandard" beschriebene autogene Transplantat erfüllt die biologischen Anforderungen an ein ideales Augmentationsmaterial und gilt prinzipiell als die sicherste Form für den Patienten im Hinblick auf die osteogene Neuformation, dank fehlender immunologischer Abstoßungsreaktionen (Schwenzer und Ehrenfeld 2008, Khoury und Hanser 2009, Smeets et al. 2014b). Ein avaskuläres, frisch entnommenes Transplantat, beispielsweise vom Beckenkamm (Crista iliaca superior), stellt meist ein Reservoir an wichtigen Wachstumsfaktoren (z. B. PDGF, TGF-ß), vitalen mesenchymalen Stammzellen, Osteoblasten sowie Osteoprogenitorzellen zur Verfügung und besitzt somit die höchste biologische Wertigkeit im Vergleich zu 
anderen Augmentationsmaterialien (Schwenzer und Ehrenfeld 2009). Durch Bereitstellung dieser Zellen kann das osteoinduktive und osteogene Potential ausgenutzt werden, sodass ein vollständiger Umbau zu ortsständigem Knochen abläuft (Khoury und Hanser 2009). Das Überleben der transplantierten vitalen Zellen im Empfängergebiet ist dennoch nicht immer sichergestellt und kann zum Scheitern der genannten Eigenschaften des Spongiosatransplantates führen (Sandhu et al. 1999). Wenngleich der Eigenknochen die besten Eigenschaften und Anforderungen an ein ideales KEM erfüllt, ist die Verwendung mit vielen Risiken verbunden, insbesondere bei der Entnahme aus extraoralen Spenderregionen. Zum einen ist die Verfügbarkeit limitiert, zum anderen nimmt die Qualität der Spongiosa mit zunehmendem Alter ab (Marx und Garg 1998). Risiken wie Blutungen, Infektionen, Schmerzen, neurologische Schädigungen sowohl bei der Entnahme als auch beim Zweiteingriff sind nicht zu unterschätzen (Niedhart et al. 2003). Überdies stellt die Vollnarkose und Entnahmemorbidität für den Patienten eine zusätzliche Belastung dar (Jäger et al. 2005, Plenk und Lederer 2008). Weitere Nachteile sind in der Notwendigkeit eines Zweiteingriffs und den höheren wirtschaftlichen Kosten zu sehen (Szabo et al. 2005). In der klinischen Anwendung fanden Arbeitsgruppen heraus, dass transplantierte Spongiosa vom Beckenkamm nach Socket Preservation mit starken Höhenverlusten einherging (Swart und Allard 1985, Vermeeren et al. 1996, Verhoeven et al. 1997). In volumetrischen Untersuchungen von Donovan et al. (1993) und Johansson et al. (2001) trat sogar ein Verlust von $50 \%$ des augmentierten Beckenknochens nach bereits sechs Monaten ein.

Mit dem Ziel das autogene Transplantat aufgrund genannter Risiken und begrenzter Verfügbarkeit ersetzen zu können, sind frühzeitig Knochenersatzmaterialien entwickelt worden.

\subsubsection{Alloplastische KEM}

Menschlicher Knochen ist $\mathrm{zu}$ rund $70 \%$ aus Calcium $\left(\mathrm{Ca}^{2+}\right)$ und Phosphat $\left(\mathrm{PO}_{4}{ }^{3-}\right)$ in Form von modifiziertem Hydroxylapatit zusammengesetzt, die restlichen $30 \%$ bestehen aus Wasser sowie organischen Bestandteilen (Felsenberg 2001). Auf der Basis dieser chemischen Elemente werden durch Regulierung der Zusammensetzung verschiedene Materialien synthetisch hergestellt, die sich primär durch ihre Resorptionsrate unterscheiden. Alloplastische Materialien, die am häufigsten in der Oralchirurgie zum Einsatz kommen, sind ß-Tricalciumphosphat (ß-TCP; $\left.\mathrm{Ca}_{3}\left(\mathrm{PO}_{4}\right)_{2}\right)$, Hydroxylapatit $\left(\mathrm{HA} ; \mathrm{Ca}_{10}\left(\mathrm{PO}_{4}\right)_{6}(\mathrm{OH})_{2}\right)$ und biphasisches Calciumphosphat (B-TCP + HA) (Ruffieux und Köhli 2010). Calciumphosphate werden seit über 25 Jahren erfolgreich verwendet und sind wissenschaftlich umfassend dokumentiert (Le Geros 1988). 


\subsection{4 ß-Tricalciumphosphat}

Das ß-TCP (Cerasorb ${ }^{\circledR}$ M, Curasan AG, Kleinostheim) ist ein synthetisches, phasenreines ( $\geq 99 \%$ ) und resorbierbares Material in Form eines polygonalen Granulats (Tadic und Epple 2004). Es findet Anwendung in der Oralchirurgie zur Sinusbodenaugmentation (Zerbo et al. 2004, Knabe et al. 2008), zur Auffüllung von Defekten nach Zystektomien (Zerbo et al. 2001) und Wurzelspitzenresektionen, zur Socket Preservation sowie im Bereich der gesteuerten Knochenregeneration (GBR) als vorbereitende Maßnahme zur Verbesserung des Implantatlagers (Plenk und Lederer 2008).

Die Oberfläche ist unregelmäßig geformt, um das Verkanten in der Defekthöhle zu ermöglichen und damit Mikrobewegungen während der Einheilungsphase zu verhindern. Das Material verfügt über eine interkonnektierende, offen gestaltete Multiporosität von circa 65 \% bestehend aus Mikro-, Meso- und Makroporen, die eine Zellversorgung und durchgängige Angiogenese begünstigen soll (Bohner und Baumgart 2004, Peters und Reif 2004, Palm et al. 2006, Bilk 2007). Die ins Zentrum der Partikel wirkenden Kapillarkräfte fördern die osteogene Zellproliferation und den Stoffwechsel über die Blutzirkulation (Eggli 1987, Lu et al. 1999). Das offene Porensystem ermöglicht weiterhin einen Austausch von Nähr- und Botenstoffen mit dem Vorteil, dass sich Keime nicht in die Poren einschließen und sich dem zellulären Abwehrmechanismus des Körpers entziehen können (Palm et al. 2006, Lan Levengood et al. 2010). In den größeren Makro- und Mesoporen ist Raum für einsprossende Blutgefäße und die Knochenneubildung als Voraussetzung für eine frühzeitige Angiogenese und Vaskularisation. Sowohl aufgrund der osteokonduktiven Eigenschaften als auch der vergleichsweise vorhersagbaren Resorptionsfähigkeit von ß-TCP findet simultan zur aktiven Zellvermehrung und Knochenbildung der Resorptionsprozess des Granulats statt. Eine vorzeitige Auflösung des Materials unterbleibt und die Neubildung des Knochens bildet sich weitgehend synchron zur Degradation (Merten et al. 2003, Bilk 2007). Eine durchschnittliche Primärpartikelgröße von $7-10 \mu \mathrm{m}$ sollte bei der Herstellung des Biomaterials nicht unterschritten werden, um eine zu frühe Degradation in kleine Partikel und damit eine Entzündungsreaktion im umgebenden Gewebe (Peters und Reif 2004) oder den Abtransport in die benachbarten Lymphknoten zu vermeiden (De Groot 1988). Bei ß-TCP gelingt es durch steuerbare Sinterungsprozesse genau definierte physikalische und chemische Materialeigenschaften zu erzeugen, die das Material zu einem qualitativ hochwertigen und in seinem biologischen Verhalten vorhersagbaren Produkt machen (Peters und Reif 2004). 
Im Körper wird das ß-TCP durch zwei Mechanismen abgebaut. Zunächst kommt es zur physiologischen Hydrolyse mit Freiwerden von Calcium- und Phosphationen (Zerbo et al. 2005, Knabe et al. 2008). Auf der zellulären Ebene erfolgt der Abbau durch multinukleäre, osteoklastenähnliche Zellen und mononukleäre Phagozyten (Kondo et al. 2005, Nair et al. 2006, Horowitz et al. 2009c, Kolk et al. 2012) ohne Reizung des umliegenden Gewebes nach circa vier bis zwölf Monaten. Grundvoraussetzung ist das Entfernen des pathologischen Gewebes vor dem Einbringen des mit Defektblut getränkten ß-TCPs, um einen direkten Kontakt mit dem Lagerknochen zu gewährleisten (Palti und Hoch 2002b, Palm et al. 2006, Bilk 2007).

\subsubsection{Hydroxylapatitkeramiken}

Die synthetisch hergestellten Hydroxylapatitkeramiken sind aus hochkristallinem Hydroxylapatit aufgebaut und damit ein schwer lösliches Material mit der geringsten Resorptionsrate (Tadic und Epple 2004, Ruffieux und Köhli 2010). Während das HA eine höhere biomechanische Belastbarkeit aufweist (Maus et al. 2007), zeichnet sich beispielsweise das ß-TCP-Granulat besonders in der Resorptionskinetik durch simultane knöcherne Substitution aus. HA besitzt auch die osteokonduktive Fähigkeit und ist biokompatibel, wird jedoch nicht knöchern substituiert, sondern integriert und steht im direkten Kontakt zu den Knochentrabekeln (Maus et al. 2007).

\subsubsection{Allogene Transplantate}

Ein allogenes Transplantat wird von einem Knochenspender auf einen Organismus der gleichen Spezies übertragen. Sie werden als mineralisierte (freeze dried bone allograft, FDBA) oder demineralisierte Knochenblöcke (demineralized freeze-dried bone allograft, DFDB) aus Knochendatenbanken angeboten. In einem aufwendigen Aufbereitungsprozess wird die Knochenmatrix von immunogenen und potenziell infektiösen Rückständen gereinigt (Smeets et al. 2014b). Ein allogener Knochenblock besitzt die größte Ähnlichkeit zum autogenen Knochen, aufgrund des Gerüstaufbaus und der Volumenstabilität. Weiterhin besitzt es osteokonduktive Eigenschaften, die zu einer schnelleren Knochenbildung im Vergleich zu synthetischen oder xenogenen Materialien beitragen (Smeets et al. 2014a). Nach der Demineralisation der Knochenmatrix und damit einer Freilegung von verbliebenen endogenen BMPs kann das Material eine osteoinduktive Wirkung im Empfängerlager entfalten (Eickholz 2012). Trotz guter klinischer Resultate bestehen immunologische Risiken für den Empfänger wegen möglicher Übertragung von Infektionen wie HIV und Hepatitis (Becker et al. 1995, Hauschild und Bader 2004), weshalb eine strenge Aufklärungspflicht vor dem Einsatz dieser Transplantate vorgeschrieben ist. 


\subsubsection{Xenogene Transplantate}

Transplantate xenogenen Ursprungs (artfremder Spezies) können tierischer Herkunft sein (meist bovin) oder von Algen und Korallen (phykogen) abstammen (Wagner und Nawas 2004). Aufgrund ihrer inneren Oberfläche und dem Hydroxylapatitgerüst haben diese Materialien zwar einen sehr guten osteokonduktiven Effekt, erfüllen jedoch nicht die Anforderungen an ein ideales KEM. Um Abstoßungsreaktionen im Empfängerlager zu vermeiden, werden diese Materialien chemisch und physikalisch aufbereitet und gereinigt. Eine mögliche Übertragung von Proteinrückständen und Krankheitserregern boviner Materialien wird in der Literatur dennoch kontrovers diskutiert (Schwartz et al. 2000, Horowitz et al. 2009c, Smeets et al. 2014a), weshalb auch beim Einsatz tierischer KEM eine Aufklärungspflicht gegenüber dem Patienten einzuhalten ist (Laurencin und El-Amin 2008). Der fehlende beziehungsweise ausgesprochen langsame Remodellierungsprozess sorgt für eine gute Volumenstabilität des rein osteokonduktiven Materials. Aufgrund des langjährigen Verbleibs als biofunktioneller Fremdkörper am Implantationsort kann es jedoch zu Abkapselungen des Granulats und zur Stimulierung der Makrophagenaktivität kommen (Schlegel und Donath 1998). Das Beimischen von autogenem Knochen, Wachstums- und Differenzierungsfaktoren soll die Regenerationszeit des Materials in großen Defekten verkürzen (Eickholz 2012). Relative oder absolute Kontraindikationen für die Verwendung von KEM stellen Erkrankungen wie schwere Parodontitiden, Patienten mit Immundefizienz, nach laufender und abgeschlossener Bisphosphonattherapie und vorangegangener Strahlenbehandlung im Defektbereich dar (Smeets et al. 2014a). In Tabelle 2 sind wichtige Eigenschaften und Wirkungsweisen der Augmentationsmaterialien zusammengefasst aufgelistet.

Tabelle 2: Materialien zum defizitären Knochenaufbau mit wichtigen Eigenschaften und Wirkungsweisen (Merten et al. 2003, Wagner und Nawas 2004, Smeets et al. 2014)

\begin{tabular}{|c|c|c|c|c|}
\hline & $\begin{array}{l}\text { Immunologische } \\
\text { Einteilung }\end{array}$ & Materialherkunft & Wirkungsweise & Beispiele \\
\hline \multirow[t]{4}{*}{ Transplantation } & $\begin{array}{l}\text { autogen } \\
\text { (autolog) }\end{array}$ & $\begin{array}{l}\text { gleiches } \\
\text { Individuum }\end{array}$ & $\begin{array}{l}\text { osteokonduktiv, } \\
\text { osteoinduktiv, } \\
\text { osteogen }\end{array}$ & $\begin{array}{l}\text { Crista iliaca, } \\
\text { Scapula, } \\
\text { Fibula }\end{array}$ \\
\hline & $\begin{array}{l}\text { allogen } \\
\text { (homolog) }\end{array}$ & $\begin{array}{l}\text { gleiche Spezies } \\
\text { (Spender) }\end{array}$ & $\begin{array}{l}\text { osteokonduktiv, } \\
\text { (osteoinduktiv) }\end{array}$ & FDBA, DFDB \\
\hline & $\begin{array}{l}\text { xenogen } \\
\text { (heterolog) }\end{array}$ & andere Spezies & osteokonduktiv & bovin, porcin \\
\hline & phytogen & pflanzlich & osteokonduktiv & $\begin{array}{l}\text { Algen, } \\
\text { Korallen }\end{array}$ \\
\hline Implantation & alloplastisch & synthetisch & osteokonduktiv & ß-TCP, HA \\
\hline
\end{tabular}




\subsection{Socket Preservation}

Nicht nur für die Implantatprothetik ist eine ästhetische Proportion zwischen Hart- und Weichgewebe entscheidend, auch unter einem Brückenzwischenglied sollte die Weichgewebskontur nach einer Zahnentfernung möglichst in einer natürlichen Form erhalten bleiben. Dies gilt insbesondere für die kosmetisch anspruchsvolle Frontzahnzone des Oberkiefers. Wird im Bereich der Extraktionsalveole der Remodellierungsprozess eingeleitet, kommt es zum Knochenverlust (Carlsson und Persson 1967, Atwood 1971). Ein Knochendefizit verlangt im Nachhinein nach umfangreichen Augmentationsmaßnahmen und bedeutet finanziellen Mehraufwand für den Patienten. Weniger aufwendig ist diesbezüglich der Erhalt der vertikalen und horizontalen Knochendimension durch präventive Maßnahmen direkt nach der schonenden Zahnextraktion (Quayle 1990). Der aus dem Englischen stammende Begriff Socket Preservation (Erhalt des Sockels) beschreibt die Methode zum Alveolarkammerhalt und -aufbau unter Verwendung von Knochenersatzmaterialien (Hille 2005). Ohne augmentative Unterstützung kann zum einen das Weichgewebe in die Alveole kollabieren und zum anderen bereits in den ersten sechs Monaten ein Knochenverlust von 3-4 mm resultieren, was für die spätere implantologische Versorgung einen ästhetischen Nachteil bedeutet (Sclar 1999). Im Verlauf von zwei bis drei Jahren kann die Resorptionsrate sogar bis auf 40-60 \% zunehmen (Hille 2005). Das Auffüllen einer Extraktionsalveole unmittelbar nach der Zahnentfernung, mit einem resorbierbaren KEM wie dem B-TCP und das Anbringen einer Membran, sollen dem Zweck dienen, die Vorhersagbarkeit des Knochenvolumens für die spätere Versorgung zu ermöglichen. Seitens des Operateurs ist vor Beginn der Augmentation auf eine adäquate Lagerkonditionierung und eine geeignete Schnittführung zu achten, die einen möglichst spannungsfreien Wundverschluss zulässt. Ist dies nicht möglich, sollten Membrantechniken im Sinne der gesteuerten Geweberegeneration (GTR) zur Unterstützung der kinematischen Stabilität des Augmentates während der Umbauphase genutzt werden. Entzündungsfreiheit und eine ausreichende Vaskularisation begünstigen in diesem Zusammenhang die Regeneration (Merten et al. 2003).

\subsection{Membranen}

Unter Zuhilfenahme geeigneter Membrantechniken finden moderne Augmentationsmaterialien in der Zahnheilkunde und der Mund-Kiefer-Gesichtschirurgie eine breite Anwendung zur Knochenregeneration. Mit dem Ziel „restitutio ad integrum" ist unzureichendes Knochenangebot zur dentalen Implantation heutzutage in den meisten 
Fällen behandelbar, ohne dass autogener Knochen transplantiert werden muss (Bilk 2007).

Um die Proliferation von schnell proliferierenden Epithel- und Bindegewebszellen in den augmentierten Knochen zu verhindern (Gottlow et al. 1986), werden resorbierbare oder nicht-resorbierbare Barrieremembranen zur gesteuerten Knochen- (GBR) und Geweberegeneration (GTR) verwendet. Das Ausmaß der Regeneration hängt nicht nur von der Morphologie des Knochendefektes an sich ab (Karring et al. 1993), sondern auch von Materialeigenschaften der verwendeten Membran. Neben der Biokompatibilität sollte die Barriere einen gewissen Schutz vor Infektionen bieten (Palti und Hoch 2002b) und dem Augmentat weitestgehend Volumen- und Formstabilität geben. Bei Anwendung der nicht-resorbierbaren Membranen ist der erforderliche Zweiteingriff zur Entnahme des Materials als nachteilig zu bewerten. Am häufigsten kommen aus diesem Grund Membranen auf Kollagenbasis, beispielsweise aus porcinem Pericard, zur Anwendung. Eine Barrierezeit von zwei bis drei Monaten sollte eine resorbierbare Membran mindestens aufweisen (Smeets et al. 2014b).

Unter Verwendung resorbierbarer Membranen können kleine Flächen zur Mundhöhle exponiert sein, bei größerer Fläche müssen nicht-resorbierbare Membranen zur Anwendung kommen, um das Augmentat vor Infektionen zu schützen (Horowitz et al. 2009b).

Ein alternativer Ansatz, komplett auf tierische und synthetische Membranen zu verzichten, besteht in der Verwendung eines wachstumsfaktorenreichen Plasmas aus Eigenblut (PRGF: plasma rich in growth factors). Durch Zentrifugation werden bei diesem biotechnischen Vorgang konzentrierte Mengen an Wachstumsfaktoren aus den körpereigenen Thrombozyten gewonnen (Anitua et al. 2006). Die PRGF-Fraktion kann, mit KEM gemischt, in die frische Extraktionsalveole eingebracht werden. Das therapeutische Ziel besteht in der Steigerung der Proliferationsfähigkeit von ortsständigem Gewebe, der Revaskularisierung und Knochenregeneration. Die Wirkung ist auf den mitogenen sowie proliferativen Einfluss freigesetzter Wachstumsfaktoren (PDGF, TGF-ß, IGF-I usw.) auf die Endothel- und Knochenvorläuferzellen zurückzuführen (Anitua et al. 2006, Schwenzer und Ehrenfeld 2008). Aus der oberen Plasmafraktion lässt sich durch Aktivierung mit Calciumchlorid eine elastische Fibrin-Membran herstellen, die einen Verschluss der Extraktionsalveole zulässt, ohne aufwendige Mukoperiostplastiken durchführen zu müssen. Eine beschleunigte Heilung der Alveolenschleimhaut und Verbesserung der Knochenqualität konnte mit dieser Methode in Studien nachweislich erzielt werden (Whiteman et al. 1997, Anitua et al. 2006). 


\subsection{Heilung der Extraktionsalveole}

Die Umbauvorgänge der Zahnalveole sind von Cardaropoli et al. (2003) ausführlich ausgearbeitet und beschrieben worden. Zum besseren Verständnis des Nutzens einer Augmentation zur Socket Preservation werden die Grundlagen der sekundären Knochenheilung, basierend auf der genannten Arbeit, zusammenfassend dargestellt.

Die Heilung einer Extraktionsalveole vollzieht sich über mehrere Stufen. Nach einer Zahnextraktion wird die Alveolenkortikalis iatrogen verletzt, Blut strömt aus dem umliegenden Knochengewebe in das Knochenfach und bildet ein stabiles Blutkoagulum aus (Amler et al. 1960). Der marginale Anteil wird von Entzündungszellen, überwiegend neutrophilen Granulozyten, bedeckt. In diesem Bereich findet nach drei Tagen durch Einsprossung von Blutgefäßen ein Umbau des Koagulums statt (Cardaropoli et al. 2003). In dieser Phase sind vermehrt Makrophagen und Lymphozyten zu finden. Im zentralen Anteil der Alveole vollzieht sich eine Lyse der Erythrozyten mit einhergehender Nekrotisierung des Koagulums und Umbau zum Granulationsgewebe. Sieben Tage später dominieren neu gebildete Gefäße, verschiedene Arten weißer Blutkörperchen, Mesenchymzellen und Kollagenfasern die Extraktionsalveole. Sharpeysche Fasern des Zahnhalteapparates sind fast vollständig abgebaut. Aus den umliegenden Knochenwänden und den Volkmann-Kanälen formieren sich zunehmend die Osteoklasten und leiten die Knochenremodellierung ein. Bereits nach 14 Tagen liegen kleinere Areale von unreifem Hartgewebe, dem Geflechtknochen vor, welche sich von den Alveolenwänden hin zum Zentrum expandieren.

Die Alveole ist nach 30 Tagen komplett von einer keratinisierten Epithelschicht verschlossen. Im Inneren bilden sich größere Areale aus Geflechtknochen und umliegenden fibrösen Gewebe. Osteone werden zunehmend ausgeformt und stehen mit den Alveolenwänden in Verbindung. In dieser Phase haben einige Bereiche aus Geflechtknochen eine Resorption durch Osteoklasten erfahren, was einen Indikator für den Remodellingprozess darstellt. Dieser Vorgang wird ebenfalls am krestalen Rand des lamellären Knochens der Extraktionsalveole beobachtet.

Eine Hartgewebsbrücke aus Geflechtknochen trennt nach 60 bis 90 Tagen die Mukosa von der Extraktionsalveole. Apikal hat sich ein gut vaskularisiertes Knochenmark ausgebildet. Weiter zentral findet nach 90 Tagen der Umbau von Geflechtknochen zum lamellären Knochen und der Remodellingprozess an den ehemaligen Alveolenwänden statt. 
Im Zeitraum von 120 bis 180 Tagen ist der Geflechtknochen sowohl in der ehemaligen Alveole als auch krestal durch lamellären Knochen ersetzt. Das Periost bedeckt die neu gebildete Kortikalis und bildet das Attachement zwischen dem neu gebildeten Knochen und der Mukosa (Schenk 1991, Cardaropoli et al. 2003).

In einer an Hunden durchgeführten Studie wurde beobachtet, dass bereits in den ersten acht Wochen die Aktivität der Osteoklasten zum krestalen Knochenabbau an den Wänden der Extraktionsalveole geführt hat (Araujo und Lindhe 2005). Bei sehr dünnen bukkalen Knochenwänden läuft demnach eine vollständige Resorption ab. Bekräftigt wird diese Annahme durch eine Studie von Nevins et al. (2006), die Autoren untersuchten mittels $\mathrm{CT}$, inwieweit die bukkale Knochenlamelle nach der Socket Preservation erhalten werden kann. Sie postulierten einen Schutz der Alveolenwände und Volumenerhalt durch augmentative Maßnahmen, dennoch blieben die Knochenwände nicht in allen Fällen erhalten.

Bezüglich der zur Knochenregeneration benötigten Zeitintervalle sind in klinischen Studien interindividuelle Unterschiede festgestellt worden (Trombelli et al. 2008). Den entscheidenden Einfluss auf die Knochenheilung hat die periostale Begrenzung, sie bildet das ortsspezifische Signalareal für die osteoblastären Stammzellen. Fehlt die knöcherne Unterstützung, kollabiert das Weichgewebe in die Alveole und schränkt somit den Raum ein, den die Osteoblasten für die Wiederherstellung der ursprünglichen Anatomie benötigen. Selbst bei Erhalt des Periostes ist bei jedem Verlust der externen Kortikalis ein Schwund an Hartsubstanz aufgrund der fehlenden dreidimensionalen Stabilität zu erwarten (Khoury und Hanser 2009). Bei einem critical size defect (CSD) bleibt vermutlich zeitlebens ein unverknöcherter Restdefekt, da nach zehn bis zwölf Monaten die „autochthone Knochenregeneration“ beendet ist (Schmitz und Hollinger 1986, Merten et al. 1994, Merten et al. 2003). 


\subsection{Zielsetzung und Fragestellung}

Die Überwachung der Umbauvorgänge von KEM im Kieferknochen ist in der klinischen Praxis durch zwei- oder dreidimensionale Röntgenaufnahmen möglich. Die Röntgenopazität des ß-TCPs gibt dabei Aufschluss über den Verbleib am Ort der Implantation und kann als Indikator für den Vergleich der Opazität zwischen dem Defekt und dem ortsständigen Knochen genutzt werden. Bei zweidimensionaler Darstellungstechnik wie dem OPG ist eine genaue Aussage über die tatsächliche Knochenqualität nur eingeschränkt möglich. Für den Operateur ist genau diese Information von enormer Wichtigkeit für die weitere Therapieplanung, vor allem im Rahmen einer späteren Implantatversorgung.

In der retrospektiven Studie galt es zu evaluieren, welche klinische Wirksamkeit die Augmentation von Kieferknochendefekten mit ß-TCP unter Routinebedingungen bei unterschiedlichen dental-chirurgischen Indikationen (WSR, Socket Preservation, Osteotomien, Zystektomien, Implantationen) darstellt. Die Aufgabe bestand darin eine digitale Bildanalysetechnik (ImageJ) zur Bestimmung der relativen Knochendichte (RKD) nach Augmentation von Kieferknochendefekten an zweidimensionalen Röntgenbildern zu untersuchen und dieses Verfahren zu standardisieren. Zwar haben Studiengruppen (Chiapasco et al. 2000, Ihan Hren und Miljavec 2008) diese Messmethode bereits für Untersuchungen in Leerdefekten genutzt, doch ist bisher keine vergleichbare Evaluation im Zusammenhang mit aufgefüllten Defekten mit ß-TCP in unterschiedlichen Indikationsgruppen bekannt.

Im Einzelnen sollten folgende Ziele verfolgt und Fragestellungen beantwortet werden:

a) Evaluation der Interrater-Reliabilität des Messverfahrens sowie Bestimmung der relativen Knochendichte im Gesamtkollektiv mittels ImageJ.

b) Lässt die Bestimmung der relativen Knochendichte Rückschlüsse auf die Knochenqualität nach Augmentation mit ß-TCP beziehungsweise auf das Degradationsverhalten des Materials nach einer bestimmten Zeit zu?

c) Erreicht der mit ß-TCP augmentierte Knochendefekt die gleiche Knochendichte nach Degradation des synthetischen Materials oder ist diese sogar höher als ursprünglich?

d) Kann mithilfe der genannten Messmethode eine vollständige Knochenregeneration festgestellt werden?

e) Besteht eine Korrelation zwischen den relativen Knochendichten und den röntgenologischen Befunden? 
f) Gibt es klinische Komplikationen nach Augmentation wie Infektionen, Verlust des Augmentates und Wundheilungsstörungen?

g) Haben demografische Daten wie Alter und Geschlecht des Patienten sowie Lokalisation der Defekte Einfluss auf die Messung oder die Knochendichte?

h) Resultierend aus den Ergebnissen soll die Eignung des ß-TCPs in den unterschiedlichen Indikationsgruppen beurteilt werden. 


\section{Patienten und Methodik}

\subsection{Patientenkollektiv}

In einer retrospektiven klinischen Untersuchung sind Patientendaten zum Heilungsverlauf nach knochenregenerativen operativen Maßnahmen, die in einem Zeitraum von 2006 bis 2012 in der MGK in Kassel stattfanden, digital erfasst und ausgewertet worden.

Vor Therapiebeginn sind Anamnese, sämtliche Patientendaten, klinische sowie röntgenologische Befunde erhoben worden. Alle Patienten wurden routinemäßig über den operativen Eingriff und mögliche Risiken sowie Komplikationen aufgeklärt. Sie gaben eine schriftliche Einverständniserklärung zum therapeutischen Prozedere und zur Verwendung ihrer Daten zu wissenschaftlichen Zwecken.

Klinische und röntgenologische Kontrolluntersuchungen sind direkt nach dem operativen Eingriff und durchschnittlich 5 bis 17 Monate später durchgeführt worden. Der Abstand der Kontrollzeitpunkte richtete sich dabei nach dem jeweiligen Heilungsund Regenerationsverlauf des Patienten und wurde nicht einheitlich festgelegt. Daraus resultieren unterschiedliche zeitliche Abstände zwischen postoperativem Röntgenbild und der Verlaufsaufnahme im Gesamtkollektiv.

Die Studie ist mit den Richtlinien der Ethikkommission in Göttingen (Antragsnummer: DOK_63_2016) konform und wurde durch sie genehmigt.

\subsubsection{Indikationsgruppen}

Die Einteilung des Patientenkollektivs in Gruppen ergab sich aus präoperativen Diagnosen und der Indikation des Eingriffs in Wurzelspitzenresektionen, Alveolarkammaufbau zur Socket Preservation nach Zahnextraktionen, Osteotomien von Weisheitszähnen, Exkochleationen von Zysten und Implantatinsertionen. Eine Unterteilung der Implantatgruppe in laterale Augmentationen, Implantatinsertionen nach Alveolarkamm- und nach Sinusbodenaugmentationen wurde vorgenommen. Demografische und klinische Parameter wie Alter, Geschlecht, Defekte des Ober- und Unterkiefers, Komplikationen sowie der Zeitraum zwischen Operation und der Verlaufskontrolle flossen in die Auswertung ein. 


\subsection{Operationsverfahren}

Die Eingriffe wurden je nach Umfang der Behandlungsmaßnahme und Lokalisation des Operationsfeldes entweder in Lokalanästhesie oder in Intubationsnarkose von einem Chirurgen durchgeführt. Das verwendete Lokalanästhetikum Citocartin ${ }^{\circledR}$ mit einem Epinephrinzusatz von 1:100000 (Heraeus Kulzer $\mathrm{GmbH}$ ) diente standardmäßig zur Schmerzausschaltung und Durchblutungsminderung im Operationsgebiet. Bis auf die laterale Augmentation nach Implantatinsertion und Sinusbodenelevation war das Vorgehen zur gesteuerten Knochenregeneration der einzelnen Indikationsgruppen identisch. Zur Vorbereitung der Defektregion wurde das nekrotische und entzündliche Gewebe sorgfältig exkochleiert. Bei unzureichender Blutung des Knochens ist dieser mit einer Kugelfräse angefrischt worden, um ausreichende Penetration des KEMs mit knochenbildenden Zellen zu erreichen. Zusätzlich ist das ß-TCP-Granulat mit Eigenblut aus dem Knochendefekt getränkt und wandständig in die Defektstelle eingebracht worden. Auf Vermeidung einer starken Kondensation des Granulats wurde aus zwei Gründen geachtet einerseits zum Schutz der Porenstruktur und andererseits zum Erhalt der wichtigen Hohlräume zwischen den Partikeln. Die Angiogenese und damit die Nutrition knochenbildender Zellen wäre ansonsten eingeschränkt gewesen. In den meisten Fällen kam eine resorbierbare Membran zur Abdeckung der Defektfläche zum Einsatz, wenn ein spannungsfreier Verschluss mittels Mukoperiostlappen nicht sichergestellt werden konnte. Diese Maßnahme diente dem Zweck, das Einwachsen von Bindegewebe in das Augmentat und dessen vorzeitige Resorption zu verhindern. Zur Vermeidung einer postoperativen Infektion erhielten alle Patienten prophylaktisch für fünf bis sieben Tage das Antibiotikum Clindamycin $600 \mathrm{mg}$ (Clindamycinrathiopharm ${ }^{\circledR}$ ), zur täglich zweimaligen Einnahme im Abstand von zwölf Stunden. Alle Patienten wurden zur täglichen Spülung der Mundhöhle mit einer 0,12-prozentigen Chlorhexidin-Diglukonatlösung (GUM Paroex ${ }^{\circledR}$, Sunstar Deutschland GmbH) für sieben Tage instruiert.

Weitere Besonderheiten einzelner Eingriffe werden im Folgenden dargestellt.

\subsubsection{Wurzelspitzenresektionen}

Nach einer lokalen Anästhesie im Operationsgebiet wurde eine Lappenpräparation zur Darstellung des apikalen Bereichs der zu resezierenden Wurzelspitze durchgeführt. Der Winkelschnitt nach REINMÖLLER oder der Bogenschnitt nach PARTSCH dienten als Standardzugang. Unter Schonung größerer Blutgefäße und Nerven wurde der Schnitt im Ober- und Unterkiefer von vestibulär, idealerweise an der Mukogingivalgrenze beziehungsweise etwas unterhalb gesetzt, um eine mögliche Unbeweglichkeit des 
Mukoperiostlappens während des Heilungsprozesses zu gewährleisten. War die Ausdehnung des knöchernen Defektes bis zur befestigten Gingiva zu erwarten, hat sich der Zahnfleischrandschnitt mit vertikalen Entlastungsinzisionen bewährt. Die Resektion der palatinalen Wurzel der Oberkiefermolaren erfordert einen zusätzlichen Zugang von palatinal. Präoperativ ist eine Verbandplatte zur Adaptation der Gaumenschleimhaut angefertigt und postoperativ eingegliedert worden. Der Knochenabtrag an der zu resezierenden Wurzelspitze erfolgte mit einer Kugelfräse bei einer Umdrehungszahl von $2000 \mathrm{U} / \mathrm{min}$ unter ständiger Kühlung mit einer 0,9-prozentigen physiologischen Kochsalzlösung (B Braun Melsungen AG). Mit einem scharfen Löffel wurde im nächsten Schritt die Exkochleation des Granulations- oder Zystengewebes vorgenommen und zur histologischen Untersuchung eingeschickt. Unter Einbeziehung des gesamten Wurzelquerschnitts wurde die betroffene Wurzelspitze mit einer Kugel- oder Lindemannfräse gekappt. Zum Ausschluss von möglichen Wurzelfrakturen, weiteren Wurzelkanälen und Isthmusverbindungen ist die Wurzeloberfläche genau inspiziert worden. Anschließend erfolgten die retrograde Präparation der Wurzelkanäle mit einem ultraschallbetriebenen Instrument (Piezosurgery ${ }^{\circledR}$, mectron) oder einer kleinen Kugelfräse sowie der retrograde Zementverschluss (Super EBA ${ }^{\circledR}$, Bosworth Company). Wie bereits beschrieben wurde der knöcherne Defekt mit ß-TCP aufgefüllt und der Mukoperiostlappen mit einem nicht-resorbierbaren monofilen Faden speicheldicht vernäht (Prolene ${ }^{\circledR}$ 3-0 oder 4-0).

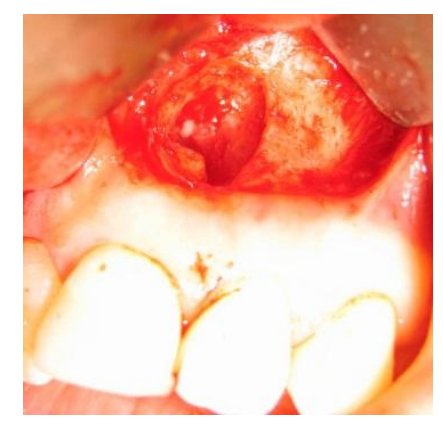

a)

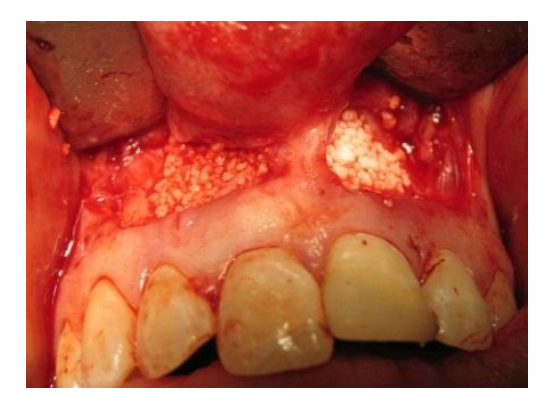

b)

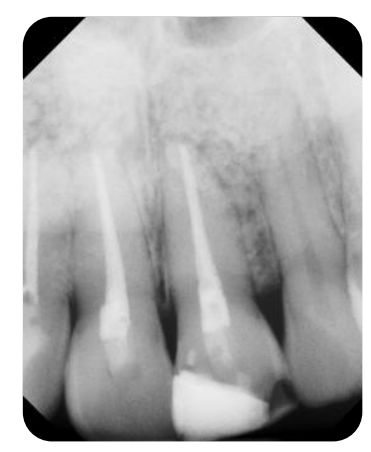

c)

Abbildung 3: WSR am Zahn 21 (a) sowie Knochendefektauffüllung mit $\beta$-TCP (b) und postoperativem Zahnfilm (c)

\subsubsection{Socket Preservation}

Die Entfernung nicht erhaltungswürdiger Zähne erfolgte möglichst atraumatisch unter Erhalt vestibulärer und oraler Knochenwände der Extraktionsalveole. Mehrwurzelige Zähne wurden nach Abtrennung der Zahnkrone intraalveolär geteilt. Unter Verwendung eines scharfen Löffels ist jegliches Entzündungsgewebe entfernt und das ß-TCP-Eigenblutgemisch in die Alveole eingebracht worden. Die Abdeckung der 
augmentierten Alveole erfolgte meist mit einer PRGF-Eigenblutmembran (PRGF $\left.{ }^{\circledR}, \mathrm{BTI}\right)$. Sie wurde unter die Mukoperiostränder zirkulär der Alveolenwände geschoben und durch Nähte fixiert.

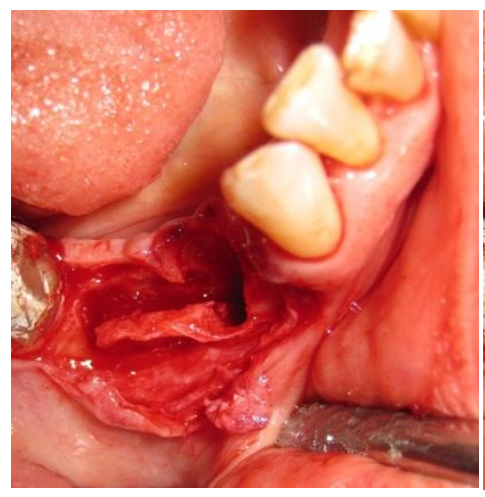

a)

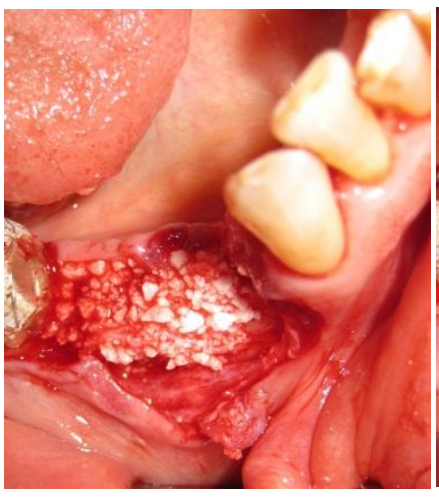

b)

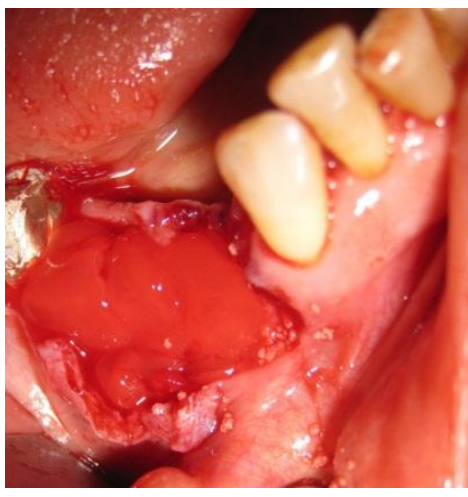

c)

Abbildung 4: Zustand nach Zahnentfernung (a) mit Defektaufbau zur Socket Preservation (b) und Abdecken mit einer PRGF-Eigenblutmembran (c)

\subsubsection{Osteotomie der Weisheitszähne}

Zur Darstellung des Operationsfeldes ist eine Inzision distal des Zwölfjahresmolaren auf dem Kieferkamm nach dorsal und marginal entlang des Molaren ausgeführt worden. Zur besseren Übersicht erfolgte eine Entlastungsinzision mesial des zweiten Molaren. Von der Inzision her wurde der Mukoperiostlappen abgelöst und der Knochen dargestellt. Vestibuläre Osteotomie zur Freilegung des größten Kronendurchmessers erfolgte mittels Kugelfräse unter ständiger Kühlung mit Kochsalzlösung. Je nach Verlagerungsart ist der Zahn einfach oder mehrfach durchtrennt worden. Nach Exposition des Weisheitszahnes wurde das Zahnsäckchen oder das Zystengewebe vollständig kürettiert. Auf wandständige Defektauffüllung des ß-TCPs mit einem dichten Wundverschluss wurde großen Wert gelegt.

\subsubsection{Exkochleation von Zysten}

Die Therapie der Wahl zur Entfernung von Zysten und pathologischen Raumforderungen im Kieferknochen war die komplette Exkochleation und histopathologische Aufbereitung des Gewebes. Zur Stabilisierung des Blutkoagulums fand eine Defektauffüllung mit ß-TCP statt. In ausgedehnten Defekten wurde der kortikale Knochen mit einer Osteosyntheseplatte stabilisiert. 


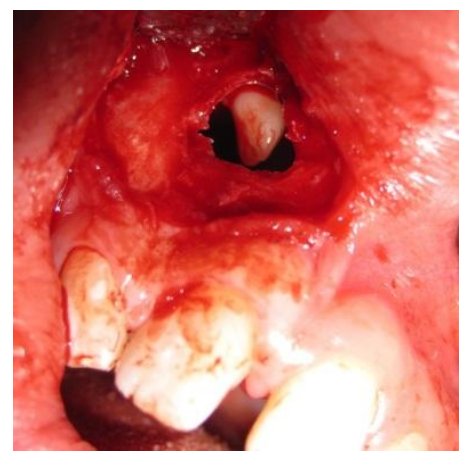

a)

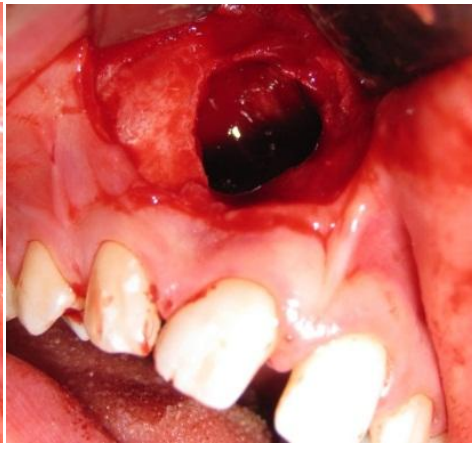

b)

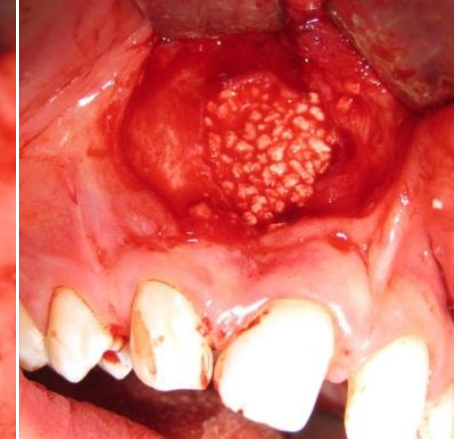

c)

Abbildung 5: Defektdarstellung (a), Exkochleation einer follikulären Zyste im ersten Quadranten (b) und Knochendefektauffüllung mit $\beta-T C P(c)$

\subsubsection{Implantation}

Das Setzen dentaler Implantate wurde nach dem jeweiligen Bohrprotokoll des entsprechenden Implantatsystems durchgeführt. Tabelle 3 zeigt die Anzahl und Systeme der in die Untersuchung aufgenommenen Implantatfälle.

Tabelle 3: Verwendete Implantatsysteme

\begin{tabular}{|l|l|l|l|l|l|}
\hline $\begin{array}{l}\text { Implantat- } \\
\text { system/ } \\
\text { Firma }\end{array}$ & $\begin{array}{l}\text { SLActive }^{\circledR} / \\
\text { Straumann }^{\circledR}\end{array}$ & $\begin{array}{l}\text { Xive }^{\circledR} / \\
\text { Dentsply } \\
\text { Implants }\end{array}$ & $\begin{array}{l}\text { Hilfs- } \\
\text { implantate/ } \\
\text { Nobel } \\
\text { Biocare }^{\mathrm{TM}}\end{array}$ & $\begin{array}{l}\text { OsseoSpeed } \\
\text { Astra Tech } \\
\text { Implant } \\
\text { System }\end{array}$ & $\begin{array}{l}\text { Ankylos }^{\oplus} / \\
\text { Dentsply } \\
\text { Implants }\end{array}$ \\
\hline Anzahl & 89 & 35 & 5 & 4 & 2 \\
\hline
\end{tabular}

Je nach Kieferverhältnissen sind drei Therapiemaßnahmen im Zusammenhang mit Implantationen erfolgt. Laterale Augmentationen an der Implantatschulter, Implantationen in eine nach vorheriger Socket Preservation augmentierte Alveole nach circa sechsmonatiger Regenerationszeit sowie Implantationen mit simultaner Sinusbodenaugmentation sind analysiert worden. Im Gegensatz zu den bereits genannten Indikationsgruppen wurden zum ß-TCP gesammelte autogene Knochenspäne aus dem Implantatbohrloch hineingemischt. Alle Defekte wurden speicheldicht mit einem nichtresorbierbaren monofilen Faden vernäht (Prolene $\left.{ }^{\circledR} 4-0,5-0\right)$.

\subsubsection{Implantation mit lateraler Augmentation}

Bei knöchernen Defiziten zirkulär der inserierten Implantate ist eine zusätzliche Augmentation mit ß-TCP-Eigenknochengemisch erfolgt. Bei größeren Defekten dienten Kollagen-, PLLA- (poly-L-lactide acid) oder PRGF-Membranen der Abdeckung. Ansonsten ist der Mukoperiostlappen speicheldicht vernäht worden. 


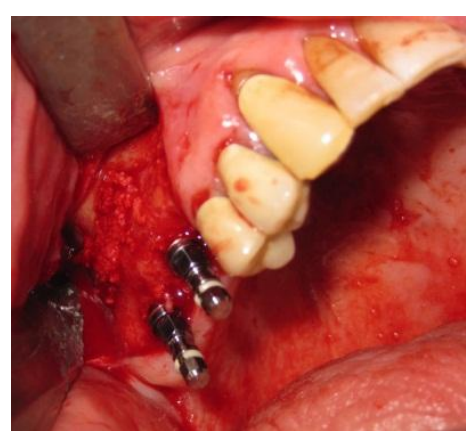

a)

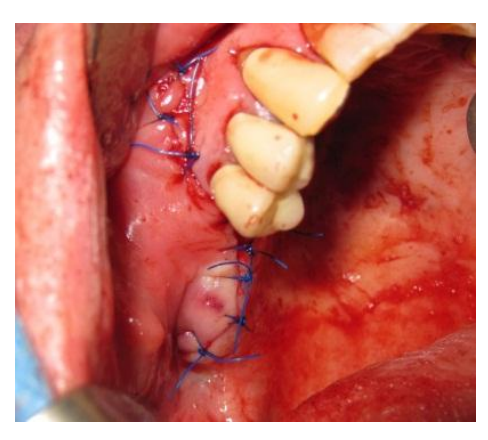

d)

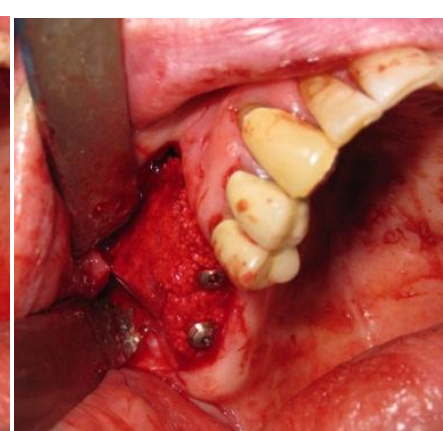

b)

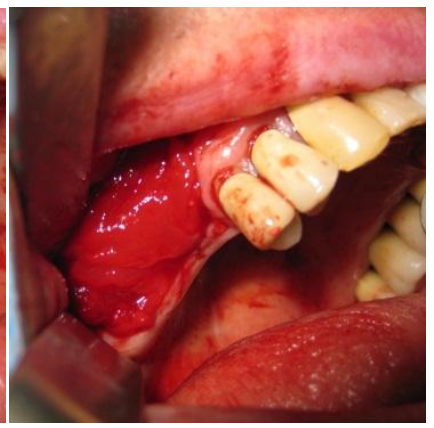

c)

Abbildung 6: Implantatinsertion im ersten Quadranten (a) mit lateralem Knochendefektaufbau mit $\beta$ TCP, einer PLLA-Membran (b) und PRFG-Membran (c) zur Stabilisierung, Adaptation des Mukoperiostlappens mittels monofiler Naht (d)

\subsubsection{Implantation nach Socket Preservation}

Zum Zweck einer möglichen Implantation werden Alveolen nach vorheriger Zahnextraktion aufgebaut, um in erster Linie eine günstige Position der Dentalschrauben und ein günstiges Implantat-Kronen-Verhältnis zu schaffen. Nach Einhaltung der Regenerationszeit aufgefüllter Alveolen von vier bis sechs Monaten wurden Implantate inseriert.

\subsubsection{Implantation nach Sinusbodenaugmentation}

Fehlt nach einem Zahnverlust der funktionelle Reiz auf den Alveolarknochen, bildet sich der unbelastete Kieferkamm zurück. Im lateralen Oberkiefer reduziert sich der Knochen zusätzlich von apikal durch die Pneumatisation der Kieferhöhle (Sinus maxillaris). Um das ungenügende Knochenangebot vor der Insertion dentaler Implantate zu verbessern, wurde simultan eine externe Sinusbodenaugmentation mit Anlegen eines fazialen Knochenfensters nach Tatum (1986) durchgeführt. Nach Abpräparation der Schneider'schen Membran wurde das Fenster in die Kieferhöhle in kranialer Richtung eingeklappt, wobei es im oberen Anteil mit der Kieferhöhlenschleimhaut in Verbindung blieb. Der iatrogen geschaffene Raum diente der Auffüllung mit dem ß-TCP-Eigenblutgemisch. Nach gleichzeitiger Implantatinsertion wurde je nach 
Größe des Fensters der fehlende Anteil der fazialen Kieferhöhlenwand mit einer Membran (Kollagen- oder PLLA-Membran) abgedeckt und der Mukoperiostlappen vernäht. Membrantechniken kamen jedoch nicht in allen Fällen zum Einsatz.

\subsection{Versuchsmaterialien}

\subsubsection{B-Tricalciumphosphat}

Zur Knochendefektauffüllung kam das ß-TCP (Cerasorb ${ }^{\circledR}$ M, Curasan AG, Kleinostheim) der Korngröße 500-1000 $\mu$ m zum Einsatz. Nach Herstellerangaben und Angaben aus der Literatur verfügt das polygonale Granulat über eine Phasenreinheit von $\geq 99 \%$. Die Beschaffenheit der Oberfläche mit einer 65-prozentigen, offen gestalteten Multiporosität hat die Zellversorgung und durchgängige Angiogenese zum Ziel (Palm et al. 2006, Bilk 2007).

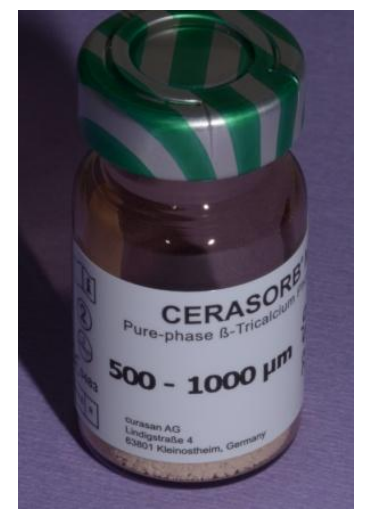

Abbildung 7: Cerasorb $^{\circledR} M$

\subsubsection{Autogener Knochen}

In der Implantatgruppe sind die bei der Implantatbohrung herausgelösten spongiösen Knochenspäne mittels Knochenkollektor gesammelt und dem ß-TCP zur lateralen Augmentation am inserierten Implantat beigemischt worden.

\subsubsection{Membranen}

Eine wichtige Voraussetzung für das Einheilen des KEMs bildet der speicheldichte Wundverschluss der Mundschleimhaut nach dem Eingriff. Im Zuge der Extraktion von nicht-retinierten Zähnen und Auffüllen der Defekte zur Socket Preservation, war in den meisten Fällen ein Verschluss des Defektes mit Weichgewebe allein nicht möglich. Im Frontzahnbereich war es aus ästhetischen Gründen nicht sinnvoll einen Mukoperiostlappen zu präparieren, um den Defekt plastisch zu decken. In diesen Fällen wurde zur Abdeckung eine aus Eigenblut gewonnene PRGF-Membran verwendet. 


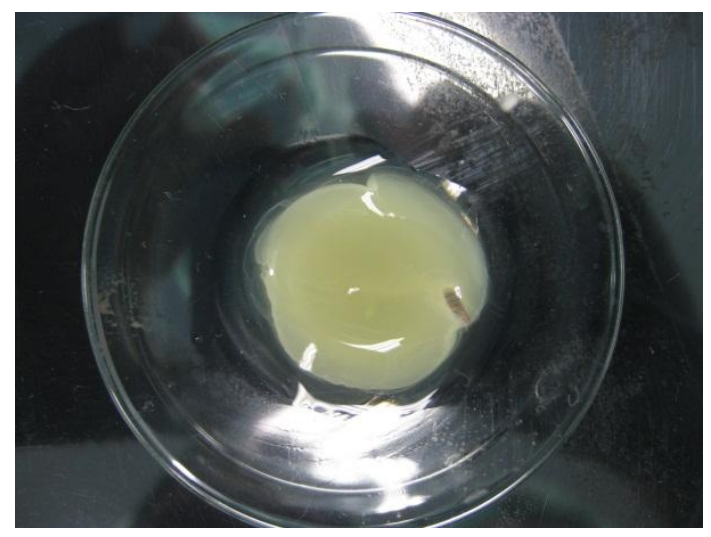

Abbildung 8: $P R F G^{\circledR}$-Eigenblutmembran

Bei der lateralen Augmentation und den Sinusaugmentationen wurde je nach Bedarf eine resorbierbare Membran auf Kollagenbasis (Resodont ${ }^{\circledR}$ ) oder PLLA (Resorb $X^{\circledR}$ ) eingesetzt. Das Verhalten und der mögliche Einfluss einer Membran auf die Augmentation war nicht primär Teil der Studie und fand, vor allem aufgrund der nicht einheitlichen Verwendung, in der Untersuchung keinerlei Berücksichtigung.

\subsection{Röntgenologische Aufnahmen}

Grundsätzlich werden im Rahmen der oralchirurgischen Behandlungen postoperative Röntgenaufnahmen zur Kontrolle sowohl nach Osteotomien, WSR und Zystektomien als auch nach Implantatinsertion angefertigt. Auf diese Weise können der Verbleib von Wurzelresten, pathologischen Veränderungen, der Operationsverlauf und die korrekte Position der Implantate kontrollieren werden. Je nach operativer Maßnahme war eine medizinisch notwendige klinische und röntgenologische Nachuntersuchung zum Ausschluss von Rezidiven im Operationsgebiet nach sechs bis zwölf Monaten indiziert.

In Bezug auf die durchgeführte Studie sind keinerlei zusätzliche Röntgenbilder zu wissenschaftlichen Zwecken angefertigt worden. Die Auswertung richtet sich rein retrospektiv nach bereits vorhandenen, zur Routineuntersuchung angefertigten Aufnahmen und dokumentierten Befunden.

Nach Entfernung mehrerer Zähne oder Insertion von Implantaten ist ein Orthopantomogramm (Kodak $8000 \mathrm{C}$, Digital Panoramic and Cephalometric System) in standardisierter Technik (meist $73 \mathrm{kV}, 12 \mathrm{~mA}, 9.4 \mathrm{~s}$ ) angefertigt worden. Die Einstellung wurde jeweils auf das Gewicht und das Alter des Patienten ausgerichtet und bei ein und derselben Person immer mit der gleichen kV- und $m A-E i n s t e l l u n g$ durchgeführt. 
Um ein aussagekräftiges OPG zu erhalten, wurde darauf geachtet, dass alle Metallgegenstände im Kopf-Hals-Bereich entfernt waren, der Patient sich in der richtigen Position befand, sich während des Vorgangs nicht bewegte und angewiesen wurde die Zunge flach an den Gaumen zu drücken.

Bei einzelnen Zähnen sind Zahnfilmaufnahmen (Kodac 2000, Intraoral X-ray System) in Rechtwinkeltechnik angefertigt worden. Die Dosis und die Belichtungszeit richteten sich dementsprechend nach der Kieferregion und Größe des Patienten.

Da insbesondere bei den Implantatpatienten auch im späteren Verlauf Maßnahmen wie prothetische Versorgungen erfolgt sind, standen Röntgenbilder nach einem Untersuchungszeitraum von bis zu 55 Monaten zur Verfügung.

\subsection{Klinische Nachuntersuchungen der Patienten}

In der frühen postoperativen Verlaufsphase stellten sich die Patienten zwei Tage nach dem Eingriff zur Wundkontrolle in der Klinik vor. Das Operationsgebiet wurde mit einem Chlorhexidin-Gel zur Desinfektion bestrichen. Nach sieben Tagen fand die intraorale Nahtentfernung statt. Da der klinische Verlauf interessierte, sind Frühkomplikationen wie Wunddehiszenzen, Infektionen, Schwellungen, Schmerzen oder Verlust des Augmentates dokumentiert und für die jeweilige Indikationsgruppe ausgewertet worden. Hierzu wurde eine Codierungsskala mit den Werten von eins bis zehn festgelegt.

Diejenigen Patienten, die sich zur Verlaufskontrolle in der Praxis wieder vorstellten, wurden klinisch und röntgenologisch nachuntersucht. Die Daten von Patienten, die zwar operiert und die Defektauffüllungen mit ß-TCP erhielten, sich zur Verlaufskontrolle jedoch nicht mehr vorgestellt haben, sind erfasst, aber nicht in die Studie aufgenommen worden.

\subsection{Messverfahren zur Berechnung der relativen Knochendichte}

Auf digitalen Röntgenaufnahmen wurden der Verbleib und das Resorptionsverhalten von ß-TCP eruiert. Die Opazität des Materials war bereits durch Blickdiagnose gut von dem umliegenden gesunden Knochen zu unterscheiden. Im weiteren Heilungsverlauf stieg die Schwierigkeit, den Defekt optisch vom gesunden Knochen abzugrenzen. Zur Unterstützung der meist subjektiven Beurteilung mittels Blickdiagnose kam aus diesem Grund die Bildanalysesoftware ImageJ (1.44 p, Wayne Rasband, National Institutes of Health, USA) zum Einsatz. Messdaten der relativen Knochendichte auf postoperativen Aufnahmen sind mit denen auf der Verlaufsaufnahme verglichen worden. Die 
Auswertung diente der Einschätzung über den Grad der Osseointegration des synthetischen Materials und sollte darlegen, ob eine nutzbringende Verwendung des ß-TCPs zur Knochenregeneration in der klinischen Anwendung gegeben ist. Diese Methode wurde vorab auf die Reproduzierbarkeit der Messwerte, die Objektivität und die Interrater-Reliabilität getestet.

\subsection{Validierung des Messverfahrens}

Zur Evaluation, ob eine benutzerunabhängige Verwendung des Programms ImageJ möglich ist, wurden Vorversuche zur Validierung durchgeführt. Aus dem breiten Indikationsfeld sind zehn zufällig ausgewählte OPGs drei Untersuchern mit unterschiedlicher klinischer Erfahrung zur Verfügung gestellt worden. Alle erhielten dieselben zehn Fälle zur eigenständigen Analyse. Sie wurden mit der Handhabung der Software vertraut gemacht. Vor Beginn der eigenständigen Messungen wurde gemeinsam ein Messprotokoll entwickelt. In dieser Trainingsphase sind an weiteren Röntgenbildern verschiedener Indikationen Kriterien zum Umfahren der Defekte und der gesunden angrenzenden Knochenregionen festgelegt worden. Das Messprotokoll diente den Untersuchern als Leitfaden für die individuellen Messungen der zehn OPGs und zur Validierung der Bildanalyse sowie für die spätere Hauptuntersuchung aller Indikationsgruppen durch eine Person.

Das Messprotokoll beinhaltet folgende Regeln (Geiger et al. 2016a, Geiger et al. 2016b):

a) Die Defektregion und der umliegende gesunde Knochen müssen separat voneinander mit der Freihandauswahl (freehand selections) umfahren werden und dürfen sich weder berühren noch überschneiden.

b) Beide ROls sollten in etwa die gleiche Pixelanzahl aufweisen, das heißt möglichst gleich groß ausgewählt werden. Das Volumen der Umgebungsregion richtet sich dabei nach der Defektgröße und sollte zirkulär angeordnet sein.

c) Anatomische Nachbarstrukturen, die nicht zum Knochen oder dem Defekt gehören, würden die Messung verfälschen und müssen ausgeschlossen werden. Dazu zählen:

- Zahnwurzeln, Wurzelfüllmaterial

- Kompaktastrukturen: Lamina dura, Linea obliqua, Crista zygomaticoalveolaris

- Kiefer- und Nasenhöhlen

- Canalis submandibularis, Foramen mentale

- Aufgrund falscher Zungenposition projizierte Artefakte 
d) Für eine Vergleichbarkeit der Grauwerte auf unterschiedlichen Röntgenaufnahmen sollten diese mit gleichen Einstellungen $(\mathrm{kV}, \mathrm{mA})$ und Qualität durchgeführt worden sein.

e) Berechnung der Grauwerte bei der anschließenden Bildanalyse sollte idealerweise an Aufnahmen derselben Bildformate geschehen. Besonders geeignet ist die unkomprimierte TIFF-Bilddatei, weil die Pixel mit ähnlichen Grauwerten nicht zusammengerechnet werden wie im JPEG-Format.

Erfüllten Röntgenbilder nicht die vorgegebenen Standards war eine adäquate Messung nicht durchführbar, so dass diese Aufnahmen aus der Studie ausgeschlossen wurden. Nach strenger Einhaltung der Messregeln führten alle drei Untersucher ihre Analyse ohne Rücksprache und zeitlich versetzt an einem PC durch. Jeder Defekt und die dazu gehörige Knochenumgebung wurden jeweils fünf Mal umfahren, um intraindividuelle Messfehler gering zu halten. Anschließend ist aus beiden gemittelten Werten (Defekt, Knochenumgebung) ein Quotient der relativen Knochendichte (QRKD) errechnet worden. Pro Untersucher ergaben sich zehn Messwerte des QRKD, die im Hinblick auf die Intra- und Interrater-Reliabilität einer statistischen Auswertung unterzogen wurden, um die Messmethode auf ihre Präzision und Benutzerunabhängigkeit zu prüfen.

\subsection{Anwendung der Bildanalyse auf einzelne Indikationsgruppen}

Für jeden Indikationsfall wurde am postoperativen Röntgenbild und auf der Aufnahme nach bestimmter Verlaufszeit der Quotient zur Bestimmung der relativen Knochendichte ermittelt. Jeder augmentierte Defekt und der dazugehörige umliegende Knochen wurden dreimal umfahren. Der mittlere Grauwert für die beiden Knochenbereiche war für die Berechnung des QRKD relevant. Das wiederholte Umfahren diente dem Zweck, Messfehler zu minimieren. Zwei Werte des QRKD für das postoperative digitale Röntgenbild und die Aufnahme nach der Verlaufszeit pro Indikationsfall wurden anschließend miteinander verglichen. Die Hauptuntersuchung zur Messung der relativen Knochendichte führte ausschließlich eine Person durch, um mögliche interindividuelle Messfehler zu vermeiden.

\subsubsection{Der mittlere Grauwert}

Mit der Bildanalysesoftware ImageJ wurden in dem umzeichneten Bereich (ROI) die Pixel berechnet und als mittlerer Grauwert wiedergegeben. Die Grauwerte sind im verwendeten Programm von 0-255 definiert. Auf der Grauwertskala entspricht der schwarze Punkt 0 (vollständige Strahlendurchlässigkeit) und der weiße Punkt dem Wert 255 (vollständige Strahlenabsorption). In dem umfahrenen Bereich auf dem 
digitalen Röntgenbild wurden Pixel summiert und als der mittlere Grauwert wiedergegeben.

\subsubsection{Errechnen der relativen Knochendichte (RKD)}

Aus dem mittleren Grauwert des Defektes und dem mittleren Grauwert des umliegenden Knochens wurde der Quotient gebildet:

$$
R K D=\frac{\text { Mittlerer Grauwert Defekt }}{\text { Mittlerer Grauwert umliegender Knochen }} \times 100
$$

Die Ermittlung eines Quotienten aus zwei Regionen auf einem OPG macht zwei Röntgenbilder vergleichbar und minimiert Aufnahmefehler (Ihan Hren und Miljavec 2008), weil der Referenzbereich immer auf demselben Röntgenbild liegt. Der Vergleich zwischen dem postoperativen Röntgenbild und der Verlaufskontrolle soll Aufschluss über den Heilungsverlauf geben, der im idealen Fall bei 1 beziehungsweise $100 \%$ liegt.

\subsubsection{Anleitung zur Benutzung des Bildanalyseprogramms ImageJ}

1. Vor Beginn der Messung zur Bestimmung der RKD im Röntgenbild werden die Messparameter definiert.

Unter Analyze $\rightarrow$ Set Measurements werden folgende Messparameter mit einem Häkchen versehen: Area, Standard deviation, Min \& max gray value und Display label. Im selben Fenster wird unter Decimal places eine $\mathbf{3}$ eingetragen und mit $\mathbf{O K}$ bestätigt.

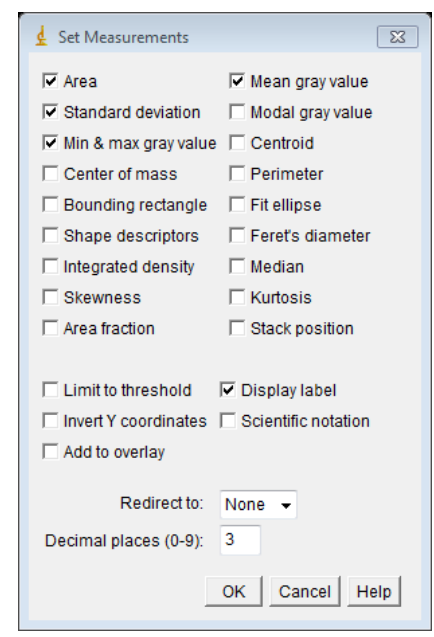

Abbildung 9: Festlegen der Messparameter

Diese Werte erscheinen nach dem Umfahren der Defekte in einer Tabelle. 
2. Das zu untersuchende Röntgenbild wird im nächsten Schritt mit File $\rightarrow$ Open geöffnet.

3. Zur besseren Visualisierung der augmentierten Defekte kann der untersuchte Bereich mit dem Symbol Magnifying glass (Lupe) zentriert und vergrößert werden.

4. In der Symbolleiste wird nun das Freehand selections Symbol ausgewählt.

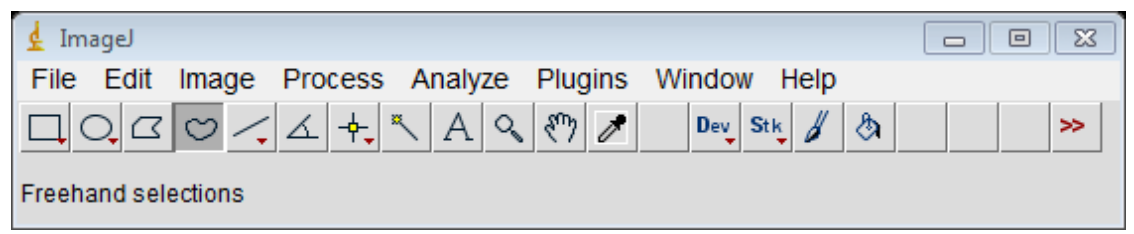

Abbildung 10: Symbolleiste ImageJ

Durch einmaliges Anklicken und Festhalten der linken Maustaste wird die Messung am Röntgenbild begonnen. Die Taste wird solange festgehalten, bis der Defekt einmal komplett umfahren ist.

Sollen mehrere zur gleichen Messung dazugehörende Defekte erfasst werden, wird die Steuerungstaste (Strg) während des gesamten Messvorgangs gedrückt gehalten.

Nicht zum Defekt gehörende Bereiche können aus dem Feld durch Festhalten der AltTaste und gleichzeitigem Umfahren der überflüssigen Bereiche extrahiert werden. Mit dem Gedrückthalten der Umschalttaste (Shift) können Bereiche dazugefügt werden.

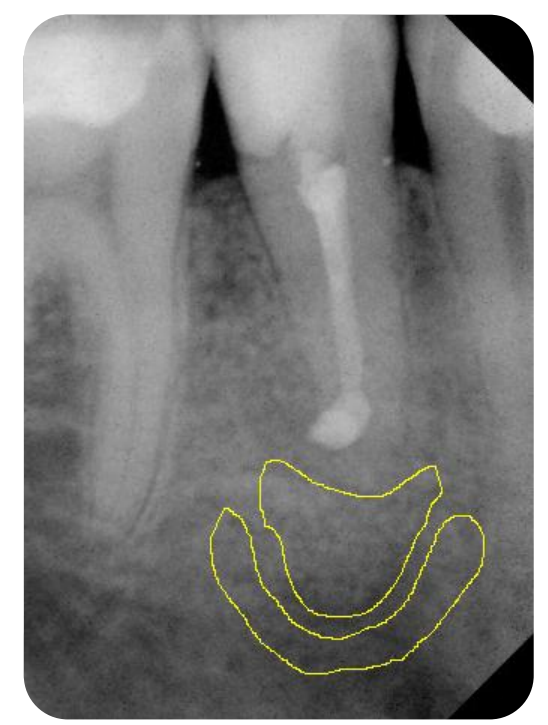

Abbildung 11: Ausgewählte ROIs mit $\beta$-TCP-augmetiertem Defekt und gesundem angrenzenden Knochen

5. Der Speichervorgang erzeugter Messwerte wird durch Klicken auf Analyze $\rightarrow$ Measure oder Strg $+\boldsymbol{M}$ durchgeführt und mittels Copy \& Paste in einer Tabelle gespeichert. 
6. Umfahrene Bereiche können gespeichert und auf andere Röntgenbilder übertragen werden. Auf diese Weise sind bei der ersten Messung erstellte ROls für Verlaufsröntgenbilder reproduzierbar. Unter Edit $\rightarrow$ Selection $\rightarrow$ Add to Manager $(S t r g+T)$ wird der ROI Manager aufgerufen, dort werden die Messdaten automatisch hinterlegt. In ein und demselben Bild wurden jeweils der mit ß-TCP aufgefüllte Defekt und anschließend der gesunde Knochen aus der unmittelbaren Umgebung dreimal umfahren. Das mehrmalige Umfahren diente dem Ziel, die intraindividuellen Messfehler zu minimieren. Aus den drei Werten jeweils für den Defekt und den umliegenden Knochen wurde der Mittelwert gebildet und anschließend zur Berechnung des QRKD verwendet.

\subsection{Qualitative Beurteilung der Röntgenbilder}

Zusätzlich wurden Röntgenbilder nach der Operation und nach der Verlaufszeit visuell von einem Untersucher beurteilt. Hierbei war das Degradationsverhalten des ß-TCPS alleiniges Kriterium. Das Festlegen einer Codierungsskala (1-6) diente zur systematischen Einordnung der bewerteten Daten.

\subsection{Statistische Auswertung}

Alle statistischen Analysen wurden mit der Software $\mathrm{R}$ (Version 3.0.2, www.rproject.org) im Institut für Medizinische Biometrie und Statistische Bioinformatik der Universität Göttingen durchgeführt. Für die Analyse der Messwiederholungen wurde das R-Paket 'geepack' verwendet. Die Verteilung der Variablen in den fünf Indikationsgruppen (WSR, Socket Preservation, Osteotomie, Zysten, Implantate) wurden durch den Mittelwert sowie die Standardabweichung für metrische Variablen beschrieben. Für die nominalen Variablen wurden die absoluten und relativen Häufigkeiten berechnet.

Krippendorffs alpha galt als Maß für die Übereinstimmung zwischen den drei Untersuchern in den Vorversuchen zur Anwenderkalibrierung. In allen statistischen Tests war das Signifikanzniveau auf alpha $=5 \%$ festgesetzt.

Die Quotienten der relativen Knochendichte (QRKD) sind für die jeweilige Indikationsgruppe, das Geschlecht, den Ober- und Unterkiefer durch den Mittelwert sowie die Standardabweichung beschrieben worden. Des Weiteren wurde der Einfluss des Geschlechts, der Kieferposition und der Komplikationen auf die einzelnen Quotienten der RKD in dem univariaten Regressionsmodell für Messwiederholungen 
analysiert. Der Korrelationskoeffizient nach Pearson wurde für metrische Variablen und die Quotienten angegeben.

In einem multivariaten Regressionsmodell ist der Effekt aller Parameter auf die Quotienten unter Berücksichtigung von Messwiederholungen geprüft worden.

In der Implantatgruppe sind zwischen den beiden Komplikationsgruppen ja (Code 1-2) und nein (Code 3-6) die Verteilung der Parameter angeführt worden. Der Einfluss aller Parameter wurde auf die Komplikationen im univariaten und multivariaten logistischen Regressionsmodell für Messwiederholungen ausgewertet. 


\section{Ergebnisse}

\subsection{Ergebnisse der Anwenderkalibrierung zur Validierung der Messung}

Von drei Untersuchern durchgeführte Vorversuche zur Anwenderkalibrierung der Bildanalyse mit dem Programm ImageJ erfolgten an zehn ausgewählten OPGs unterschiedlicher Indikationen. Für jeden Untersucher ergaben sich aus fünf Messwiederholungen für jedes analysierte Röntgenbild zehn Mittelwerte des QRKD, die intra- und interindividuell verglichen wurden. Die Mittelwerte fielen innerhalb der zehn Fälle erwartungsgemäß unterschiedlich aus, weil die Röntgenbilder nicht derselben Indikationsgruppe angehörten. Ergebnisse der Vorversuche können der Tabelle 4 entnommen werden. Jede Spalte gibt den Mittelwert des QRKD und die Standardabweichung für den jeweiligen Untersucher wieder. Eine intraindividuelle Standardabweichung von +/- 0,01 bis +/- 0,06 kann bei Untersucher 3 beobachtet werden. Bei Untersucher 1 hat sich eine Standardabweichung von +/- 0,01 bis +/- 0.04 und bei Untersucher 2 eine Abweichung von +/- 0,01 bis +/- 0,03 in den Messungen ergeben. Die gemessenen Werte liegen alle nahe dem Mittelwert, dies spricht für eine gute intraindividuelle Übereinstimmung.

Tabelle 4: Mittelwert mit Standardabweichung der fünf Messwerte des QRKD für jeden Fall und Untersucher

\begin{tabular}{|l|l|l|l|}
\hline Fall & Untersucher $\mathbf{1}$ & Untersucher $\mathbf{2}$ & Untersucher $\mathbf{3}$ \\
\hline 1 & $0.55+/-0.01$ & $0.52+/-0.01$ & $0.54+/-0.01$ \\
\hline 2 & $0.61+/-0.02$ & $0.59+/-0.03$ & $0.70+/-0.03$ \\
\hline 3 & $0.62+/-0.01$ & $0.69+/-0.03$ & $0.74+/-0.06$ \\
\hline 4 & $0.84+/-0.03$ & $1.02+/-0.03$ & $0.98+/-0.02$ \\
\hline 5 & $0.92+/-0.04$ & $0.94+/-0.02$ & $0.94+/-0.03$ \\
\hline 6 & $0.85+/-0.01$ & $0.89+/-0.02$ & $0.82+/-0.02$ \\
\hline 7 & $0.83+/-0.03$ & $0.91+/-0.03$ & $0.91+/-0.04$ \\
\hline 8 & $1.08+/-0.03$ & $0.99+/-0.03$ & $1.03+/-0.01$ \\
\hline 9 & $0.98+/-0.02$ & $0.98+/-0.02$ & $0.99+/-0.01$ \\
\hline 10 & $0.84+/-0.01$ & $0.86+/-0.02$ & $0.86+/-0.01$ \\
\hline
\end{tabular}


Statistisch ist die Übereinstimmung der interindividuellen Untersuchungstechnik ermittelt worden. Als Maß für die Übereinstimmung zwischen den Untersuchern diente Krippendorffs alpha (Tab. 5).

Tabelle 5: Krippendorffs alpha als ein Maß für die Interrater-Reliabilität zwischen den drei Untersuchern in den Vorversuchen

\begin{tabular}{|l|l|l|}
\hline Untersucher & Fall & Krippendorffs alpha \\
\hline 3 & 10 & 0.92 \\
\hline
\end{tabular}

Das Ergebnis von 0,92 impliziert eine hohe Interrater-Reliabilität. In Abbildung 12 sind die Mittelwerte des QRKD für jeden Fall und pro Untersucher aufgeführt. Gleiche interindividuell errechnete QRKD-Mittelwerte sind in Fall fünf, sieben, neun und zehn überlagert dargestellt.

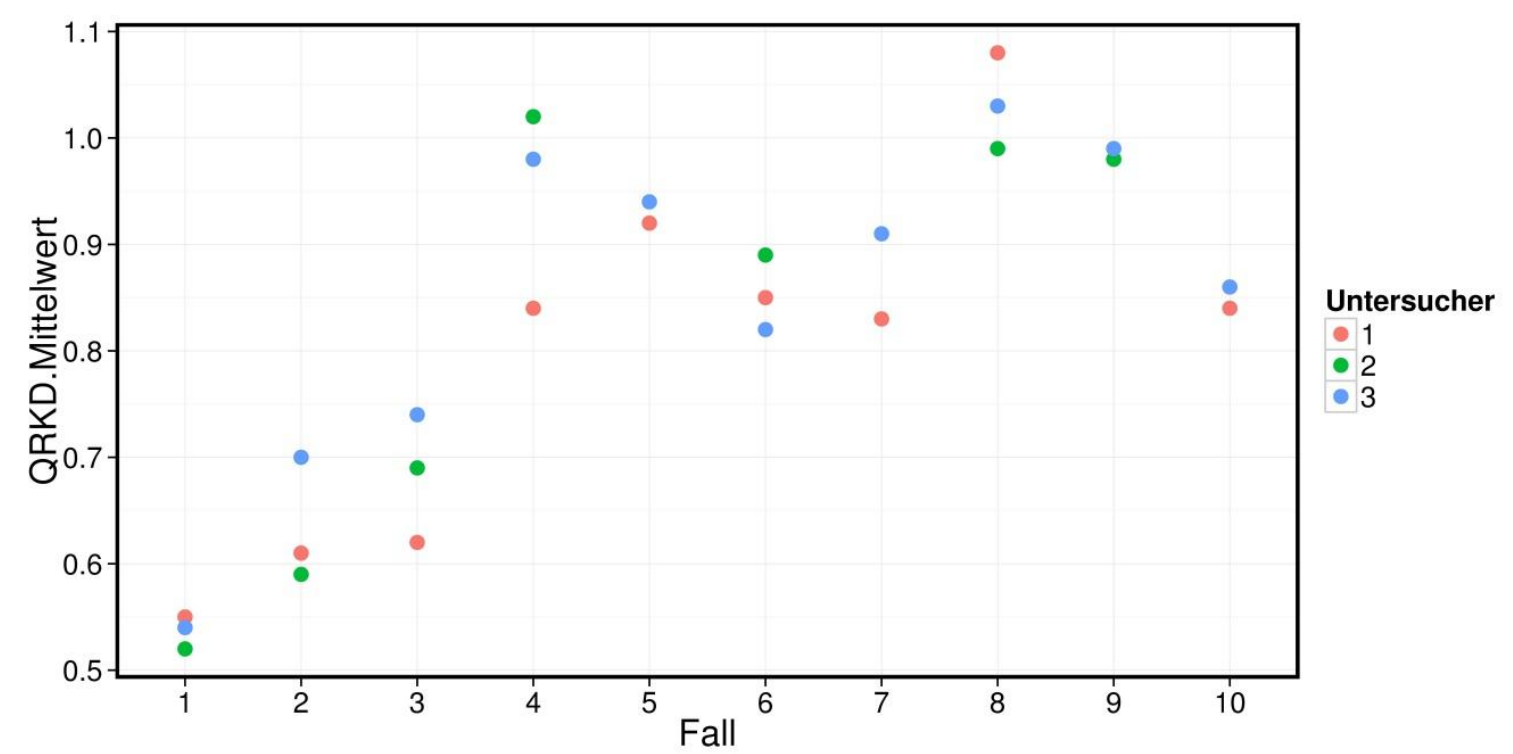

Abbildung 12: Mittelwerte der zehn gemessenen Fälle, die Punkte repräsentieren die einzelnen Untersucher

Die Evaluation der Beispielfälle mit ImageJ erfüllt aufgrund der hohen Reliabilität und unter Einhaltung des vorab festgelegten Messprotokolls (Abschnitt 2.7) die Voraussetzung für ein reproduzierbares und präzises Messverfahren. Für die Bestimmung der relativen Knochendichte im Gesamtkollektiv, konnte die Bildanalyse für eine systematische Auswertung angewendet werden. 


\subsection{Patientenkollektiv}

Bei insgesamt 560 Patienten wurde im Zeitraum von 2006 bis 2012 in 984 Defekten eine Augmentation mit ß-TCP durchgeführt und eine Einteilung nach Indikationsgruppen vorgenommen. Bei einigen Patienten mussten mehrere Defekte im Kieferknochen rehabilitiert werden. Eine Vielzahl der Fälle musste aufgrund fehlender postoperativer Röntgenbilder aus der Evaluation eliminiert werden, weil ein Großteil der Patienten aus Überweiserpraxen stammte und die Weiterversorgung dort fortgeführt wurde. Die Untersuchung stützte sich insgesamt auf 411 Defektfälle. Häufige Indikationen waren Wurzelspitzenresektionen $(n=181)$, das Auffüllen von Alveolarkammdefekten zur Socket Preservation $(n=47)$, Osteotomien $(n=34)$, Zysten $(n=14)$ und Augmentationen in Verbindung mit Implantaten $(n=135)$. Das Patientenalter lag zwischen 13 und 85 Jahren (Mittelwert 49 J), 233 der Patienten waren weiblich und 178 männlich. Im Unterkiefer wurden 214 Defekte und im Oberkiefer 197 Defekte augmentiert. Als Ausgangspunkt der Untersuchung dienten postoperative Röntgenaufnahmen und die Verlaufsröntgenbilder. Kontrollaufnahmen sind nach 158 bis 495 Tagen (Median; Mittelwert 231-542) erfolgt.

Die Verteilung der 411 analysierten Fälle der einzelnen Indikationsgruppen mit zugeordneten demografischen Daten wird in Tabelle 6 und Abbildung 13 dargestellt. Wurden bei einem Patienten mehrere Defekte aufgefüllt, sind dessen Parameter jedem Fall zugeordnet worden, um im späteren Verlauf eine mögliche Einflussnahme untersuchen zu können.

Tabelle 6: Indikationsgruppen mit absoluten und relativen Häufigkeiten der nominalen Variablen und der metrischen Variable mit Mittelwert und Standardabweichung

\begin{tabular}{|l|l|l|l|l|l|l|}
\hline Parameter & Wert & $\begin{array}{l}\text { WSR } \\
\text { (Gruppe 1) }\end{array}$ & $\begin{array}{l}\text { Socket } \\
\text { Preservation } \\
\text { (Gruppe 2) }\end{array}$ & $\begin{array}{l}\text { Osteotomien } \\
\text { (Gruppe 3) }\end{array}$ & $\begin{array}{l}\text { Zysten } \\
\text { (Gruppe 4) }\end{array}$ & $\begin{array}{l}\text { Implantate } \\
\text { (Gruppe 5) }\end{array}$ \\
\hline & & $\mathrm{n}=181$ & $\mathrm{n}=47$ & $\mathrm{n}=34$ & $\mathrm{n}=14$ & $\mathrm{n}=135$ \\
\hline Alter & & $47+/-14$ & $53+/-16$ & $44+/-18$ & $48+/-21$ & $55+/-14$ \\
\hline Geschlecht & $\mathrm{m}$ & $88(48.6 \%)$ & $21(44.7 \%)$ & $15(44.1 \%)$ & $8(57.1 \%)$ & $46(34.1 \%)$ \\
\hline & $\mathrm{w}$ & $93(51.4 \%)$ & $26(55.3 \%)$ & $19(55.9 \%)$ & $6(42.9 \%)$ & $89(65.9 \%)$ \\
\hline Kiefer & OK & $91(50.3 \%)$ & $28(59.6 \%)$ & $7(20.6 \%)$ & $5(35.7 \%)$ & $66(48.9 \%)$ \\
\hline & UK & $90(49.7 \%)$ & $19(40.4 \%)$ & $27(79.4 \%)$ & $9(64.3 \%)$ & $69(51.1 \%)$ \\
\hline
\end{tabular}




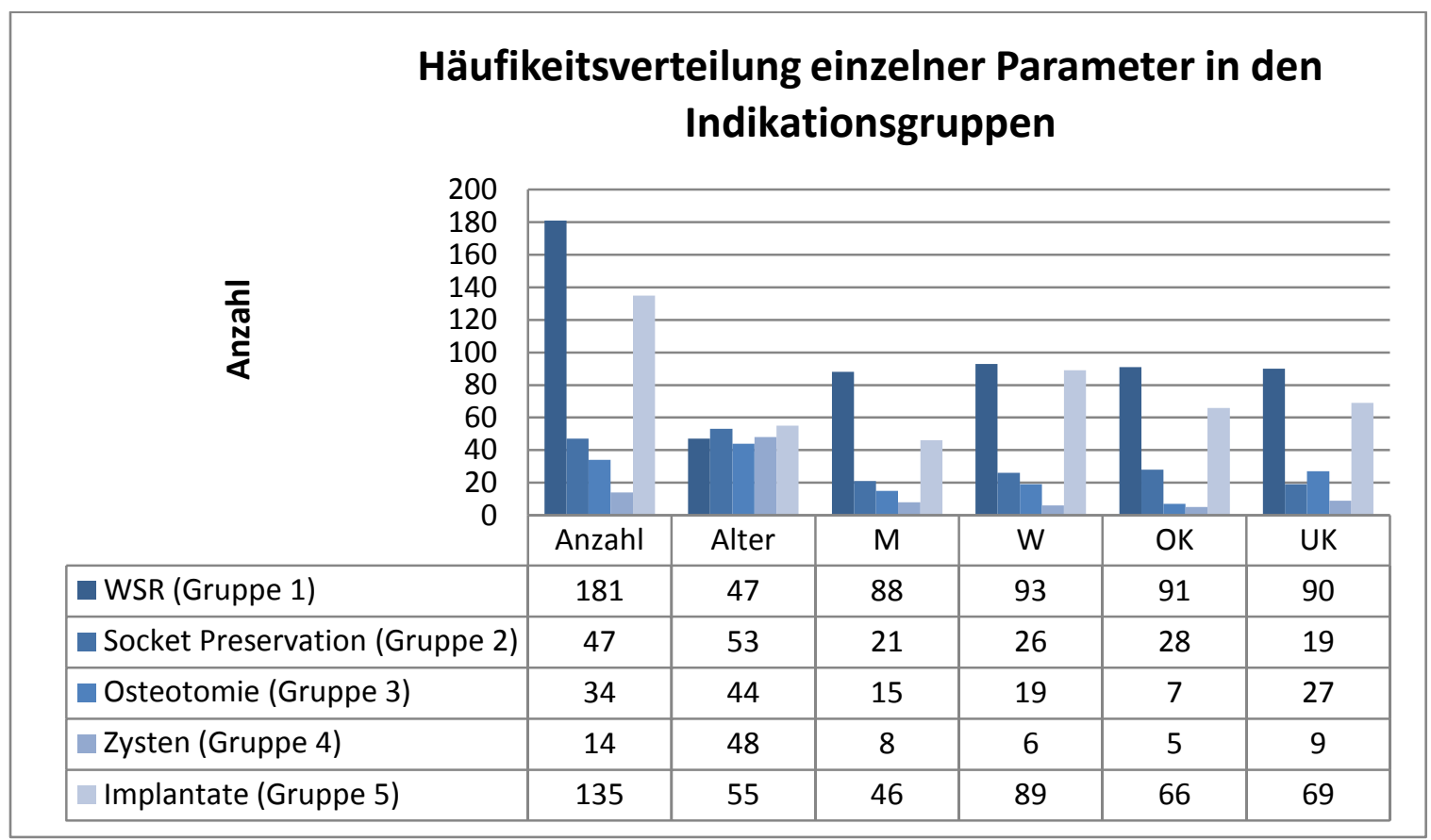

Abbildung 13: Indikationsgruppen mit Häufigkeitsverteilung der Parameter: Anzahl, Alter, Geschlecht, Ober- und Unterkiefer

\subsubsection{Quotient der relativen Knochendichte (QRKD)}

Der Vergleich des durchschnittlichen QRKD unter den einzelnen Indikationsgruppen in Tabelle 7 zeigt in den ersten beiden Gruppen postoperativ einen höheren Wert an als in Gruppe drei und vier. Im Verlauf nähert sich der Quotient der Gruppen eins und zwei dem Wert 1, während er in Gruppe drei und vier größer 1 wird. In Bezug auf den zeitlichen Verlauf ergibt sich für die Gruppe der Zysten ein Mittelwert von 498 Tagen zwischen der postoperativen Kontrollaufnahme und dem Verlaufsröntgenbild. Diese Gruppe weist im Vergleich den höchsten QRKD im Verlauf auf.

Tabelle 7: Quotienten der relativen Knochendichte in den jeweiligen Indikationsgruppen mit Mittelwert, Standardabweichung und dem Zeitintervall in Tagen

\begin{tabular}{|l|l|l|l|l|}
\hline Parameter & $\begin{array}{l}\text { WSR } \\
\text { (Gruppe 1) }\end{array}$ & $\begin{array}{l}\text { Socket } \\
\text { Preservation } \\
\text { (Gruppe 2) }\end{array}$ & $\begin{array}{l}\text { Osteotomien } \\
\text { (Gruppe 3) }\end{array}$ & $\begin{array}{l}\text { Zysten } \\
\text { (Gruppe 4) }\end{array}$ \\
\hline QRKD postoperativ & $1.06+/-0.19$ & $1.05+/-0.18$ & $0.99+/-0.17$ & $0.93+/-0.17$ \\
\hline QRKD Verlauf & $1+/-0.19$ & $0.99+/-0.14$ & $1.06+/-0.21$ & $1.08+/-0.36$ \\
\hline Postop. Verlaufszeit & $323+/-372$ & $231+/-166$ & $381+/-435$ & $498+/-412$ \\
\hline
\end{tabular}


Eine kleine Abweichung im Vergleich der Medianwerte mit den Mittelwerten zeigt sich in Tabelle 8. Die geringe Abweichung der QRKD ergibt sich aus der Abhängigkeit der Mittelwerte gegenüber Ausreißern, die in diesem Fall sehr gering ausfällt. Die unterschiedliche Zeitspanne zwischen den Aufnahmen wird umso deutlicher wiedergegeben. Aufgrund dessen sollen in Kapitel 4 die Medianwerte der Hauptuntersuchung als Grundlage für die Diskussion herangezogen werden.

Tabelle 8: Mediane der QRKD innerhalb jeder Indikationsgruppe mit dazugehöriger postoperativer Verlaufszeit in Tagen

\begin{tabular}{|l|l|l|l|l|}
\hline Parameter & $\begin{array}{l}\text { WSR } \\
\text { (Gruppe 1) }\end{array}$ & $\begin{array}{l}\text { Socket Preservation } \\
\text { (Gruppe 2) }\end{array}$ & $\begin{array}{l}\text { Osteotomien } \\
\text { (Gruppe 3) }\end{array}$ & $\begin{array}{l}\text { Zysten } \\
\text { (Gruppe 4) }\end{array}$ \\
\hline QRKD postoperativ & 1.04 & 1.03 & 1.03 & 0.89 \\
\hline QRKD Verlauf & 1 & 0.97 & 1.02 & 0.98 \\
\hline Postop. Verlaufszeit & 158 & 175 & 180 & 321 \\
\hline
\end{tabular}

Die Abbildung 14 zeigt grafisch die Medianwerte der vier Indikationsgruppen im Vergleich, während diese postoperativ eine größere Spannweite um den Wert 1 aufweisen, nähern sie sich im Verlauf dem Wert 1 in allen vier Gruppen an.

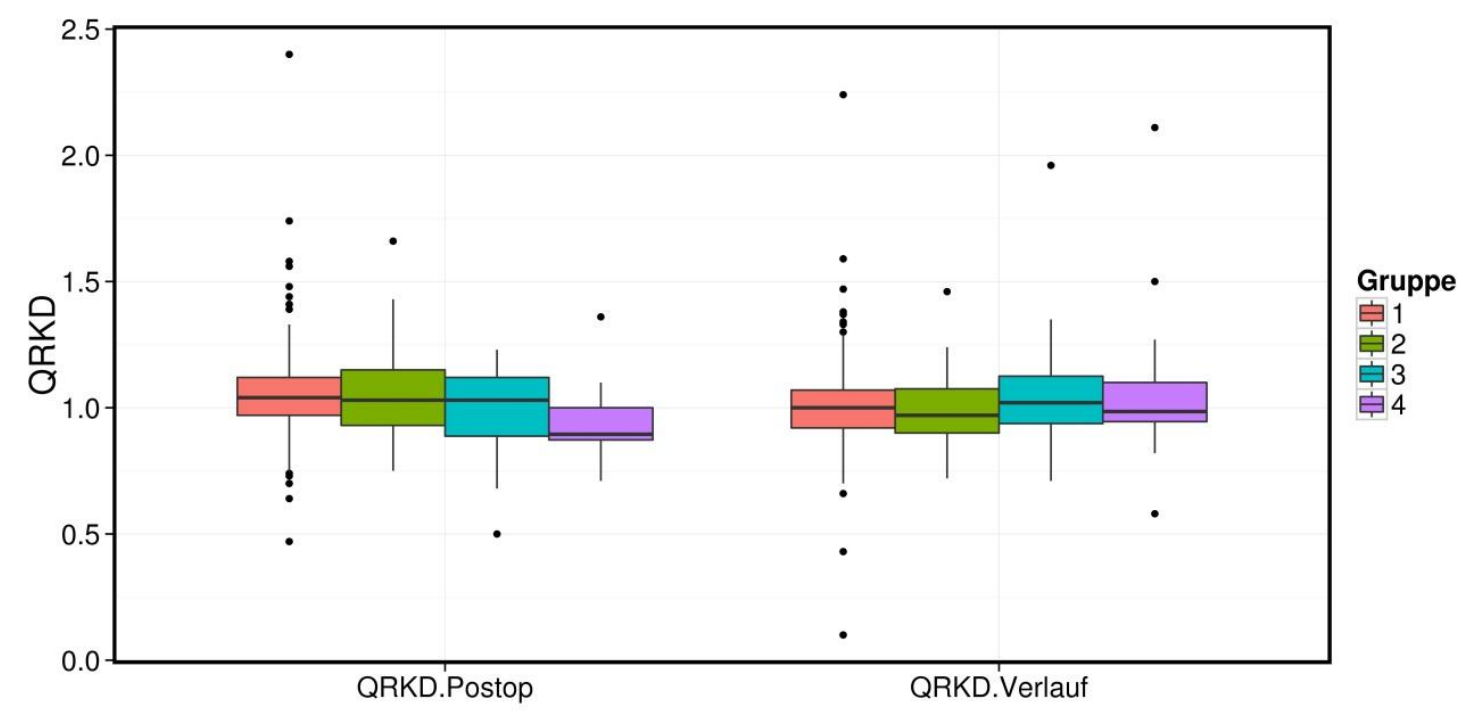

Abbildung 14: Boxplot mit Median und Quartil (1. und 3. Quartil) innerhalb der Indikationsgruppen (Gruppe 1 - WSR, Gruppe 2 - Socket Preservation, Gruppe 3 - Osteotomien, Gruppe 4 - Zysten)

Der Quotientwert errechnet sich aus dem mittleren Grauwert der Defektregion und dem mittleren Grauwert des angrenzenden gesunden Knochens. Bei einem Wert von 1 (100\%) entspricht die relative Knochendichte im Defekt der des umliegenden gesunden Knochens. In der Gruppe der Zysten ist die Steigerung der Knochendichte beziehungsweise die Knochenregeneration am deutlichsten zu erkennen. Von 
ursprünglichen $89 \%$ ist die relative Knochendichte im Defekt auf $98 \%$ gestiegen und damit annähernd genauso dicht wie der umliegende gesunde Knochen. In den anderen drei Gruppen zeigt sich ein ähnliches Bild nach der Verlaufszeit, hier waren die ursprünglichen Werte postoperativ jedoch höher.

\subsubsection{Quotient der relativen Knochendichte postoperativ (QRKD postoperativ)}

Bei Betrachtung der Quotienten im Einzelnen konnte direkt postoperativ ein signifikanter Effekt auf den QRKD festgestellt werden ( $p=0,0267)$ (Tab. 9). Im Oberkiefer sind die Knochendichtewerte höher ausgefallen als im Unterkiefer $(p=0,0340)$ (Tab. 10, Abb. 15). Weiterhin wurde der Einfluss von Geschlecht, Alter, der Zeit zwischen dem Eingriff und der Kontrolluntersuchung sowie von Komplikationen auf den QRKD postoperativ untersucht. Ein Einfluss dieser Faktoren auf den Knochendichtewert konnte nicht nachgewiesen werden (Tab. 11).

Tabelle 9: Ergebnisse der multivariaten linearen Regression für QRKD postoperativ

\begin{tabular}{|l|l|l|l|}
\hline Parameter & Reg.koeffizient & Std.fehler & p \\
\hline Geschlecht & -0.03201 & 0.02302 & 0.1644 \\
\hline Alter & 0.00041 & 0.00076 & 0.5910 \\
\hline Kiefer & -0.05399 & 0.02437 & 0.0267 \\
\hline Postop. Verlaufszeit & -0.00001 & 0.00002 & 0.7608 \\
\hline Komplikationen & -0.00365 & 0.03304 & 0.9121 \\
\hline
\end{tabular}

Tabelle 10: Mittelwert mit Standardabweichung des QRKD postoperativ bei Frauen, Männern, Ober- und Unterkiefer, Komplikationsgruppe Ja/Nein sowie der p-Wert der univariaten Regressionsmodelle

\begin{tabular}{|l|l|l|l|}
\hline Parameter & Wert & QRKD postoperativ & p \\
\hline Geschlecht & m & $1.06+/-0.16$ & 0.2732 \\
\hline Kiefer & W & $1.03+/-0.21$ & \\
\hline & OK & $1.07+/-0.20$ & 0.0340 \\
\hline Komplikationen & UK & $1.02+/-0.18$ & \\
\hline & Ja & $1.05+/-0.21$ & 0.8718 \\
\hline & Nein & $1.04+/-0.19$ & \\
\hline
\end{tabular}




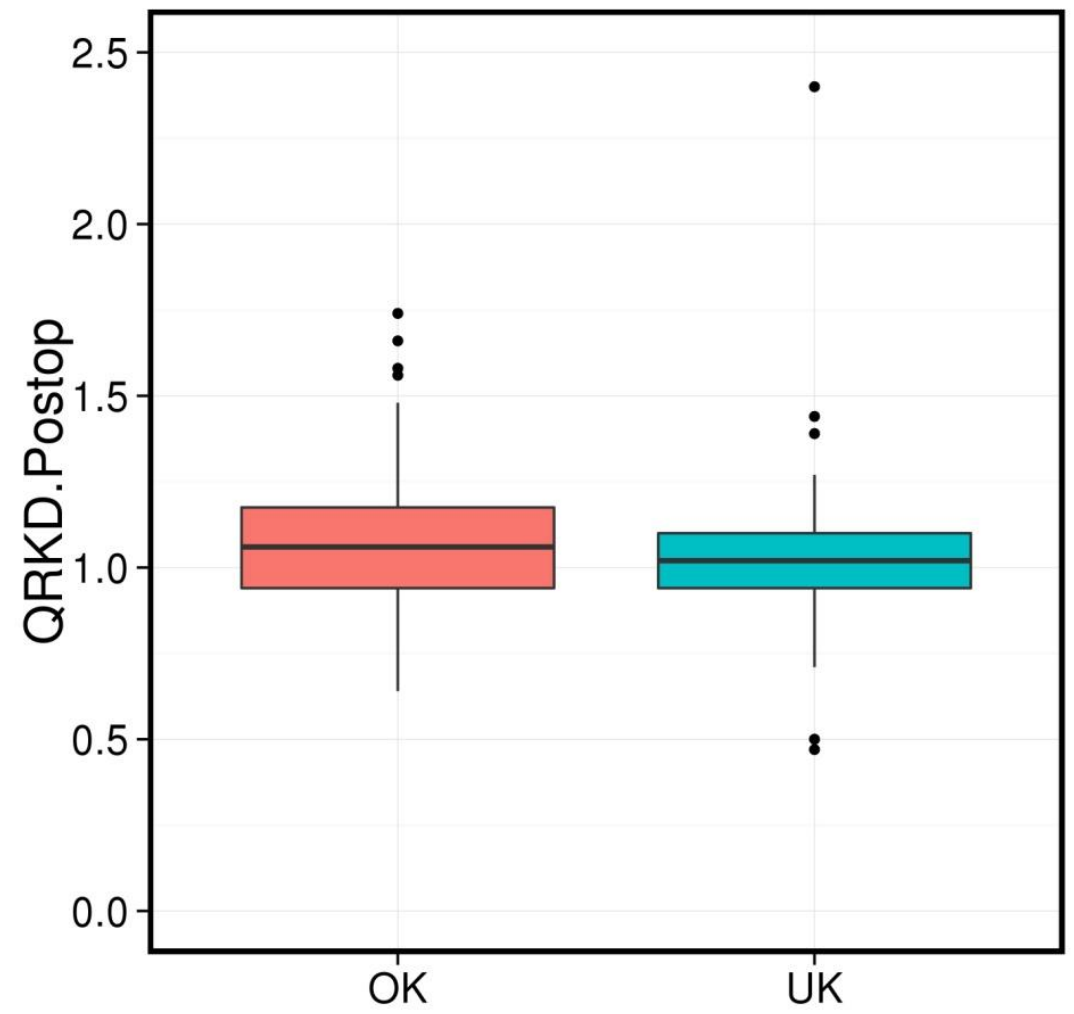

Abbildung 15: Boxplot zur Darstellung der Knochendichtewerte postoperativ zwischen Ober- und Unterkiefer

Tabelle 11: Korrelationskoeffizient nach Pearson für $Q R K D$, das Alter und die Zeit zwischen OP und Verlauf in Tagen mit zugehörigem $p$-Wert

\begin{tabular}{|l|l|l|}
\hline Parameter & Pearsons.r & $\mathbf{p}$ \\
\hline Alter & 0.0324 & 0.5918 \\
\hline Postop. Verlaufszeit & -0.0094 & 0.8760 \\
\hline
\end{tabular}




\subsubsection{Quotient der relativen Knochendichte Verlauf (QRKD Verlauf)}

Eine signifikante Abhängigkeit von QRKD postoperativ auf QRKD Verlauf konnte statistisch festgestellt werden. Ein hoher postoperativer Knochendichtewert ging mit einem hohen Quotientwert im Verlauf einher ( $p<0,001)$ (Tab. 12).

Tabelle 12: Ergebnisse der multivariaten Regression für QRKD Verlauf

\begin{tabular}{|l|l|l|l|}
\hline Parameter & Reg.koeffizient & Std.fehler & p \\
\hline Geschlecht & -0.03837 & 0.02119 & 0.0702 \\
\hline Alter & -0.00053 & 0.00085 & 0.5365 \\
\hline Kiefer & -0.00273 & 0.02163 & 0.8996 \\
\hline QRKD postoperativ & 0.36430 & 0.10070 & $<0.001$ \\
\hline Postop. Verlaufszeit & 0.00001 & 0.00003 & 0.7085 \\
\hline Komplikationen & -0.03370 & 0.04066 & 0.4072 \\
\hline
\end{tabular}

Es konnte weiterhin kein Einfluss von Geschlecht, Alter, der Zeit zwischen den Eingriffen und den Kontrolluntersuchungen sowie von Komplikationen auf den QRKD nach der Kontrollzeit festgestellt werden (Tab. 13, 14).

Tabelle 13: Mittelwert mit Standardabweichung des QRKD Verlauf bei Frauen, Männern, Ober- und Unterkiefer, Komplikationsgruppe Ja/Nein sowie der p-Wert der univariaten Regressionsmodelle

\begin{tabular}{|l|l|l|l|}
\hline Parameter & Wert & QRKD Verlauf & p \\
\hline Geschlecht & m & $1.04+/-0.18$ & 0.0395 \\
\hline Kiefer & W & $0.99+/-0.21$ & \\
\hline & OK & $1.02+/-0.24$ & 0.4218 \\
\hline Komplikationen & UK & $1.00+/-0.15$ & \\
\hline & Ja & $1.04+/-0.28$ & 0.4048 \\
\hline & Nein & $1.01+/-0.18$ & \\
\hline
\end{tabular}

Tabelle 14: Korrelationskoeffizient nach Pearson für QRKD Verlauf, das Alter und die Zeit zwischen OP und Verlauf in Tagen mit zugehörigem $p$-Wert

\begin{tabular}{|l|l|l|}
\hline Parameter & Pearsons.r & p \\
\hline Alter & -0.0445 & 0.4617 \\
\hline Postop. Verlaufszeit & 0.0201 & 0.7390 \\
\hline QRKD postoperativ & 0.3574 & $<0.001$ \\
\hline
\end{tabular}


Das Streudiagramm (Abb. 16) zeigt den linearen Zusammenhang beider Quotienten postoperativ und im Verlauf. Die positive Steigung der Regressionsgeraden weist auf eine tendenzielle Korrelation zwischen beiden Quotienten hin.

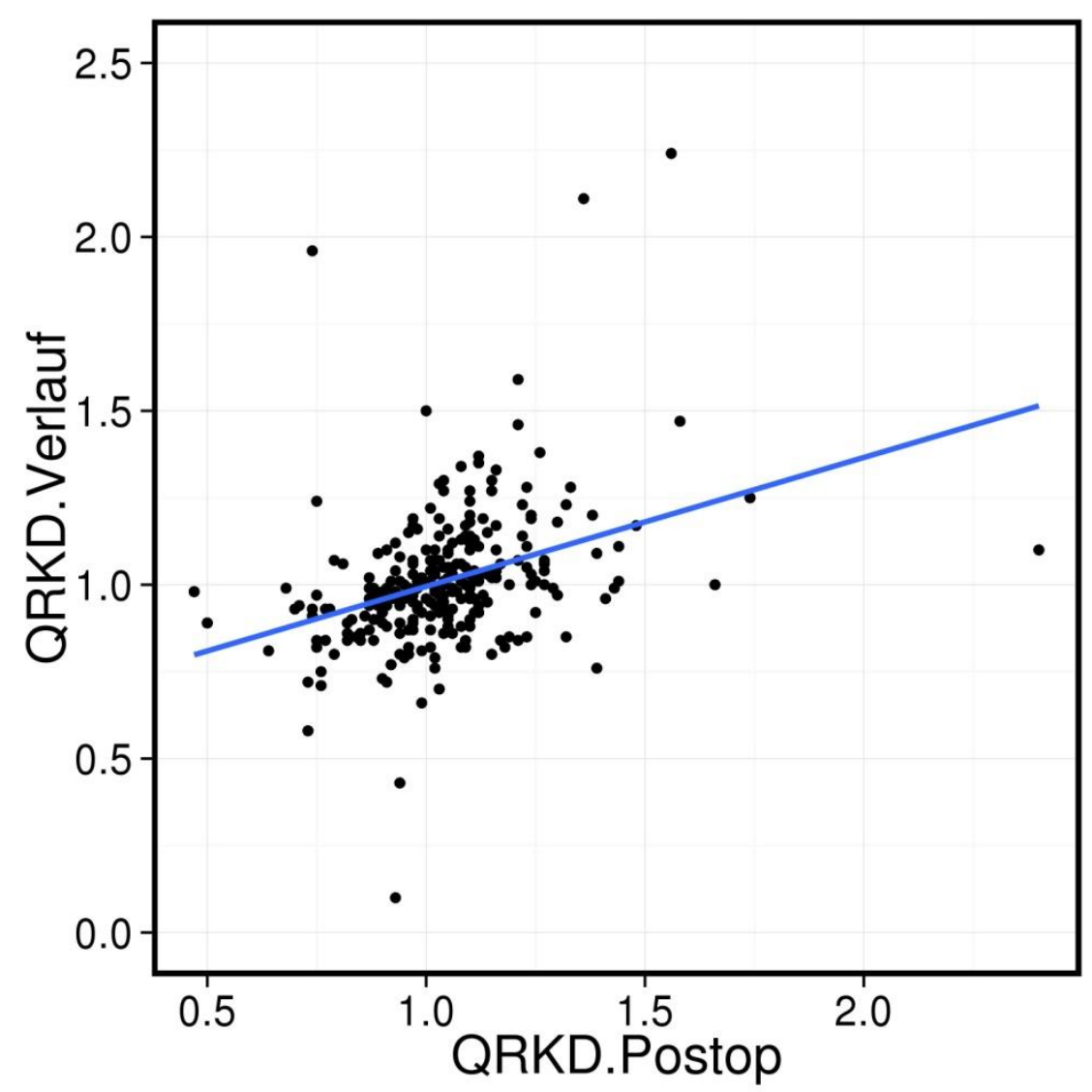

Abbildung 16: Scatterplot zur Darstellung des linearen Zusammenhangs zwischen QRKD postoperativ und QRKD Verlauf 


\subsection{Qualitative Bewertung der Röntgenbilder}

Die Beurteilung der Röntgenbilder und Bewertung über den Degradationsgrad des KEMs erfolgte anhand subjektiver Einschätzung in den Gruppen eins bis vier. Eine Bewertungsskala mit einer Codierung von eins bis sechs wurde festgelegt (Abb. 17).

Codierung - Röntgenologische Beurteilung über Degradationsgrad ß-TCP

- Code 1 = Sehr gute Degradation

- Code 2 = Gute Degradation

- Code 3 = ß-TCP röntgenologisch noch erkennbar

- Code 4 = Kleine apikale Aufhellung

- Code 5 = Große apikale Aufhellung (kein Umbau in Eigenknochen)

- Code 6 = Rezidiv/ Misserfolg im Augmentat

Abbildung 17: Bewertungsskala für die qualitative Beurteilung der Degradation von $\beta$-TCP auf den Röntgenaufnahmen

Anhand der klinischen Fallbeispiele (Abb. 18-23) soll im Folgenden die Interpretation der radiologischen Bewertung und der Codierung veranschaulicht dargestellt werden.

\section{Code 1:}

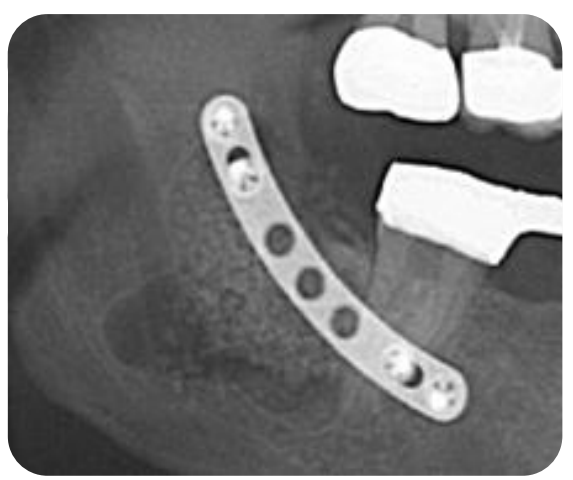

a) QRKD postoperativ: 0,88

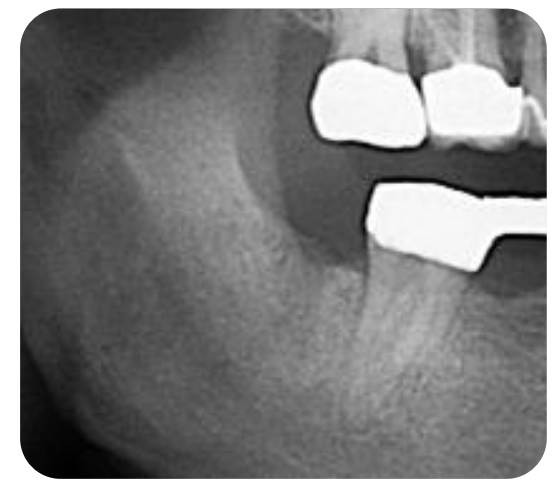

b) QRKD Verlauf: 0,99 (nach 558 Tagen) 


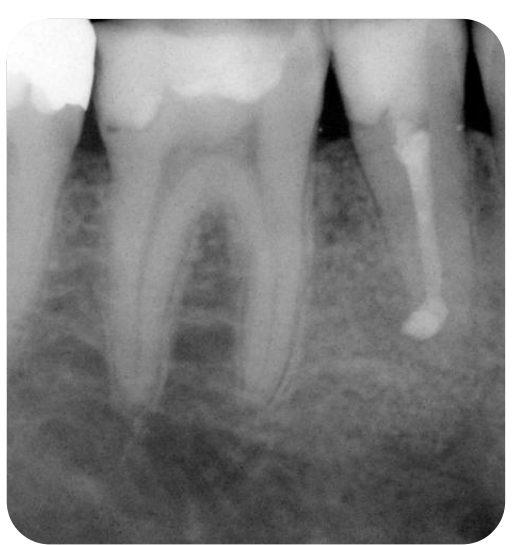

c) QRKD postoperativ: 0,93

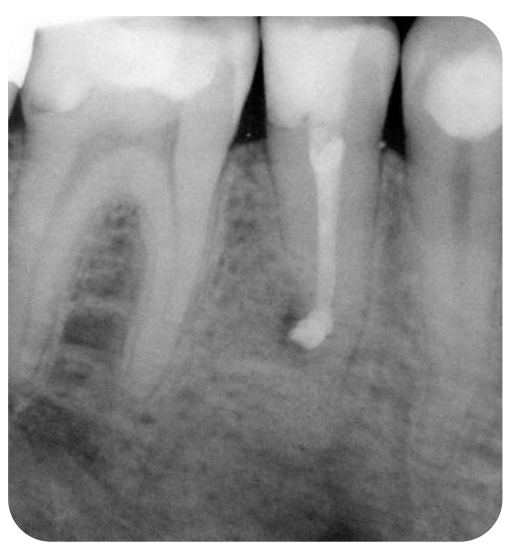

d) QRKD Verlauf: 1,04 (nach 123 Tagen)

Abbildung 18: a) Augmentation mit $\beta-T C P$ bei Zustand nach Osteotomie und Zystektomie, b) ursprünglicher Knochendefekt ist vom umliegenden Knochen visuell nicht mehr zu unterscheiden; c) WSR postoperativ und d) nach der Verlaufszeit mit dazugehörigem QRKD

\section{Code 2:}

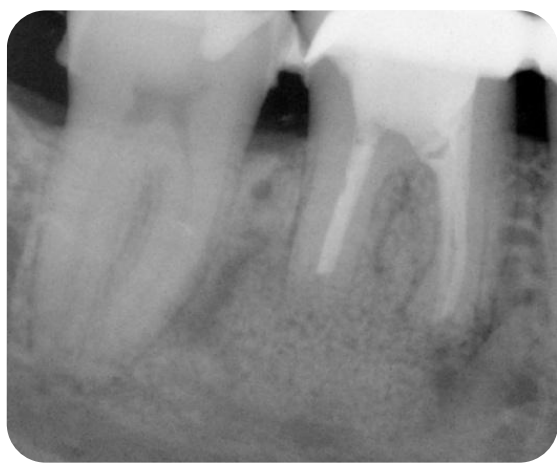

a) QRKD postoperativ: 1,01

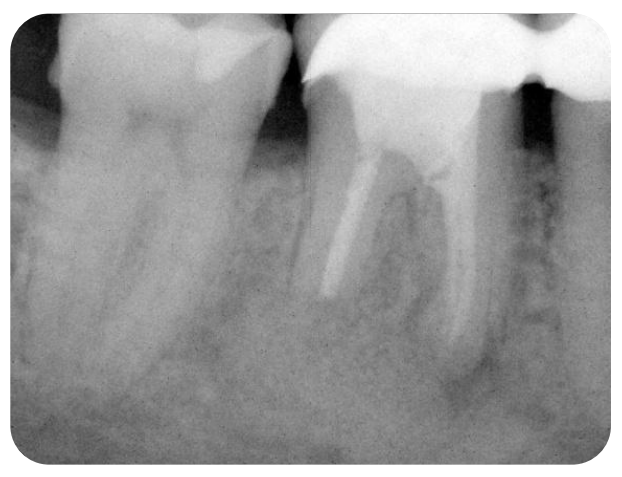

b) QRDK Verlauf: 1,07 (nach 145 Tagen)

Abbildung 19: Code 2 WSR a) postoperativ und b) nach der Verlaufszeit von 145 Tagen mit dem QRKD

\section{Code 3:}

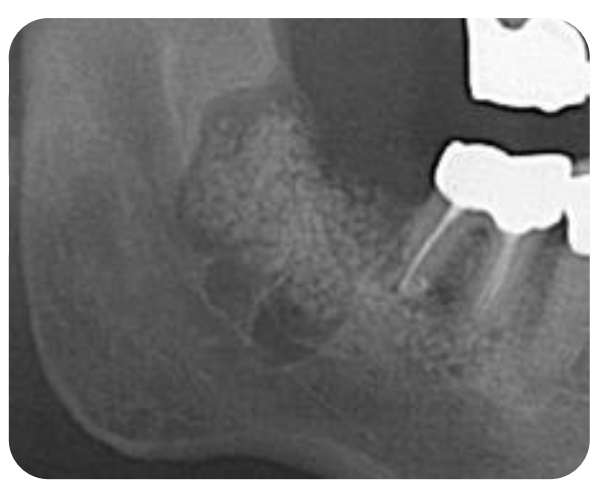

a) QRKD postoperativ: 1,14

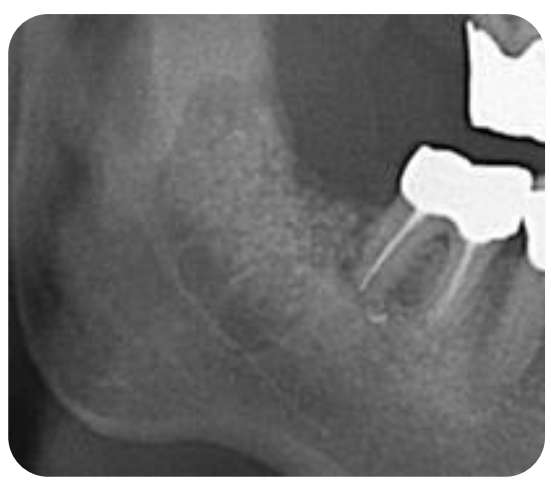

b) QRKD Verlauf: 1,15 (nach 99 Tagen)

Abbildung 20: a) Zustand nach Osteotomie und Zystektomie und b) der Verlaufszeit nach 99 Tagen 


\section{Code 4:}

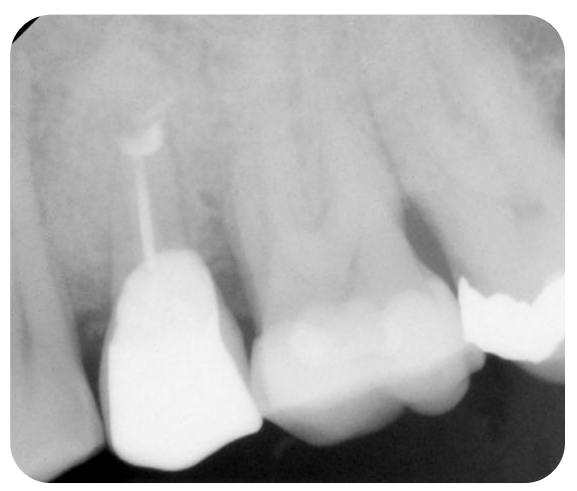

a) QRKD postoperativ: 1,1

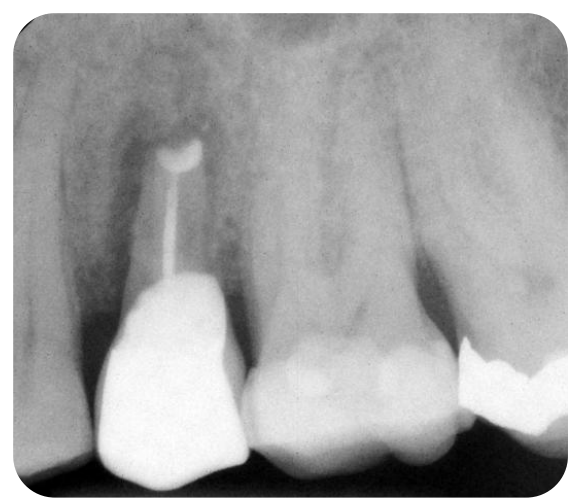

b) QRKD Verlauf: 0,9 (nach 117 Tagen)

Abbildung 21: Code 4 a) nach WSR und b) im Verlauf nach 117 Tagen mit kleiner Aufhellung

\section{Code 5:}

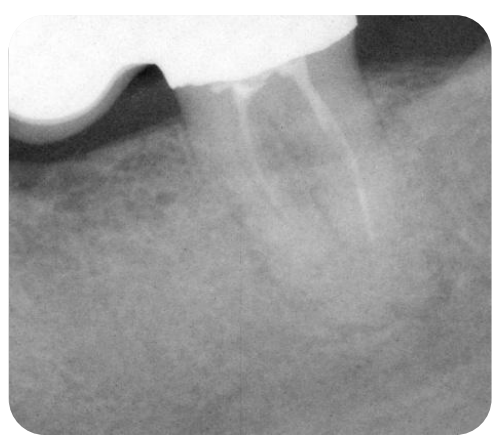

a) QRKD postoperativ 1,11

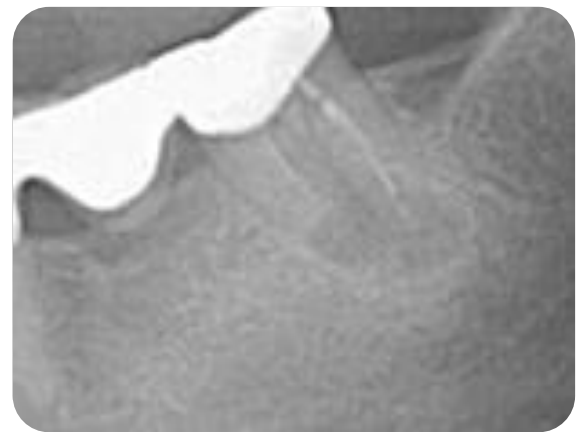

b) QRKD Verlauf: 0,96 (nach 1528 Tagen)

Abbildung 22: a) Zustand nach WSR und b) im Verlauf nach 1528 Tagen mit deutlich erkennbarer apikaler Aufhellung

\section{Code 6:}

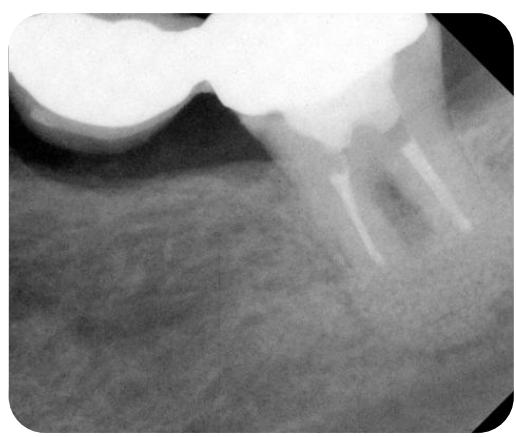

a) QRKD postoperativ 1,17

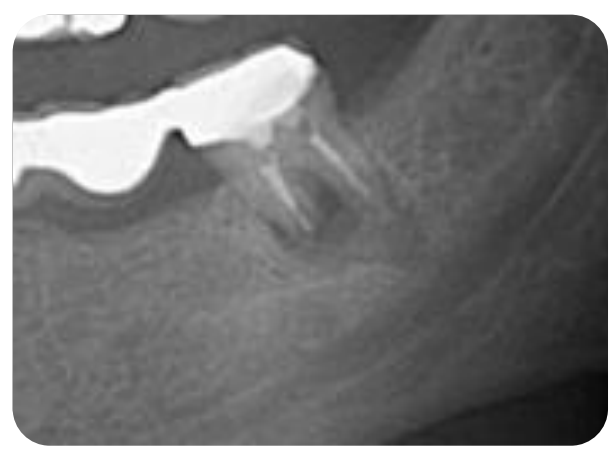

b) QRKD Verlauf 0,84 (nach 1512 Tagen)

Abbildung 23: a) Zustand nach WSR und b) nach 1512 Tagen mit Auftreten einer Rezidivostitis 
Die Tabelle 15 sowie die Abbildung 24 zeigen die Häufigkeitsverteilung der radiologischen Bewertungskriterien über das Degradationsverhalten von ß-TCP.

Tabelle 15: Absolute und relative Häufigkeiten der Bewertungscodes (Qualitative Bewertung) innerhalb jeder Indikationsgruppe

\begin{tabular}{|l|l|r|r|r|r|}
\hline Parameter & Code & \multicolumn{1}{l|}{$\begin{array}{l}\text { WSR } \\
\text { (Gruppe 1) }\end{array}$} & $\begin{array}{l}\text { Socket } \\
\text { Preservation } \\
\text { (Gruppe 2) }\end{array}$ & $\begin{array}{l}\text { Osteotomie } \\
\text { (Gruppe 3) }\end{array}$ & \multicolumn{1}{l|}{$\begin{array}{l}\text { Zysten } \\
\text { (Gruppe 4) }\end{array}$} \\
\hline & & $\mathrm{n}=181$ & $\mathrm{n}=47$ & $\mathrm{n}=34$ & 14 \\
\hline $\begin{array}{l}\text { Qualitative } \\
\text { Bewertung }\end{array}$ & 1 & $47(26 \%)$ & $12(25.5 \%)$ & $13(38.2 \%)$ & $3(21.4 \%)$ \\
\hline & 2 & $48(26.5 \%)$ & $16(34 \%)$ & $6(17.6 \%)$ & $4(28.6 \%)$ \\
\hline & 3 & $31(17.1 \%)$ & $16(34 \%)$ & $10(29.4 \%)$ & $6(42.9 \%)$ \\
\hline & 4 & $40(22.1 \%)$ & $3(6.4 \%)$ & $3(8.8 \%)$ & $1(7.1 \%)$ \\
\hline & 5 & $9(5 \%)$ & $0(0 \%)$ & $2(5.9 \%)$ & $0(0 \%)$ \\
\hline & 6 & $6(3.3 \%)$ & $0(0 \%)$ & $0(0 \%)$ & $0(0 \%)$ \\
\hline
\end{tabular}

In 95 Fällen der Wurzelspitzenresektionen resultierte eine sehr gute bis gute Degradation des KEMs bis zur vollständigen Knochenkonsolidierung. Ein röntgenologisch noch erkennbares ß-TCP-Granulat bestand in 31 Fällen nach der Kontrollzeit. In 40 Fällen waren kleine apikale Aufhellungen aufgetreten und das Granulat war röntgenologisch sichtbar. In neun aller untersuchten Fälle zeigte sich eine ausgedehnte apikale Aufhellung, in sechs Defekten war ein deutlicher radiologischer Mineralverlust als Indiz für Entzündungsgewebe erkennbar.

Augmentationen zur Socket Preservation zeigten in zwölf Fällen ein sehr gutes und in 16 Fällen ein gutes Ergebnis mit vollständiger Knochenkonsolidierung. In 16 Fällen war das ß-TCP-Granulat im Röntgenbild noch erkennbar. Drei der Knochendefekte zeigten Aufhellungen und Zwischenräume im Augmentat. Rezidive, im Sinne von Verlust des Materials und Entstehung neuen Granulationsgewebes, traten in dieser Gruppe nicht auf.

Von 34 durchgeführten Osteotomien mit Knochenaufbau kam es in 13 Fällen zu einem sehr guten Ergebnis im Rahmen einer Knochenkonsolidierung. Sechs Defekte waren gut ausgeheilt. In zehn Fällen war das KEM röntgenologisch leicht erkennbar, in drei Alveolen waren Aufhellungen zwischen den Granulatpartikeln sichtbar. In zwei augmentierten Bereichen stellte sich im Röntgenbild das Augmentationsareal stark aufgehellt dar.

Von 14 Zystektomien sind drei Defekte sehr gut und vier gut verknöchert. In sechs Fällen war das ß-TCP-Granulat noch deutlich erkennbar und in einem Fall zeigten sich aufgehellte Bereiche im Defektbereich. Die histopathologische Untersuchung ergab ein 
heterogenes Befundergebnis. Follikuläre Zysten $(n=6)$ sowie radikuläre Zysten $(n=3)$, keratozystische odontogene Tumoren $(n=2)$, Residualzyste $(n=1)$, Osteom $(n=1)$ und Hämangiom $(n=1)$ wurden intraoperativ sorgfältig entfernt.

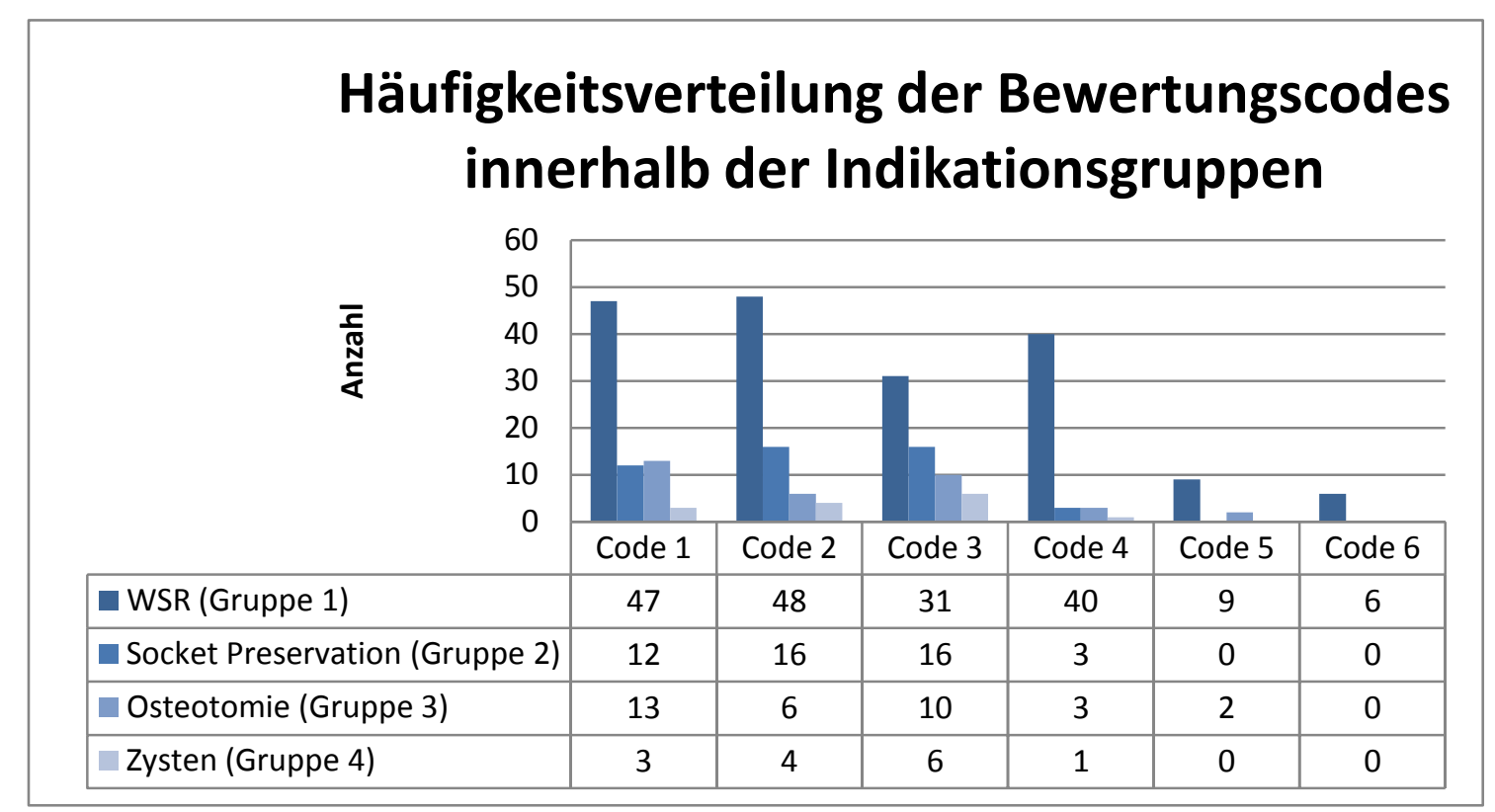

Abbildung 24: Häufigkeitsverteilung der Bewertungscodes in den Gruppen eins bis vier nach röntgenologischer Beurteilung 


\subsection{Komplikationen in den Gruppen 1 bis 4}

Klinische Komplikationen der vier Indikationsgruppen wurden anhand einer Codierungsskala evaluiert und beurteilt (Abb. 25) und in Tabelle 16 zusammengefasst.

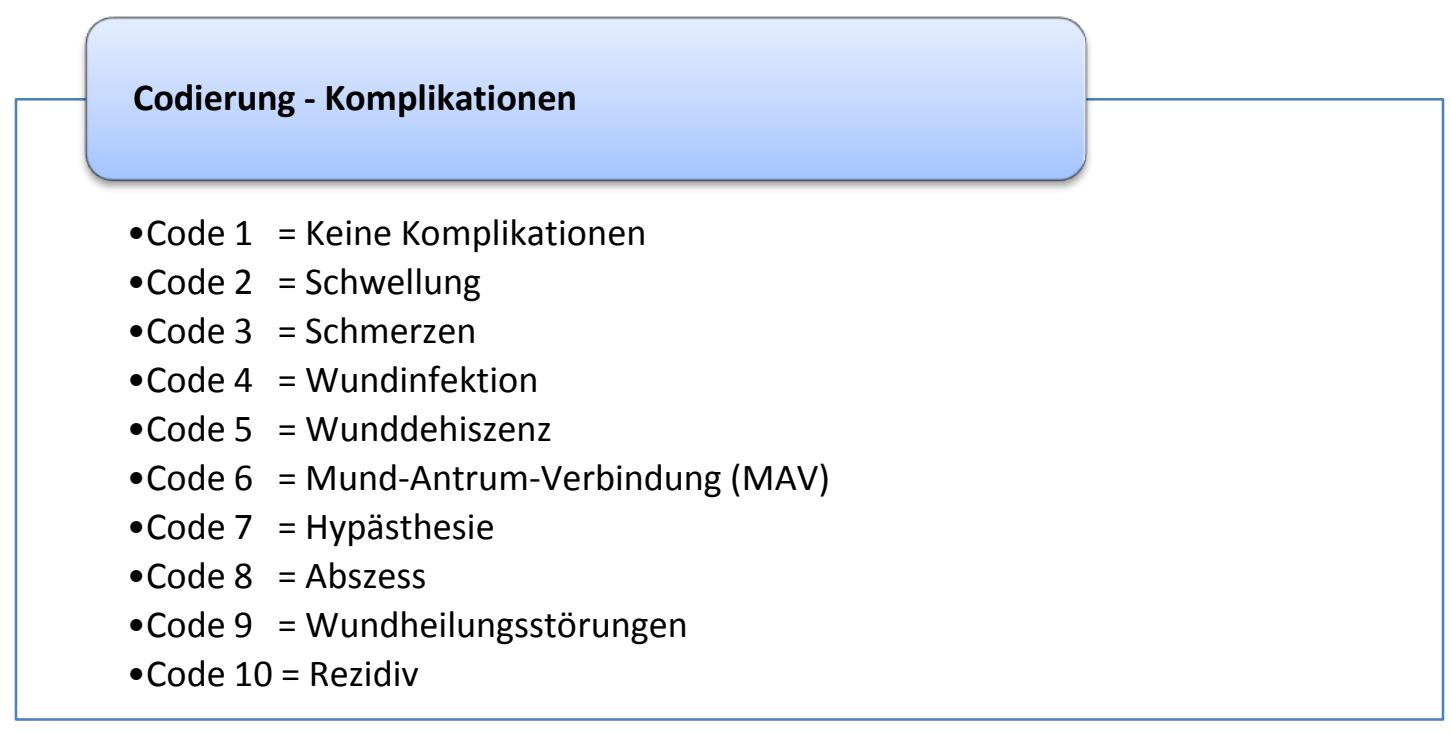

Abbildung 25: Codierungsskala zur Beurteilung der Komplikationen

Tabelle 16: Absolute und relative Häufigkeiten der Bewertungscodes (Komplikationen) innerhalb jeder Indikationsgruppe

\begin{tabular}{|l|l|r|r|r|r|}
\hline Parameter & Code & \multicolumn{1}{l|}{$\begin{array}{l}\text { WSR } \\
\text { (Gruppe 1) }\end{array}$} & $\begin{array}{l}\text { Socket } \\
\text { Preservation } \\
\text { (Gruppe 2) }\end{array}$ & $\begin{array}{l}\text { Osteotomie } \\
\text { (Gruppe 3) }\end{array}$ & $\begin{array}{l}\text { Zysten } \\
\text { (Gruppe 4) }\end{array}$ \\
\hline & & $\mathrm{n}=181$ & $\mathrm{n}=47$ & $\mathrm{n}=34$ & 14 \\
\hline Komplikationen & 1 & $143(79 \%)$ & $44(93.6 \%)$ & $28(82.4 \%)$ & $13(92.9 \%)$ \\
\hline & 10 & $16(8.8 \%)$ & $0(0 \%)$ & $0(0 \%)$ & $0(0 \%)$ \\
\hline & 2 & $1(0.6 \%)$ & $1(2.1 \%)$ & $0(0 \%)$ & $0(0 \%)$ \\
\hline & 3 & $1(0.6 \%)$ & $0(0 \%)$ & $0(0 \%)$ & $0(0 \%)$ \\
\hline & 4 & $3(1.7 \%)$ & $0(0 \%)$ & $0(0 \%)$ & $0(0 \%)$ \\
\hline & 5 & $5(2.8 \%)$ & $1(2.1 \%)$ & $0(0 \%)$ & $1(7.1 \%)$ \\
\hline & 6 & $7(3.9 \%)$ & $1(2.1 \%)$ & $2(5.9 \%)$ & $0(0 \%)$ \\
\hline & 7 & $3(1.7 \%)$ & $0(0 \%)$ & $3(8.8 \%)$ & $0(0 \%)$ \\
\hline & 8 & $1(0.6 \%)$ & $0(0 \%)$ & $1(2.9 \%)$ & $0(0 \%)$ \\
\hline & 9 & $1(0.6 \%)$ & $0(0 \%)$ & $0(0 \%)$ & $0(0 \%)$ \\
\hline
\end{tabular}

Aus der Gruppe der WSR mit 181 Fällen waren 143 komplikationslos eingeheilt. In 16 Fällen kam es zum Rezidiv mit periapikalen Entzündungen und klinischer Beschwerdesymptomatik. Eine MAV trat intraoperativ bei sieben Patienten auf und wurde vor der Defektauffüllung sorgfältig mit einer resorbierbaren Membran abgedeckt. In fünf Fällen kam es zu einer Wunddehiszenz. Jeweils bei drei Patienten wurden Wund- 
infektionen und Hypästhesien diagnostiziert. Einmalig traten die Komplikationen Schwellung, Schmerzen, Abszess und eine Wundheilungsstörung auf.

Im Patientenkollektiv zur Socket Preservation waren 44 von 47 Fällen klinisch symptomlos. In jeweils einem Fall kam es zur Schwellung, zur Wunddehiszenz und zur MAV.

In der Osteotomie-Gruppe war in 28 von 34 augmentierten Knochenkavitäten ein komplikationsloses Einheilungsverhalten des synthetischen Knochenersatzmaterials zu beobachten. In drei Fällen wurde eine Hypästhesie, in weiteren zwei Fällen eine Verbindung zur Kieferhöhle festgestellt und in einem Fall kam es zum Abszess.

Von 14 exkochleierten Zysten und augmentierten Defekten trat bei einem Patienten eine Wunddehiszenz auf. Die restlichen 13 Fälle zeigten eine unauffällige Wundheilung sowie klinische Symptomfreiheit. In Abbildung 26 sind die Ergebnisse grafisch aufbereitet.

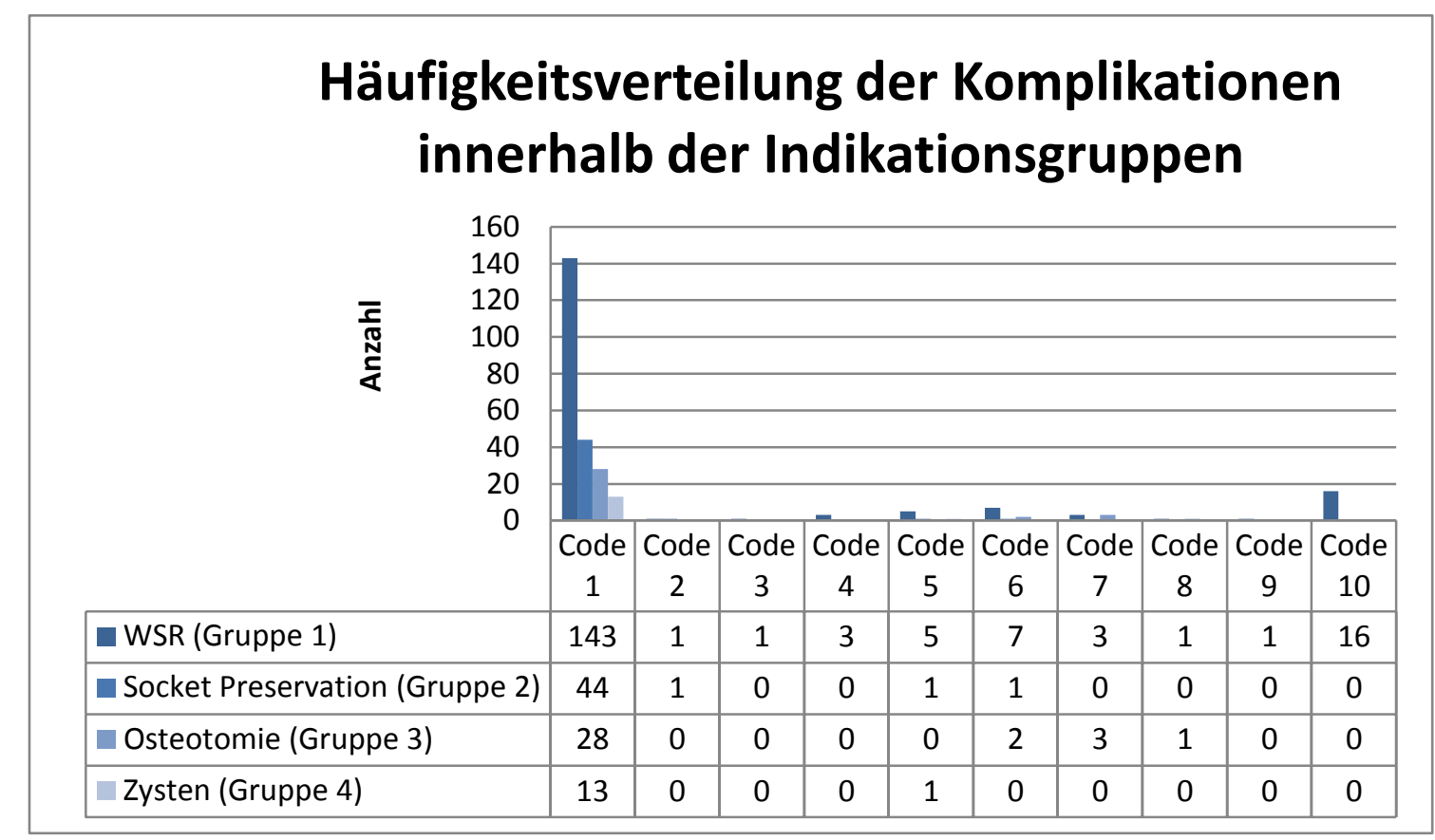

Abbildung 26: Häufigkeitsverteilung der Bewertungscodes in den Gruppen eins bis vier zur klinischen Beurteilung von Komplikationen 


\subsection{Implantatgruppe}

In dieser Gruppe sind 135 Implantate inseriert und in drei Untergruppen eingeteilt worden. Laterale Augmentationen erfolgten bei 91 Implantaten (Eingriff 1), 16 Implantate sind nach vorheriger Socket Preservation (Eingriff 2) und 28 nach einer Sinusbodenaugmentation (Eingriff 3) gesetzt worden (Abb. 27).

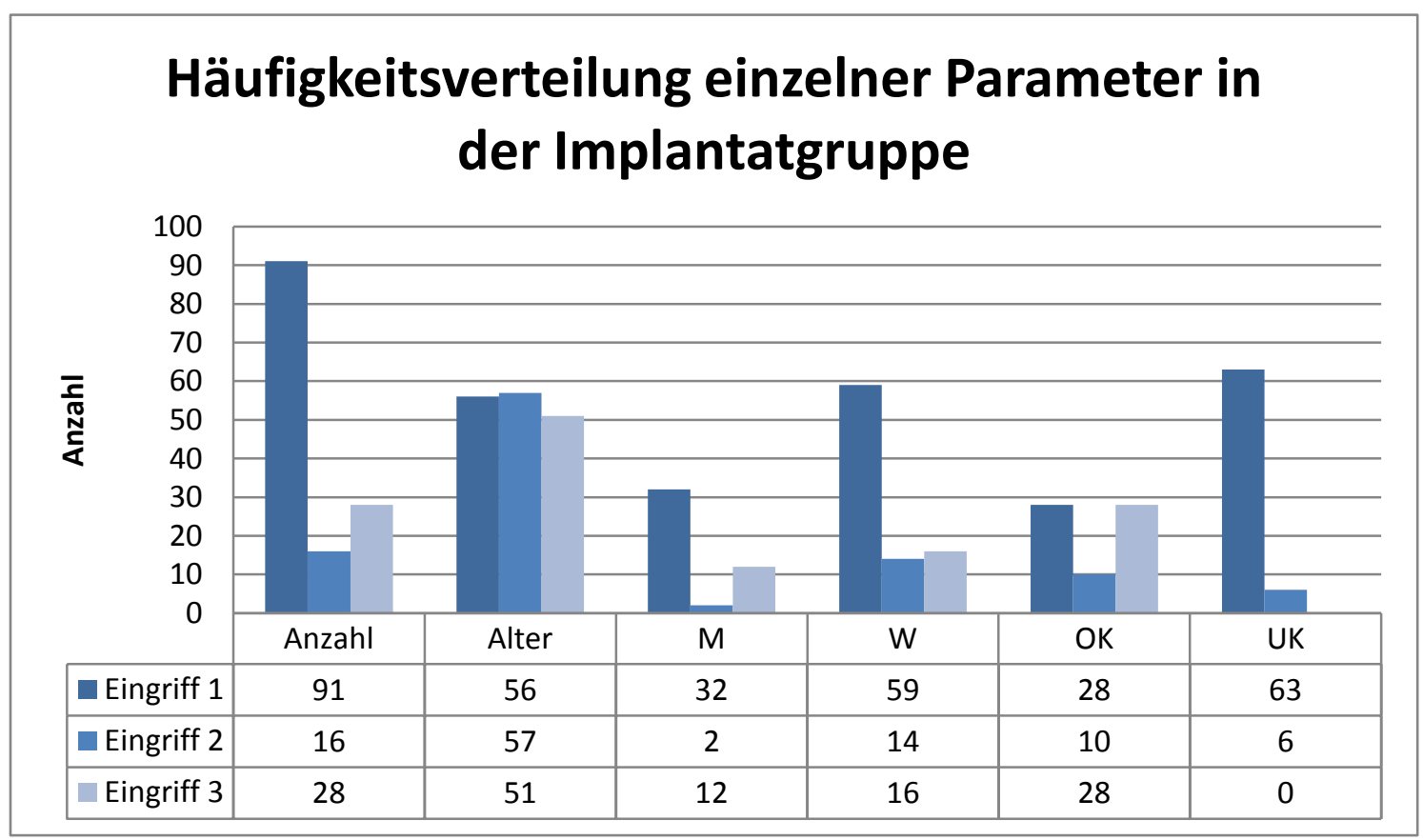

Abbildung 27: Darstellung der Parameter: Anzahl, Alter, Geschlecht, Ober- und Unterkiefer mit der Häufigkeitsverteilung in den Implantatuntergruppen laterale Augmentation (Eingriff 1), Implantation nach Socket Preservation (Eingriff 2) und Implantation nach Sinusbodenaugmentation (Eingriff 3)

Der Nachuntersuchungszeitraum wird in Tabelle 17 wiedergegeben. Die hohe Standardabweichung resultiert aus vorab nicht genau festgelegten Kontrollzeitpunkten und fiel aufgrund dessen unterschiedlich aus.

Tabelle 17: Nachuntersuchungszeitraum in Tagen

\begin{tabular}{|l|r|r|r|}
\hline Parameter & \multicolumn{1}{|l|}{ Eingriff 1 } & \multicolumn{1}{|l|}{ Eingriff 2 } & \multicolumn{1}{|l|}{ Eingriff 3 } \\
\hline & $\mathrm{n}=91$ & $\mathrm{n}=16$ & $\mathrm{n}=28$ \\
\hline Postop. Verlaufszeit & $483+/-420$ & $543+/-380$ & $509+/-415$ \\
\hline
\end{tabular}




\subsubsection{Einheilung und Komplikationen}

Zur Beurteilung der Einheilungstendenz dentaler Implantate sind Röntgenbilder während der Verlaufskontrolle qualitativ beurteilt worden. Eine Codierungsskala von eins bis sechs diente der Evaluation von Erfolgs- und Misserfolgsraten in dem Untersuchungszeitraum (Abb. 28). Die absoluten und relativen Häufigkeiten der Bewertung einzelner Untergruppen sind in Tabelle 18 wiedergegeben.

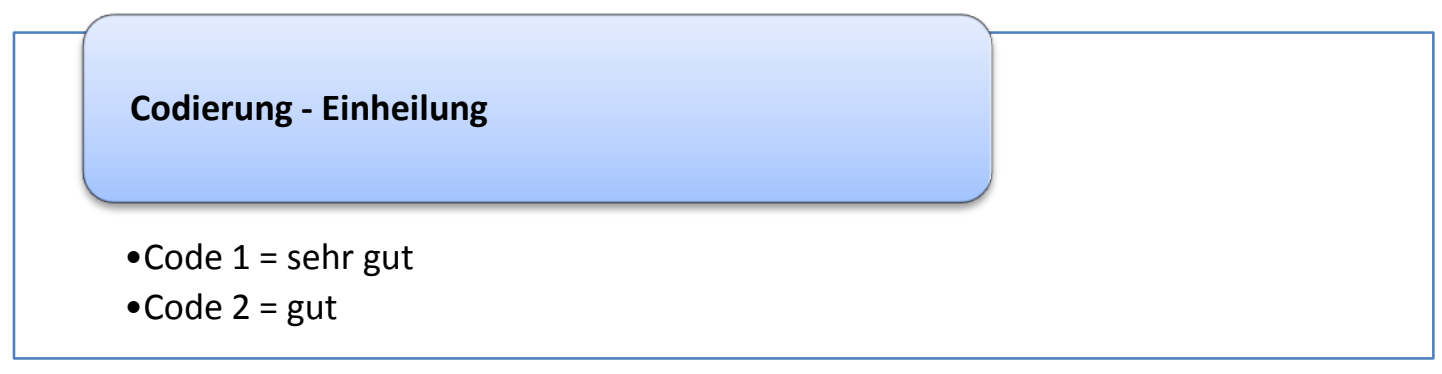

Codierung - Komplikationen

- Code 3 = lateraler Knochenabbau

- Code 4 = Implantatverlust

-Code 5 = Periimplantitis

Abbildung 28: Codierungsskala zur Beurteilung von Implantateinheilung und Komplikationen

Nachfolgend ist für jede Codierung ein klinisches Beispiel aufgeführt (Abb. 29-33).

\section{Code 1:}

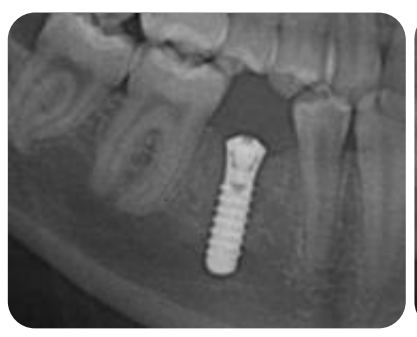

a)

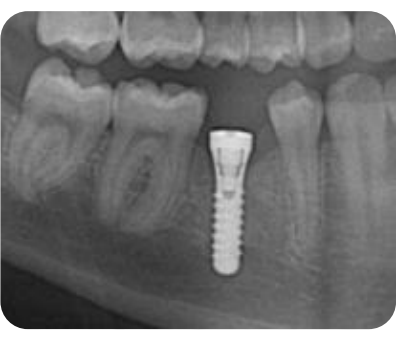

b)

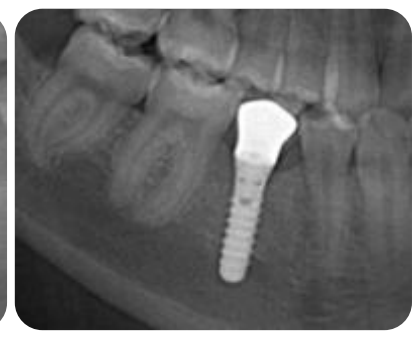

c)

Abbildung 29: a) Postoperatives Röntgenbild, b) nach 144 Tagen und c) nach 279 Tagen ohne lateralen Knochenverlust 


\section{Code 2:}
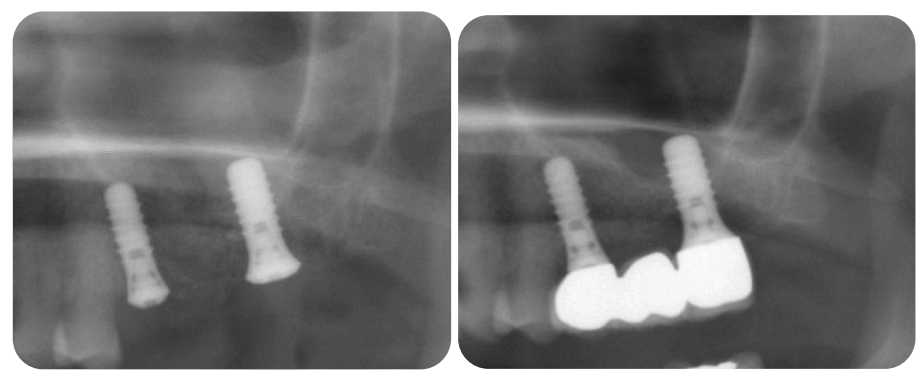

a)

b)

Abbildung 30: a) Inserierte Implantate 25-27 mit Sinuslift, b) Zustand nach 296 Tagen: am 25 kaum Knochenabbau (Code 2), während sich am 27 ein schüsselförmiger Defekt deutlich darstellt (Code 3)

\section{Code 3:}
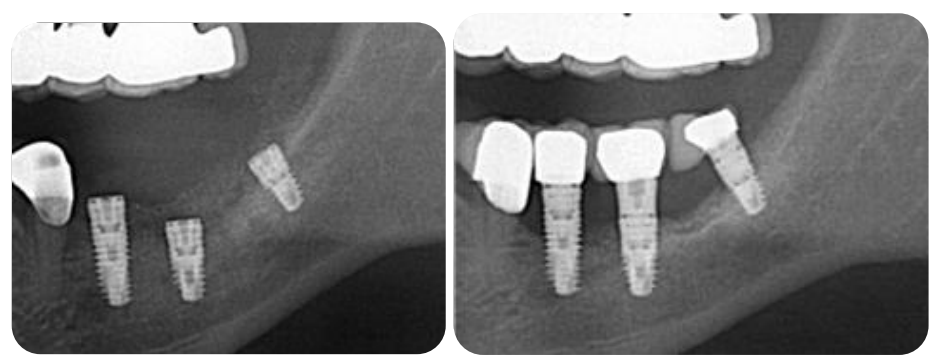

a)

b)

Abbildung 31: a) Postoperatives Röntgenbild mit lateralem $\beta$-TCP-Aufbau, b) nach 584 Tagen zeigt sich ein starker Knochenrückgang um die Implantatschulter

\section{Code 4:}
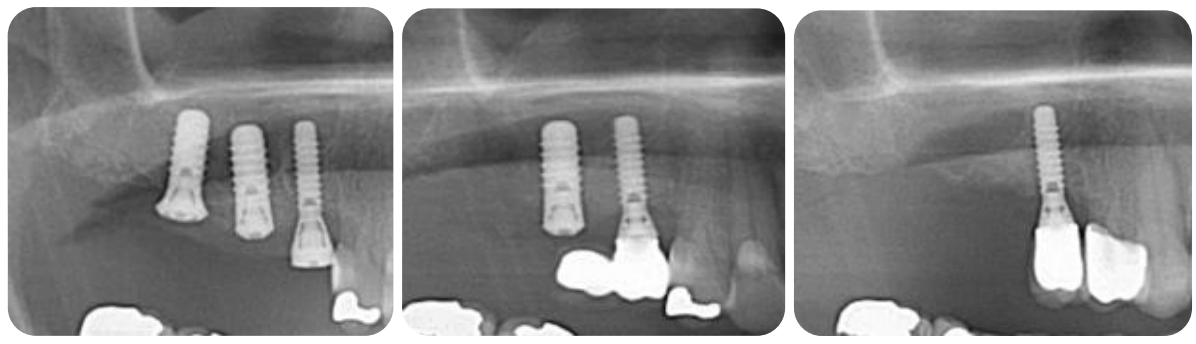

a)

b)

c)

Abbildung 32: a) Zustand nach Sinuslift mit $\beta-T C P$ und Implantatinsertion regio 16 und 17, b) Verlust des Implantates 17 nach 69 Tagen, c) Verlust des Implantates 16 nach 405 Tagen 


\section{Code 5:}

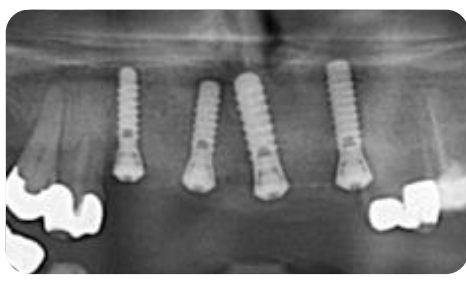

a)

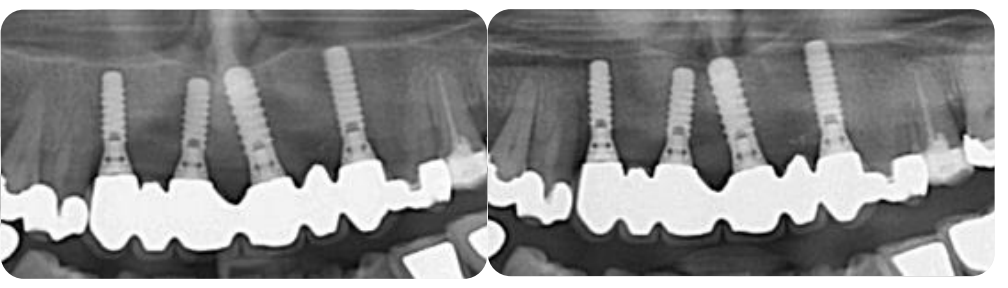

c)

Abbildung 33: a) Postoperative Aufnahme nach Implantatinsertion, b) Periimplantitis an Implantaten 11 und 21, Aufnahmen nach 254 Tagen und c) nach 1250 Tagen

Tabelle 18: Darstellung der absoluten und relativen Häufigkeiten bezüglich Einheilung und Komplikationen in der Implantatgruppe

\begin{tabular}{|l|l|r|r|r|}
\hline Parameter & Code & \multicolumn{1}{|c|}{ Eingriff 1 } & \multicolumn{1}{|c|}{ Eingriff 2 } & \multicolumn{1}{c|}{ Eingriff 3 } \\
\hline & & $\mathrm{n}=91$ & $\mathrm{n}=16$ & $\mathrm{n}=28$ \\
\hline Einheilung/Komplikationen & 1 & $42(46.2 \%)$ & $7(43.8 \%)$ & $17(60.7 \%)$ \\
\hline & 2 & $13(14.3 \%)$ & $3(18.8 \%)$ & $6(21.4 \%)$ \\
\hline & 3 & $32(35.2 \%)$ & $6(37.5 \%)$ & $3(10.7 \%)$ \\
\hline & 4 & $1(1.1 \%)$ & $0(0 \%)$ & $2(7.1 \%)$ \\
\hline & 5 & $3(3.3 \%)$ & $0(0 \%)$ & $0(0 \%)$ \\
\hline
\end{tabular}




\section{Implantatgruppe Eingriff 1}

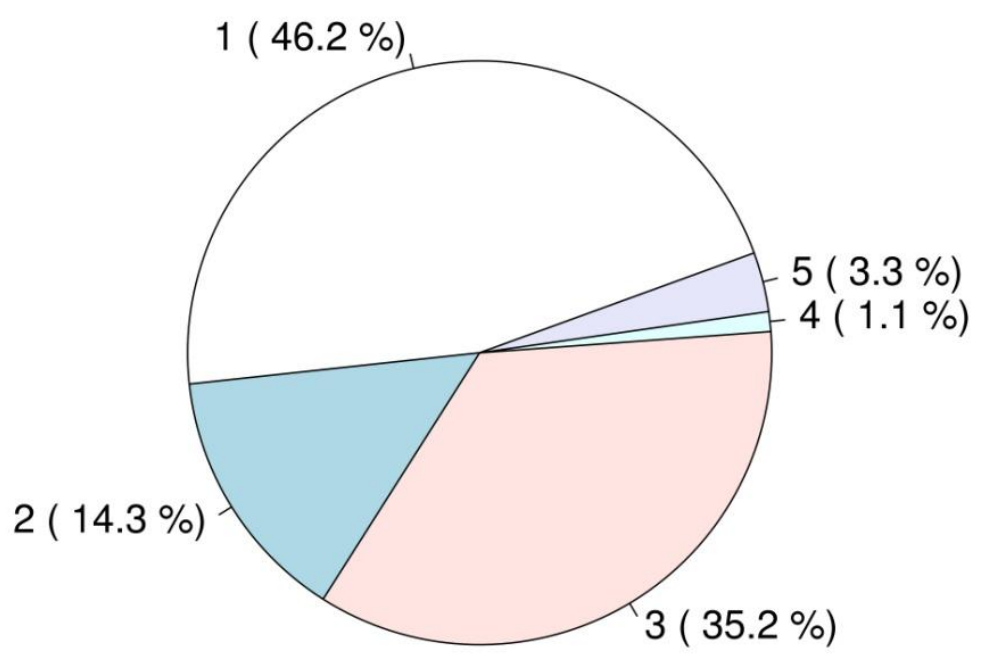

Einheilung/Komplikation
1: Sehr gut
2: Gut
3: Lateraler Knochenabbau
4: Implantatverlust
5: Periimplantitis

Abbildung 34: Tortendiagramm zeigt prozentuale Erfolgs- und Misserfolgsraten in der Gruppe der lateralen Augmentationen

Wenn die Beurteilung sehr gut und gut zusammengefasst wird, kann in 60,5\% ein Behandlungserfolg aus 91 Fällen nach Insertion der Implantate mit lateraler Augmentation in einem durchschnittlichen Kontrollzeitraum von 483 Tagen verzeichnet werden (Abb. 34). Lateraler Knochenabbau fand in 35,2 \% der Fälle statt, diese Implantate waren jedoch weiterhin osseointegriert, aufgrund dessen können diese Fälle ebenfalls als erfolgreiche Implantationen angesehen werden. Ein Implantat ging nach 676 Tagen verloren, weitere drei entwickelten im Laufe der Kontrollzeit eine Periimplantitis. 


\section{Implantatgruppe Eingriff 2}

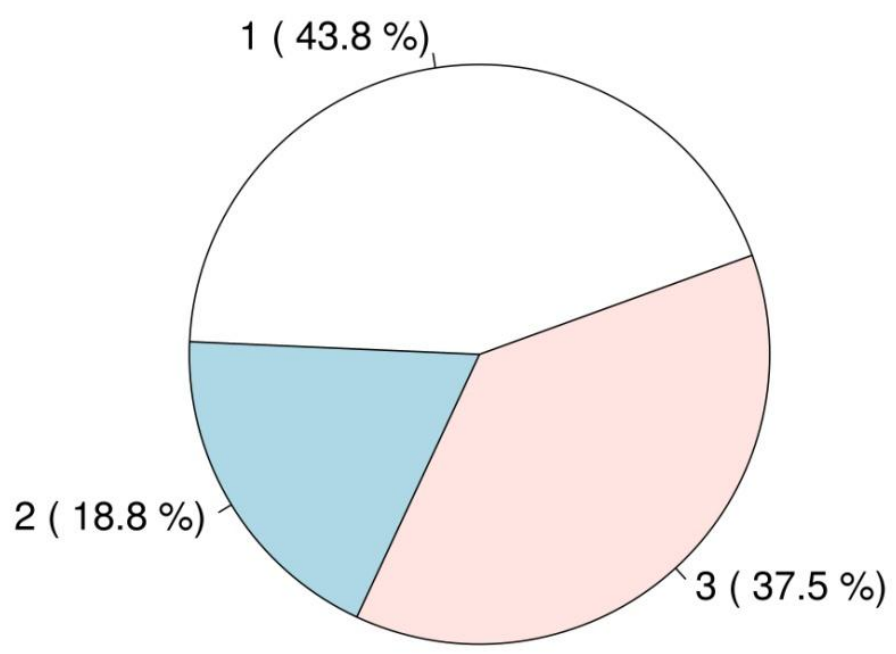

Einheilung/Komplikation
1: Sehr gut
2: Gut
3: Lateraler Knochenabbau
4: Implantatverlust
5: Periimplantitis

Abbildung 35: Tortendiagramm zeigt prozentuale Erfolgs- und Misserfolgsraten in der Gruppe der Implantation nach Socket Preservation

In $62,6 \%$ aus 16 Fällen war die Einheilung sehr gut oder gut. Ein lateraler Knochenabbau zeigte sich in 37,5\% nach der Kontrollzeit von durchschnittlich 543 Tagen, diese Implantate waren weiterhin osseointegriert. Implantatverluste oder Periimplantitis traten nicht auf (Abb. 35). 


\section{Implantatgruppe Eingriff 3}

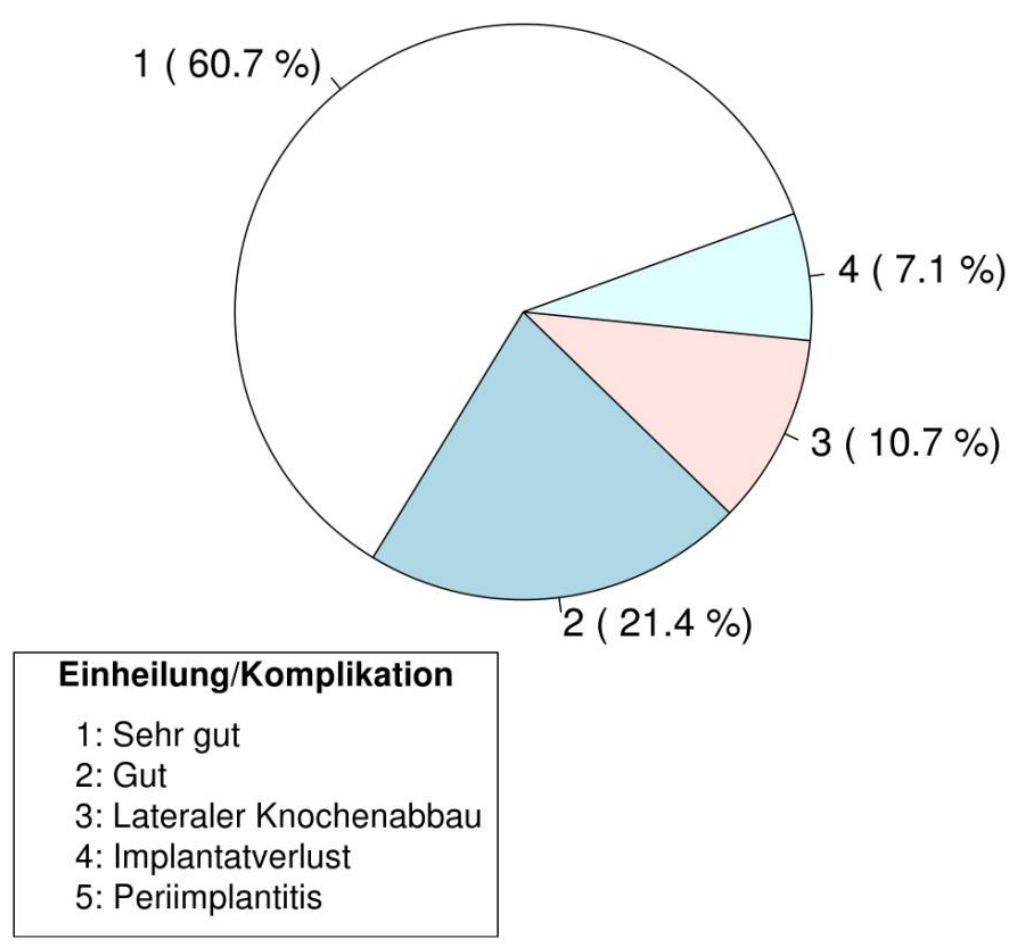

Abbildung 36: Tortendiagramm zeigt prozentuale Erfolgs- und Misserfolgsraten in der Gruppe der Implantation nach Sinusbodenaugmentation

Nach einer Sinusbodenaugmentation zeigten $82,1 \%$ der 28 Implantate im durchschnittlichen Untersuchungszeitraum von 509 Tagen eine sehr gute oder gute Einheilung. Bei $10,75 \%$ der Implantate kam es zum lateralen Knochenabbau ohne Beeinträchtigung der Osseointegration. Zwei Implantate $(7,1 \%)$ sind bei einer Patientin nach der Sinusbodenaugmentation nicht osseointegriert, eines ist nach 69 und das zweite nach 405 Tagen verloren gegangen (Abb. 36).

Geprüft wurden weiterhin eine mögliche Einflussnahme der Faktoren Alter, Geschlecht, Kieferposition sowie die Zeit zwischen der postoperativen Röntgenaufnahme und dem Verlaufsröntgenbild auf die Einheilung und die Komplikationen (Tab. 19). 
Tabelle 19: Ergebnisse der multivariaten logistischen Regression für Komplikationen Ja/Nein

\begin{tabular}{|l|r|r|r|r|}
\hline Parameter & Reg.koeffizient & Std.fehler & OR & p \\
\hline Geschlecht & 0.4482 & 0.5190 & 1.57 & 0.3878 \\
\hline Postop. Verlaufszeit & 0.0002 & 0.0005 & 1.00 & 0.6318 \\
\hline Alter & -0.0033 & 0.0203 & 1.00 & 0.8716 \\
\hline Kiefer & -0.0140 & 0.5361 & 0.99 & 0.9792 \\
\hline
\end{tabular}

Keiner der genannten Parameter hatte einen signifikanten Einfluss auf die Einheilung oder Komplikationen innerhalb der Implantatgruppe. 


\section{Diskussion}

\subsection{Studiendesign}

Der Erhalt des Knochenvolumens im Ober- und Unterkiefer ist in der Zahn- und Kieferheilkunde eine wichtige Prämisse im Hinblick auf Ästhetik, Kaufunktion und prothetische Rehabilitation. Resorptionsprozesse des alveolären Knochens nach Zahnextraktionen, durch pathologische Raumforderungen, Traumen sowie entzündliche Prozesse limitieren das Knochenangebot, was überwiegend in der anterioren Maxilla $z u$ ästhetischen und im gesamten Kieferbereich zu funktionellen Problemen führen kann. Seit Jahrzehnten wird auf dem Gebiet der augmentativen und regenerativen Verfahren geforscht, um die Knochenheilung positiv in Richtung einer schnelleren Regeneration und Funktionsfähigkeit zu beeinflussen. Aufgrund einer Vielzahl an Defektmorphologien nach Verlust von Knochengewebe besteht die Herausforderung darin ein geeignetes Material auszuwählen, welches möglichst viele Anforderungen an ein ideales KEM erfüllt.

Gegenstand der durchgeführten retrospektiven Untersuchung war das alloplastische Material ß-TCP, das sich bereits in klinischen und wissenschaftlichen Studien erfolgreich etabliert hat (Merten et al. 2003, Szabo et al. 2005, Bilk 2007). Die Hauptaufgabe der vorliegenden Studie bestand darin, die klinischen Einsatzmöglichkeiten des resorbierbaren ß-TCPs als Alternative zum autogenen Knochentransplantat zur Augmentation im Kieferbereich zu bewerten. Defekte im Zusammenhang mit Wurzelspitzenresektionen, Extraktionen von Zähnen sowie Osteotomien dritter Molaren, Zystektomien und Insertionen dentaler Implantate wurden in die Auswertung eingeschlossen. Dabei wurde eine erhebliche Datenmenge, wie sie in klinischen Studien nur schwierig zu erlangen ist, generiert. Aus einem Patientenkollektiv von 560 Personen konnten 411 Fälle ausgewertet werden, wobei zunächst 984 Kieferknochendefekte in die Analyse einflossen. Aufgrund von fehlenden postoperativen Röntgenbildern musste ein erheblicher Teil aus der Untersuchung wieder ausgeschlossen werden. Nichtsdestoweniger handelt es sich hierbei um eines der größten Patientenkollektive, die im Zusammenhang mit Knochendefektauffüllungen klinisch retrospektiv untersucht worden sind. Ähnlich hohe Fallzahlen wurden in wissenschaftlichen Studien von Palti und Hoch (2002a) sowie Schermer (2006) erzielt. In Anlehnung an bereits vorausgegangene Literaturberichte (Horch et al. 2006, Bilk 
2007, Harel et al. 2013) mit geringerer Falldokumentation konnte ein umfangreicher klinischer Überblick mit unterschiedlicher Indikationsverteilung erlangt werden.

Besonderes Augenmerk galt dem Degradations- und Resorptionsverhalten und dem Einfluss auf die Knochenregeneration. Für die Erfolgsbewertung wurden klinische und röntgenologische Befunde retrospektiv ausgewertet. Relative Knochendichten sind für jede Indikationsgruppe mittels einer Bildanalysesoftware (ImageJ) digital bestimmt worden. Augmentationen in Verbindung mit Insertion dentaler Implantate wurden qualitativ durch speziell definierte Kriterien an Röntgenaufnahmen bewertet.

\subsection{Anwenderkalibrierung zur Validierung des Messverfahrens}

Für die Bildanalyse wurde ein aus dem Internet frei verfügbares Programm, das ImageJ (1.44 p, Wayne Rasband, National Institutes of Health, USA), verwendet. Es kann gebührenfrei auf dem Rechner installiert werden und ist unkompliziert in der Bedienung. Nach einer kurzen Einarbeitung kann es vom gesamten Praxispersonal genutzt werden. Für die Untersuchung sind keine Spezialaufnahmen in klinischen Zentren erforderlich. Die bereits zur prä- und postoperativen Nachuntersuchung des Patienten angefertigten konventionellen oder digitalen Röntgenbilder genügen für die Auswertung. Aus genannten Gründen wurde die Software für die Analyse der Bilddateien ausgewählt und vor der Hauptuntersuchung auf Zuverlässigkeit und Präzision getestet.

Zur Validierung des Messverfahrens sind drei Untersucher in der Trainigsphase an unterschiedlichen Röntgenbildern im Umgang mit der Bildanalysesoftware ImageJ geschult worden. Gemeinsam ausgearbeitete, klar definierte Kriterien zum Umfahren der Defekt- und umliegenden Knochenregionen halfen bei der Abgrenzung der ROIs von den anatomischen Nachbarstrukturen wie Kieferhöhlen, Kompaktastrukturen sowie dem Nervenkanal samt Foramen mentale. Bei verzeichneten Röntgenbildern, vor allem im Bereich der Überlagerung aufgrund falscher Zungenposition, gestaltete sich die Bildanalyse als schwierig. Deswegen sind Aufnahmen, die den Bewertungskriterien nicht gerecht wurden, aus allen Untersuchungen ausgeschlossen worden. Besonders übersichtlich war die Auswahl der Defektregion, dank höherer Röntgenopazität des ß-TCPs im Kontrast zum gesunden Knochen. Demgegenüber stand die Regel, ROls gleicher Pixelanzahl sowohl für die Defekt- als auch die Umgebungsregion auszuwählen. In einigen Fällen war das zirkuläre Umfahren der Umgebungsregion durch direkte Nachbarschaft anatomischer Strukturen, insbesondere im Oberkiefer, limitiert. Die Größe des zweiten ROls musste in Ausnahmefällen geringer ausfallen beziehungsweise an dem zum Defekt benachbarten gesunden Knochen oder der 
kontralateralen Seite ausgewählt werden. Alle in den Vorversuchen definierten Kriterien galten ebenso für die Hauptuntersuchung in den Indikationsgruppen dieser Studie.

Die Resultate der Vorversuche zeigen eine intraindividuell geringe Standardabweichung von +/- 0,01 bis +/- 0,06 des QRKD vom Mittelwert. Dies spricht für eine gute Kalibrierung und Genauigkeit des einzelnen Untersuchers beim Umfahren der Defekt- und der umliegenden gesunden Knochenregion. Evaluiert wurde weiterhin die Verlässlichkeit der Untersuchungsmethode im interindividuellen Vergleich. Obwohl die Beurteiler zu unterschiedlichen Zeitpunkten ohne Absprache untereinander gearbeitet haben, ergab sich eine geringe interindividuelle Variabilität der Messergebnisse. Unter gleichen Bedingungen durchgeführte Messwiederholungen der Beurteiler spiegeln sich in einer hohen Reliabilität wider, wenn die Ergebnisse untereinander identisch sind (Weiß 2010). Statistisch bestätigt wurde die hohe Interrater-Reliabilität der vorliegenden Vorversuche durch Krippendorffs alpha bei einem Wert von 0,92. Insgesamt lässt dies den Schluss zu, dass die angewandte Messmethode ein hohes Maß an Objektivität zulässt, wenn die messende Person vorab gut instruiert und im Umgang mit dem Programm ImageJ trainiert wurde (Geiger et al. 2016a).

Die Auffassung von Reit und Hollender (1983) sowie Reit und Gröndahl (1983), eine Kalibrierung der Untersucher und das Festlegen definierter Kriterien vor Beginn einer Studie führe zur höheren interindividuellen Übereinstimmung, kann durch vorliegende Vorversuche bestätigt werden. Weitere Erkenntnisse aus röntgenologischen Evaluationen an wurzelgefüllten Zähnen belegen eine bessere Reliabilität der Ergebnisse zur Reduzierung von Falschdiagnosen durch Besprechung bestimmter Problemfälle in der Untersuchungsgruppe und wiederholtes Üben (Saunders et al. 2000, Molven et al. 2002).

\subsection{Quotient der relativen Knochendichte (QRKD)}

Die relative Knochendichte, ausgedrückt als Quotient aus mittlerem Grauwert des Kieferdefekts in Pixel und mittlerem Grauwert des umliegenden gesunden Knochens, resultiert aus dem differenten Absorptionsverhalten anatomischer Strukturen gegenüber Röntgenstrahlung und der damit verbundenen Divergenz des Schwärzungsgrades auf den digitalen Aufnahmen. Mit der Bildanalysesoftware ImageJ wurden QRKD zwischen postoperativen Aufnahmen und Bildern nach bestimmter Verlaufszeit ermittelt und miteinander verglichen. Im Mittelpunkt standen Kieferdefekte unterschiedlicher Indikationen (WSR, Socket Preservation, Osteotomien, Zysten), die mit ß-TCP ad modum Cerasorb ${ }^{\circledR} \mathrm{M}$ aufgefüllt waren. 
Einige Studien untersuchten das osseogene Regenerationspotenzial mithilfe ähnlicher computergestützter Messverfahren und bestimmten die Knochendichte. Größere Defekte nach Zystektomien blieben - im Gegensatz zu der aktuellen Arbeit - der spontanen Knochenheilung ohne Auffüllung mit KEM überlassen (Shokier und Khalifa 2009, Zhao et al. 2010). Ihan Hren und Miljavec (2008) analysierten in ihrer Studie computergestützt OPGs an 33 Unterkieferdefekten nach Exkochleationen von odontogenen Zysten und benignen Tumoren. Sie verglichen die Leerdefekte mit dem umliegenden Knochen und stellten fest, dass eine ideale Knochenheilung bei einem Indexwert von 1 (100\%) erreicht wird, wenn sich die Knochendichte im Defekt dem Dichtewert des gesunden Knochens angeglichen hat.

Die Ergebnisse der vorliegenden retrospektiven Untersuchung zeigen, dass zu Beginn der Untersuchungszeit in den Gruppen eins bis drei höhere Quotienten (1,04-1,03 Median) vorlagen als nach der Verlaufszeit. Aufgrund der höheren Dichte des ß-TCPs ergaben sich für den augmentierten Bereich höhere mittlere Grauwerte als für den umliegenden gesunden Knochen, was folglich den höheren Quotientwert erklärt. Postoperative Messwerte des QRKD fielen mit $p=0,0340$ im Oberkiefer (QRKD: 1,07) signifikant höher aus als im Unterkiefer (QRKD: 1,02). Eine mögliche Erklärung könnte auf der Tatsache beruhen, dass der Anteil an Spongiosa im Oberkiefer höher und die Grauwerte für den umliegenden Knochen damit geringer sind als im Unterkiefer, der mathematisch errechnete Quotientwert für den Oberkiefer demzufolge größer ausfällt. Diese Ergebnisse stehen in Korrelation zum Resultat von Devlin et al. (1998). Sie generierten Messdaten mittels DXA und ermittelten eine geringere Knochenmineraldichte im Oberkiefer im Gegensatz zum Unterkiefer sowie eine geringere Dichte der distalen Maxilla gegenüber der anterioren.

Den anfänglich kleinsten postoperativen QRKD von 0,89 (Median) wies Gruppe vier auf. In erster Linie handelte es sich hierbei um die größten Defekte des Gesamtkollektivs, die umzeichnete Defektregion beinhaltete neben dem alloplastischen Granulat größere, blutgefüllte, transluzent erscheinende Zonen. Der Dichteunterschied zu Defekten anderer wandständig aufgefüllter Knochendefekte spiegelte sich somit in den Grauwertmessungen wider. In Bezug auf den Verlaufswert stieg der QRKD in Gruppe vier auf 0,98 an, während er in den Gruppen eins bis drei etwas sank, sich dennoch dem Idealwert 1 näherte. Insgesamt kann die Änderung der auf den digitalen Röntgenaufnahmen ermittelten Grauwerte in aufgefüllten Defekten als Summation der beiden Prozesse Materialresorption und Knochenapposition gewertet werden. Zur vergleichbaren Einschätzung gelangten auch El-Ghannam et al. (2004). Sie verglichen Defekte aufgefüllt mit modifiziertem bioaktivem Glas mit nicht aufgefüllten Kavitäten. Die radiologische Knochendichte war in aufgefüllten Defekten anfänglich deutlich 
höher als in nicht aufgefüllten, wobei kein Vergleich mit dem gesunden Knochen als Referenz erfolgt ist. In Bezug auf die aus Pixeln errechnete Knochendichte zeigten aufgefüllte Defekte bis zur sechszehnten Woche eine deutliche Steigerung, was von den Autoren als Zeichen der Knochenapposition gewertet wurde. Im weiteren Verlauf waren die Knochendichtewerte rückläufig als Indikator für Materialresorption.

In 27 Fällen evaluierten Chiapasco et al. (2000) die spontane Knochenheilung in Defekten nach großen Zystektomien im Unterkiefer und verglichen prä- und postoperative Aufnahmen miteinander. Die Knochendichten wurden nach sechs, zwölf und 24 Monaten bestimmt. Weiterhin führten sie eine subjektive Bewertung der Aufnahmen durch. Nach sechs Monaten betrug die durchschnittliche Dichtezunahme im Defekt 37 \%, nach zwölf Monaten 48,27 \% und stieg nach 24 Monaten auf 91,01 \% an. Die Verwendung von KEM wurde in dieser Studie als nicht erforderlich eingestuft. Nach Meinung der Untersuchungsgruppe sollte die Augmentation möglichst vermieden werden aufgrund von Entnahmemorbidität sowie Infektionsgefahr bei autogenen Transplantaten und steigenden Kosten bei Verwendung von synthetischen Materialien. Zudem seien synthetische Materialien in ihrer osteogenen Potenz eingeschränkt und würden die Knochensubstitution sowie die Heilung verlangsamen. Shokier und Khalifa (2009) errechneten eine Knochendichte in Zystendefekten der Größe 6 x $3 \mathrm{~cm}$ von 72,2 \% im Unterkiefer und 79,9 \% im Oberkiefer nach 24 Monaten ohne Knochendefektauffüllung. Auch sie waren der Meinung, Defekte genannter Größe würden spontan und ohne augmentative Maßnahmen gut ausheilen.

Tatsächlich zeigen die aktuellen Studienergebnisse, dass die relative Knochendichte der augmentierten Bereiche in allen vier Gruppen zwischen $97 \%$ und $102 \%$ (Median) nach durchschnittlich fünf bis elf Monaten betrug, was als Argument für eine solide Knochenkonsolidierung im Defekt betrachtet werden kann. Die Analyse entkräftet damit genannte Studienergebnisse, dass eine Verlangsamung der Knochenregeneration durch synthetische Materialien eintritt. Zumindest gilt diese Aussage nicht für ß-TCP. Im Vergleich vieler Studien miteinander wurde belegt, dass ß-TCP als alleiniges Material oder in Kombination mit autogenem Knochen aus regionalem Gebiet eine frühere Implantation ermöglicht und die Transplantation von Beckenkammspongiosa vermieden werden kann (Palm et al. 2006, Ettl et al. 2012). Entscheidend ist ferner nicht, dass ein Defekt ausheilt, sondern wie dieser regeneriert. Unter dem Gesichtspunkt der späteren prothetischen Rehabilitation des Patienten ist der Volumenerhalt, sei es für den Sitz der Prothese oder die Insertion von Dentalimplantaten, von höchster klinischer Relevanz. 
Tendenziell bestand eine positive Korrelation zwischen QRKD postoperativ und QRKD im Verlauf $(p<0,001)$. Wie zu Anfang festgestellt, sind lokale Unterschiede der Knochendichten in den unterschiedlichen Kieferbereichen erwiesen (Devlin et al. 1998, Shapurian et al. 2006). Vor diesem Hintergrund liegt die Vermutung nahe, dass in Abhängigkeit von der vermessenen Region mit hoher Knochendichte, beispielsweise des mandibulären Frontzahnbereiches, auch im Verlauf die Knochendichte höher ausfällt als in Regionen mit bereits anfänglich geringen Dichte, wie in der posterioren Maxilla.

Aus der Höhe der Quotienten nach der Verlaufszeit konnten Rückschlüsse auf die Knochenregeneration beziehungsweise die Degradation des ß-TCPs gezogen werden. Blieben die Werte deutlich höher dem Wert 1, konnte dies als Zeichen geringer Resorption des Materials gewertet werden. Werte um den Wert 1 waren als Zeichen simultaner Materialresorption mit Knochensubstitution zu werten. Niedrigere Werte (QRKD < 0,7) sprachen für eine Degradation des Materials ohne oder mit einer eher geringen Substitution durch Eigenknochen beziehungsweise einer bindegewebigen Einlagerung im Defektbereich. Dies stand in Korrelation mit der visuellen Beurteilung der Röntgenbilder. Vorwiegend traten bei den Bewertungscodes fünf und sechs (große apikale Aufhellung und Rezidiv) niedrige Messwerte der relativen Knochendichte auf.

Eine geringere Rate an neu gebildetem Knochen könnte mit patientenspezifischen Faktoren wie höheres Alter, Störungen im Hormonhaushalt oder Calciummetabolismus in Verbindung stehen. Ebenfalls können Entzündungen im Augmentat sowie eine geringe Blutversorgung zur Verzögerung der Knochenregeneration führen (Szabo et al. 2005). Mögliche einflussnehmende Faktoren wie Alter, Geschlecht, Untersuchungszeitraum sowie Komplikationen auf den QRKD konnten in dieser Arbeit jedoch als statistisch nicht relevant angenommen werden.

Aufgrund der Ungenauigkeit bei der subjektiven visuellen Bewertung von Röntgenbildern (Zakariasen et al. 1984) ist es empfehlenswert die Methode der relativen Knochendichtebestimmung mittels Bildanalysesoftware in den täglichen Praxisalltag zu integrieren. Klinische retrospektive Verläufe und Fragestellungen zur Kieferknochenregeneration an den bereits zur Nachuntersuchung angefertigten Röntgenbildern können so besser miteinander verknüpft werden. Dies stellt weder einen zusätzlichen Aufwand für den Behandler noch eine Belastung für den Patienten dar. Dafür sollten jedoch die Kontrolltermine in einem Zeitraum von fünf bis sechs Monaten terminiert werden. 


\subsection{Kritik an der Messmethode mit ImageJ}

Für die Verwendung der Bildanalysesoftware ImageJ ergeben sich neben den genannten Vorteilen auch einige limitierende Faktoren. Im Vorfeld müssen Röntgenbilder zur Nachkontrolle der Defektregionen möglichst in gleichbleibender Qualität und in einem vorab festgelegten Kontrollzeitraum von circa fünf bis sechs Monaten angefertigt werden, um bei der Auswertung konstante und vergleichbare Messwerte zu garantieren. Defektregionen können nur dann vom umliegenden gesunden Knochen differenziert werden, wenn diese klar davon abzugrenzen sind. Aus diesem Grund eignet sich die Methode nicht nur in Leerdefekten (Ihan Hren und Miljavec 2008) sondern auch in Regionen, die mit einem röntgenopaken KEM aufgefüllt sind. Hierbei ist zu beachten, dass das Material resorbierbar und durch Eigenknochen substituierbar ist, ansonsten kann kein Erkenntnisgewinn über die relative Knochendichte gewonnen werden. Nicht oder kaum resorbierbare KEM, beispielsweise bovinen Ursprungs, können noch nach Jahren persistieren (Schlegel und Donath 1998) und auch ohne Knochendichtebestimmung visuell auf den Röntgenbildern beurteilt werden. Weiterhin machen opake Strukturen, insbesondere Implantate, die Messung im augmentierten Bereich unmöglich und sind für diese Untersuchungsmethode ungeeignet.

Mögliche Fehler können sich bei der Freihand-Auswahl der Messregionen ergeben. In diesem Zusammenhang ist darauf zu achten, dass das Messprotokoll genau befolgt wird, ansonsten sind Abweichungen in den Messergebnissen zu erwarten. Weiterhin können mit diesem Messverfahren nur relative Dichtewerte bestimmt werden. Eine Aussage über die dreidimensionale Knochenarchitektur oder -struktur ist zum jetzigen Zeitpunkt nicht möglich.

\subsection{B-Tricalciumphosphat}

Die substanzspezifischen und biologischen Eigenschaften des Materials wurden bereits in Abschnitt 1.3.4 ausführlich behandelt. Im Folgenden wird auf die wichtigsten Vorteile und Eignung des ß-TCPs innerhalb der untersuchten Indikationsgruppen eingegangen. In zahlreichen Untersuchungen, darunter auch von Tadic und Epple (2004) konnte nachgewiesen werden, dass eine Phasenreinheit von $\geq 99 \%$ des ß-TCPs besteht und das Material im Herstellungsvorgang mit gleichen Eigenschaften reproduzierbar hergestellt werden kann. Der Vergleich von vierzehn verschiedenen KEMs unterschiedlicher Herkunft mit dem natürlichen Knochen zeigte, dass außer ßTCP alle anderen untersuchten KEMs Fremdphasen aus hochkristallinen, nicht resorbierbaren Hydroxylapatiten oder allogene beziehungsweise xenogene organische 
Bestandteile aufwiesen. Das ß-TCP erfüllt dahin gehend den höchsten Qualitätsanspruch an ein sicheres Augmentationsmaterial, welches immunologische Fremdreaktionen ausschließt und dem Empfänger sehr gute Verträglichkeit garantiert. Darüber hinaus besitzt das ß-TCP osteokonduktive Eigenschaften. Indem es der stetigen Degradation simultan zur autogenen Knochenneubildung unterliegt, erfüllt das Material seine Aufgaben als Leitstruktur für einwandernde Zellen und die Platzhalterfunktion bis zur Knochenneubildung (Horch et al. 2006). Nach Abschluss der Regenerationszeit können Implantate bereits nach vier bis sechs Monaten sicher inseriert werden (Palm et al. 2006). Histomorphologisch bestätigten Plenk und Lederer (2008) in ihrer Untersuchung die Neubildung von Knochengewebe mit einer reifen Lamellenstruktur, um die bereits nach viereinhalb Monaten teilweise aufgelöste ß-TCPGranula.

\subsection{Betrachtung der einzelnen Indikationsgruppen}

\subsubsection{Wurzelspitzenresektion}

Die Ursachen einer verminderten Erfolgswahrscheinlichkeit bei der apikalen Knochenheilung eines bereits resezierten Zahnes können unbehandelte akzessorische Wurzelkanäle, das Vorliegen einer marginalen Parodontitis mit Verbindung zur Osteolyse, akute periapikale Infektionen oder Wurzelperforationen nach WKB sein. Bei persistierenden entzündlichen Prozessen ist die Zahnextraktion in Erwägung zu ziehen, um den physiologischen Knochenabbau und damit zunehmend ungünstige Knochenund Weichteilverhältnisse für eine spätere Implantation zu vermeiden (Schwenzer und Ehrenfeld 2009). In der vorliegenden Untersuchung war die postoperative Komplikationsrate in der Indikationsgruppe der WSR nach 158 Tagen (5 Monaten) mit $21 \%$ am häufigsten vertreten. Von 181 resezierten Zähnen kam es bei 16 (8,8\%) zum Rezidiv mit einhergehender Beschwerdesymptomatik. Bei auftretendem Misserfolg muss der resezierte Zahn in der Regel extrahiert werden, eine gute Verknöcherung im ehemaligen Resektionsgebiet für die spätere Implantatinsertion ist daher von enormer Wichtigkeit. Aus durchgeführten Studien zu den Einflussfaktoren des Heilungserfolges einer WSR geht hervor, dass im Vergleich zu mehrwurzeligen Zähnen die Prognose bei einwurzeligen Zähnen günstiger ist aufgrund vorteilhafter anatomischer Verhältnisse (Altonen und Mattila 1976). Zähne im Oberkiefer haben außerdem eine bessere Heilungstendenz als die des Unterkiefers (Mikkonen et al. 1983). Eine kleine Läsion, definitionsgemäß unter $5 \mathrm{~mm}$, heilt laut Hirsch et al. (1979) besser ab als Defekte eines größeren Durchmessers. Bei großen apikomarginalen Defekten von bis zu $12 \mathrm{~mm}$ kann die spontane Knochenregeneration unterbleiben und die Defekthöhle fibrös ausheilen 
(Kim und Kratchman 2006). Demnach kann bei kleineren Defekten nach WSR auf die Substitution mit KEM verzichtet werden, größere zystenbedingte Kavitäten sollten durch Einsatz von Füllmaterialien in der ossären Regeneration unterstützt werden (Nentwig 2003). Tatsächlich scheinen kleinere Defekte und Wurzelkanäle mit homogener, jedoch zu kurzer WF nach einer WSR in Kombination mit KEM besser auszuheilen als Zähne mit ungünstiger Anatomie, einer nicht suffizienten WF und parodontaler Beteiligung.

Die Erfolgswahrscheinlichkeit durchgeführter Untersuchung lag bei $79 \%$ problemlos ausgeheilter Resektionsdefekte. Kim und Kratchman (2006) erfassten eine Erfolgsrate bei WSR innerhalb unterschiedlicher Studiengruppen von 53 bis $98 \%$. Die breite Streuung ergab sich vermutlich aus den unterschiedlichen Beurteilungen des Heilungsverlaufs, der angewandten Methoden, Verwendung verschiedener Wurzelkanalfüllmaterialien und aus den nicht einheitlichen Nachuntersuchungsintervallen der einzelnen Untersuchungsgruppen (Reit und Hollender 1983, Friedmann 2005). Aufgrund des heterogenen Krankheitsbildes, geprägt durch endodontische und parodontologische Pathologien, ist die Diagnosesicherung und das Therapieverfahren in dieser Indikationsgruppe besonders erschwert (Hirsch und Clarke 1989). Trotz erfolgreich durchgeführter Operation mit vollständiger Entfernung des Granulationsgewebes und Auffüllung mit ß-TCP können erneut bakterielle Infektionen auftreten. Eine retrospektive Bewertung der Defektgenese ist ziemlich schwierig, weshalb in diesem Zusammenhang eine Codierungsskala für die Erfassung postoperativ auftretender Komplikationen und für die radiologische Bestimmung über den Degradationsgrad des ß-TCPs im Defekt entworfen wurde. An 95 (52,5\%) von 181 behandelten Zähnen der WSR-Gruppe konnte eine vollständige Knochenkonsolidierung beobachtet werden. Bei 31 periapikalen Defekten $(17,1 \%)$ war die ß-TCPGranula röntgenologisch noch leicht erkennbar, bei 40 Zähnen (22,1\%) waren kleine Aufhellungen zwischen den KEM-Partikeln zu sehen. In neun Fällen (5\%) zeigten sich größere apikale Aufhellungen und in sechs periapikalen Regionen (3,3\%) war ein deutlich sichtbarer entzündungsbedingter Mineralverlust ohne erkennbares Granulat feststellbar. Alles in allem korrelierten diese 15 röntgenologisch beurteilten Rezidivfälle mit den klinisch erhobenen Daten von 16 symptomatischen und erneut behandlungsbedürftigen Zähnen. Im Hinblick auf die Komplikationsrate von $21 \%$ stellte die chirurgische Apikoektomie die Indikationsgruppe mit der unsichersten Prognose dar, in der jede Komplikation mindestens einmal vertreten war.

Abschließend lässt die Untersuchung den Schluss zu, dass vor einer chirurgischen Intervention am Periapex sowohl pathologische, endodontologische und parodontologische Faktoren zur Entscheidungsfindung und Prognoseeinschätzung einfließen 
müssen. Hier kommt es vor allem auf die klinische Erfahrung des Chirurgen an der schließlich bewerten muss, ob ein entzündungsfreies und mikroorganismen-armes Umfeld zur Knochenregeneration mit ß-TCP geschaffen werden kann. Ist diese Voraussetzung mit relativer Sicherheit zu bewerkstelligen, sollte eine Defektauffüllung mit ß-TCP erfolgen.

\subsubsection{Socket Preservation}

In 44 Fällen (93,6 \%) verlief die postoperative Wundheilung komplikationslos. In jeweils einem Fall war eine Schwellung, eine Wunddehiszenz und MAV aufgetreten. Das Degradationsverhalten des alloplastischen Materials war in zwölf Fällen (25,5 \%) sehr gut und in 16 Fällen (34 \%) als gut zu bewerten, mit keinem erkennbaren Unterschied zum umliegenden Knochen. In weiteren 16 Fällen (34 \%) war das Granulat noch leicht erkennbar und in drei Defekten (6,4\%) zeigten sich leichte Aufhellungen im Augmentat. Aufhellungen im aufgefüllten Defektbereich müssen nicht zwangsläufig einen Misserfolg bedeuten, es kann als Indiz für den Abbau des Granulats mit Bildung des neuen Knochengewebes gewertet werden. Große Aufhellungen im Sinne von Entzündungsgewebe oder der Totalverlust des ß-TCPs traten in der Verlaufszeit von 175 Tagen (6 Monaten) nicht auf, weshalb die Gesamtprognose für diese Diagnosegruppe als sehr gut bewertet werden kann.

Horowitz et al. (2009a) gelangen beim Vergleich von aufgefüllten und nicht aufgefüllten Defekten zu einer ähnlichen Einschätzung. Die Kieferkammbreite reduzierte sich in aufgefüllten Defekten um maximal $12 \%$. Eine vollständige Resorption von ß-TCP trat in ihrer Untersuchung nach vier bis sechs Monaten ein, weshalb die Autoren zu dem Schluss kamen, dass sich ß-TCP als ein gut geeignetes Material zum Volumenerhalt des Alveolarknochens erweist und eine korrekte Positionierung der Implantate erlaubt. Im Idealfall sollte nach der Socket Preservation eine Implantation ohne zusätzliche augmentative Maßnahmen möglich sein. Doch es zeigt sich selbst nach einem erfolgreich durchgeführten Kieferkammaufbau, dass der regenerierte Knochen erneut resorbiert werden kann. In der Gruppe der Implantationen nach Socket Preservation in der aktuellen Arbeit war in 62,6\% ein sehr gutes bis gutes Ergebnis vorzufinden, in 37,5 \% trat eine laterale Knochenresorption ein. Die Frage, ob der Therapieaufwand und die Kosten für die Augmentation gerechtfertigt seien, kann im Kontext der vorliegenden Ergebnisse bei einer Erfolgswahrscheinlichkeit von über $62 \%$ mit einem klaren ja beantwortet werden. Ohne eine Socket Preservation tritt in jedem Fall innerhalb kurzer Zeit ein Verlust der ursprünglichen alveolären Knochendimension ein (Araujo und Lindhe 2005, Van der Weijden et al. 2009). 


\subsubsection{Osteotomien}

Bei 28 retinierten und verlagerten Weisheitszähnen (82,4\%) zeigte sich nach 180 Tagen (6 Monaten) ein komplikationsloser Heilungsverlauf. Jedoch waren die Komplikationen nach der Gruppe der WSR in diesem Kollektiv am häufigsten. Operationsbedingte Hypästhesien waren mit drei Fällen (8,8\%) genauso häufig vertreten wie bei den Resektionen. Ein Abszess (2,9\%) und zweimalige Eröffnung der Kieferhöhle (5,9\%) wurden detektiert. Im Vergleich mit einer klinischen Studie ohne Defektauffüllung nach 50 Osteotomien der unteren Weisheitszähne unter Verwendung visueller Hilfsmittel (Mikroskop, Endoskop) waren 88 \% komplikationslos entfernt worden (Choi 2012). In 6 \% der Fälle kam es zu Hyp- und Parästhesien und in 4 \% der postoperativen Defekte sind Entzündungen aufgetreten. Die aktuellen Ergebnisse zeigen ähnliche Komplikationsraten mit KEM, was zu dem Schluss führt, dass ß-TCP ohne klinische Nachteile oder Risiken für den Patienten verwendet werden kann.

Radiologisch wurde in der vorliegenden Arbeit in 13 Defekten (38,2\%) eine sehr gute und in sechs Fällen (17,6\%) eine gute Reossifikation beobachtet. In zehn Alveolen $(29,4 \%)$ war das Granulat noch leicht und in drei Defekten $(8,8 \%)$ stärker erkennbar. Zwei Fälle (5,9 \%) zeigten aufgehellte Bereiche zwischen den KEM-Partikeln.

Retention dritter Molaren betrifft fast $80 \%$ junger Erwachsener im westeuropäischen Kulturkreis, mit mindestens einem retinierten Weisheitszahn im Kieferknochen. Durch langjährige Persistenz können pathologische Veränderungen wie Zysten und Tumoren, ausgehend von dem Epithel der Zahnleiste, resultieren (Schwenzer und Ehrenfeld 2009). Das Auftreten einer Zyste, ausgehend von einem Weisheitszahn, liegt bei einer Inzidenz von 2,3\%, wobei eine Entartung zum Tumor in 0,79\% stattfinden kann (Güven et al. 2000). Das expansionsartige Zystenwachstum verdrängt den umliegenden Knochen, sodass nach der Entfernung des Molaren und der Zyste ein größerer Defekt verbleiben kann. Weitere Knochenresorptionen können durch großflächige $A b$ präparation des Mukoperiostlappens entstehen (Brägger et al. 1988, Fickl et al. 2011). Eine Knochendefektauffüllung erscheint in diesem Zusammenhang zur Überbrückung größerer Defektsituationen wie in der Gruppe der Zystektomien daher sinnvoll. Eine relative Knochendichte von $102 \%$ nach 180 Tagen bestätigt zudem eine vollständige Defektregeneration. 


\subsubsection{Zysten}

Im Kollektiv der Zysten trat aus 14 Fällen nur bei einem Patienten eine Wunddehiszenz nach der Augmentation mit B-TCP auf, jedoch war auch die Fallzahl gegenüber den anderen Indikationsgruppen dieser Untersuchung am niedrigsten. Die Nachbeobachtungszeit von median 321 Tagen (11 Monaten) war im Patientenkollektiv die längste. In Bezug auf die Komplikationsrate sind in anderen klinischen Untersuchungen zur Zystektomie ohne Knochendefektauffüllung keine inflammatorischen Befunde aufgetreten (Ihan Hren und Miljavec 2008) oder wurden bei einem geringen Prozentsatz von unter $5 \%$ beobachtet (Chiapasco et al. 2000). Ein hoher Stellenwert kommt der systemischen perioperativen Antibiotikagabe zu, die in den genannten Studien durchgeführt wurde und in Verbindung mit Augmentationsverfahren von der DGZMK (Deutsche Gesellschaft für Zahn-, Mund- und Kieferheilkunde) empfohlen wird. Nachweislich können durch eine prophylaktische Antibiotikagabe die postoperativen Komplikationen reduziert werden (Lindeboom und van den Akker 2003).

Eine sehr gute Degradation des ß-TCPs fand in drei (21,4\%) und eine gute Degradation in vier Fällen (28,6 \%) statt. Leicht erkennbares Material war in sechs Defekten (42,9\%) und gut erkennbares Granulat in einem Fall (7,1 \%) vertreten.

Vitale knöcherne Defektwände sind die Voraussetzung für eine effiziente Knochenregeneration. Spongiöse Markräume sorgen für die Blutversorgung und stellen mesenchymale Stammzellen sowie Präosteoblasten zur Knochenneubildung bereit. In mehrwandigen Defekten nach einer Zystektomie heilt der Knochen trotz größerer Defektmorphologien meist problemlos ab, während bei flächigen Defekten nach Verlust bukkaler Alveolenwände die Regeneration unvorhersehbar bleibt (Ruffieux und Köhli 2010). Bereits 1960 postulierte Schulte, dass mit zunehmender Größe der Zyste das Infektionsrisiko der Wunde aufgrund der Blutgerinnselretraktion zunimmt. Zur Stabilisierung wurden schon damals Kollagenschwämmchen mit Thrombin eingesetzt, um dem Koagulum Stabilität zu verleihen (Schulte 1965). Ihan Hren und Miljavec stellten 2008 fest, dass die Form des Zystendefekts für die Heilung wichtiger zu sein scheint als das Volumen. Demnach zeigten ellipsenförmige Defekte eine bessere Heilungstendenz als runde Defekte vergleichbarer Größe, weil sie einen kleineren Durchmesser aufwiesen.

Wie bereits im Kapitel 4.3 angedeutet, kann nach Stabilisierung des Blutkoagulums mit ß-TCP eine relative Knochendichte von $98 \%$ nach elf Monaten erzielt werden. Die Forschungsergebnisse von Ihan Hren und Miljavec (2008) zeigten in nicht aufgefüllten Zystendefekten ähnlich hohe Knochendichtewerte von 97 \% nach zwölf Monaten bei 
einem Defektdurchmesser von unter $30 \mathrm{~mm}$. Defekte eines größeren Durchmessers (> $30 \mathrm{~mm}$ ) erreichten jedoch nur $84 \%$ der Knochendichte in der gleichen Zeit.

Das röntgenologische Knochenvolumen in der aktuellen Arbeit konnte als stabil und gut reossifiziert betrachtet werden. Für die Versorgung größerer Defekte nach Exstirpation pathologischer Raumforderungen in der Mandibula und der Maxilla ist das $ß-$-TCP als gut geeignet und für die Knochenregeneration als förderlich einzustufen. Selbst bei Mund-Antrum-Perforationen kann eine problemlose Augmentation vorgenommen werden, wenn der Defekt durch eine resorbierbare Membran zur Kieferhöhle sicher abgedeckt wird.

\subsection{Implantatgruppe}

Für die gesamte Implantatgruppe $(n=135)$ ergaben sich Schwierigkeiten, das Programm ImageJ adäquat einzusetzen. Bei den lateralen Augmentationen ( $n=91)$ an der Implantatschulter ließ sich die Defektregion visuell nicht vom umliegenden kortikalen Knochen abgrenzen, wie es etwa in einem spongiösen Hohlraum gefüllt mit ß-TCP möglich war. Die andere Schwierigkeit stellte die relativ hohe Rate an lateralem Knochenverlust von 35,2\% zum Kontrollzeitpunkt dar, sodass das Material bereits resorbiert beziehungsweise umgebaut wurde und die Beurteilung der Röntgenbilder nur noch auf konventionelle Weise durchführbar war. Nichtsdestoweniger sind 60,5\% der gesetzten Implantate gut bis sehr gut und ohne vertikalen Knochenverlust osseointegriert. Es wäre erstrebenswert gewesen den lateralen Knochenverlust mittels einer Messung zu erfassen, jedoch fehlten im verwendeten Programm eine Anwendung zur Abstandsmessung und ein Referenzparameter auf den Röntgenbildern beispielsweise in Form einer Messkugel. Alternativ könnte das Ausmaß der Resorption zwar an konventionellen Röntgenaufnahmen gemessen werden, problematisch wäre dennoch die Beurteilung einer dreidimensionalen Struktur in nur einer Ebene (Verhoeven et al. 2000). Deshalb wurde von einer weiteren Methode abgesehen und die Röntgenbilder visuell auf eine laterale Resorption des ß-TCPs an der Implantatschulter mithilfe einer Ja-Nein-Entscheidung beurteilt. Obgleich die laterale Augmentation eine höhere Verlustrate aufwies, stellte dies keinen Misserfolg dar, denn die betroffenen Implantate waren zum Kontrollzeitpunkt funktionsstabil in situ. Lediglich drei Implantate der gesamten Gruppe gingen jeweils nach 69, 405 und 676 Tagen verloren, an weiteren drei Implantaten entwickelte sich in der Nachfolgezeit eine Periimplantitis.

Aufgrund der regelrechten Resorptionszeit von ß-TCP nach circa einem halben Jahr blieb von dem ursprünglichen Augmentat in der Gruppe der Implantationen mit 
simultaner Sinusbodenaugmentation $(n=28)$ nur ein geringer Anteil um die Implantate zurück. Diese Beobachtungen stehen im Einklang mit früheren Ergebnissen von Zerbo et al. (2004). Sie stellten mittels histomorphometrischen Messungen fest, dass der Anteil an ß-TCP nach einem Sinuslift innerhalb von sechs Monaten resorbiert wurde. Der dem ortsständigen Knochen direkt aufliegende Anteil war vollständig in eigenen Knochen umgebaut, während weiter apikal gelegene Granula aufgrund der geringeren Penetration mit Knochenzellen weniger von neu gebildetem Knochen umgeben lag. Dies ist für die vorliegende Untersuchungsmethode eine ungünstige Voraussetzung für das Umfahren der Defektregion für die Bildanalyse. Das resorbierte Material beziehungsweise die neu gebildete knöcherne Kontur um die Implantate war visuell teilweise nicht mehr erkennbar und damit für die Bestimmung der Knochendichte nicht messbar. Insofern stellt die Indikationsgruppe Sinuslift ungeeignete Rahmenbedingungen für die Messmethode mittels Graustufenbestimmung dar. Für die Bewertung von volumetrischen Knochenverlusten ist folglich ein CT (Jensen und Sindet-Petersen 1991) oder ein DVT aussagekräftiger. Lateraler Knochenabbau zwischen Implantatschulter und Alveolarkamm trat lediglich in drei Fällen (10,7 \%) auf. Mögliche Einflussfaktoren wie Alter, Geschlecht, Kieferposition, Zeit zwischen den Röntgenaufnahmen hatten weder einen relevanten Einfluss auf die Einheilung noch auf die Komplikationen.

In Bezug auf die Verwendung unterschiedlicher Augmentationsmaterialien zur Sinusbodenaugmentation zeigte sich in Studien zwischen ß-TCP und autogenen Transplantaten kein signifikanter Unterschied in der Abnahme an vertikaler Augmentathöhe (Zijderveld et al. 2009). Beide Materialien erfahren eine gewisse Schrumpfung und dennoch weisen sie eine vergleichbar gute Qualität der Knochenbildung auf (Szabo et al. 2005). Ein Höhenverlust tritt bei Verwendung beider Produkte vornehmlich im ersten Jahr ein. Reinert et al. (2003) evaluierten in diesem Zeitraum einen vertikalen Knochenabbau von $1,3 \mathrm{~mm}$ bei Verwendung von Beckenkammtransplantaten zur Sinusbodenaugmentation. Im Gegenzug zeigte eine volumetrische Untersuchung von Johansson et al. (1998) mittels CT eine Knochenresorption des autogenen Transplantates von $48 \%$. Dieser Vergleich zeigt unter anderem, dass auch die als „Goldstandard“ geltende Spongiosa (Zijderveld et al. 2005) Nachteile aufweisen kann, nicht nur bezüglich ihrer Resorption, sondern auch der Entnahmemorbidität und der damit verbundenen Komplikationen an der Donorstelle (Szabo et al. 2005, Kalk et al. 1996). Weiterhin verdeutlichen diese unterschiedlichen Ergebnisse gleichermaßen die Diskrepanz zwischen zwei- und dreidimensionalen Untersuchungsmethoden.

In der Gruppe der Implantationen in die augmentierten Alveolen nach Socket Preservation $(n=16)$ wurde der ursprüngliche Messbereich mit ß-TCP vom inserierten 
Implantat überlagert. Damit war auch hier eine Vergleichsregion im Zentrum der Augmentation nicht messbar. Der Behandlungserfolg wurde aus genannten Gründen anhand klinischer Befunde und der Verlaufsröntgenbilder analysiert. Eine deskriptive Statistik kam zur Anwendung, um die Häufigkeit von Komplikationen und die Erfolgsund Misserfolgsraten zu beschreiben. Alle Implantate waren in dieser Untergruppe osseointegriert, an sechs Implantaten (37,5\%) war radiologisch ein lateraler Knochenabbau feststellbar.

Ein zusätzlicher Nachteil in der Implantatgruppe waren die nicht einheitlichen Verlaufszeitpunkte. Beruhend auf der Tatsache, dass die meisten Patienten aus Überweiserpraxen stammten und sich teilweise zu unterschiedlichen Zeitpunkten zur Verlaufskontrolle wieder vorstellten oder vom Hauszahnarzt prothetisch weiterversorgt wurden und nicht wieder vorstellig waren. Die ermittelte Standardabweichung von 420 Tagen verdeutlicht dies, möglicherweise zulasten der Vergleichbarkeit der Patientenfälle untereinander.

Trotzdem war es möglich die Einflussnahme der Parameter Zeit, Geschlecht und Alter der Patienten sowie die Kieferposition auf die Einheilung und die Komplikationen nach Implantatinsertion in Verbindung mit Augmentationen des synthetischen Materials statistisch zu analysieren. Das multivariate Regressionsmodell zeigte keinen signifikanten Zusammenhang zwischen den Parametern. In einer retrospektiven klinischen Studie von Beyrle (2008) sind ähnliche Einflussfaktoren sowie Operationsverfahren und prä- und postoperative Komplikationen für die Überlebensrate der dentalen Implantate evaluiert worden. Das Ergebnis zeigte, dass alleine das präoperative Knochenangebot für die Einheilung und die Implantatverweildauer eine wichtige Rolle gespielt hat. Für die Osseointegration von Implantaten sind aus Sicht von Wiltfang et al. (2001) die Knochendichte nach der Augmentation und die Regenerationsfähigkeit des ortsständigen Knochens ausschlaggebend.

Hinsichtlich des lateralen Volumenverlustes zeichnete sich eine höhere Tendenz in den ersten beiden Gruppen mit 35,2\% und 37,5\% ab, während in Gruppe drei der vertikale Verlust an Knochensubstanz bei 10,7 \% lag. Der Zusammenhang könnte auf die Operationstechnik zur Sinusbodenaugmentation zurückzuführen sein. Nach Abpräparation der Schneider'schen Membran können keine weiteren Nachbarstrukturen verletzt werden, die Implantate werden grundsätzlich tiefer gesetzt, sodass zirkuläre Defekte des Kieferkamms geringer ausfallen und lateral weniger augmentiert werden muss. Für den insgesamt relativ hohen Anteil an vertikaler Kieferkammresorption um die Implantatschulter könnte das Beimischen des autogenen Knochens zum ß-TCPGranulat eine Rolle spielen. Die sehr kleinen Knochenpartikel, die aus dem Implantat- 
schacht während des Bohrens gewonnen werden, verhindern möglicherweise die Interaktion mit den ortsständigen Osteoklasten, indem diese Zellen aufgrund ihrer Größe $(100 \mu \mathrm{m})$ nicht an die Knochenpartikel „andocken“ können. Als Folge resultiert eine bindegewebige Abkapselung im augmentierten Bereich mit fehlender Knochenregeneration (Mulliken und Glowacki 1980, Merten et al. 2003). Ein weiterer Grund für den lateralen Abbau ist womöglich die geringere Blutversorgung bei der Auflagerung von KEM auf kortikalem Knochen. Im Gegensatz zur Defektauffüllung im spongiösen Knochendefekt, in dem eine Blutversorgung und Bereitstellung osteogener Zellen aus den Markräumen stattfinden kann, ist die Durchblutung der kompakten Knochenoberfläche gering (Ruffieux und Köhli 2010). Folglich wird das ß-TCP-Gerüst nicht in die Knochenheilung integriert und daraufhin abgebaut. Im Allgemeinen scheint die Mischung des ß-TCPs mit autogener Spongiosa den Resorptionsvorgang des synthetischen Materials zu beschleunigen (Horch et al. 2006). Bei dem alleinigen Einsatz von kortikospongiösen autogenen Knochenspänen zur Sinusbodenaugmentation traten in der klinischen Untersuchung von Beyrle (2008) sogar vermehrt Weichgewebsschwellungen und Sinusitiden auf als bei der Verwendung von reinem ß-TCP.

Aufgrund der positiven Eigenschaften von ß-TCP mit einer Porosität von $65 \%$ ist dieses Material für die Indikationsgruppe Sinuslift gut geeignet. Histologische Untersuchungen von Knabe et al. (2008) haben gezeigt, dass nach sechs Monaten Einheilungszeit noch verbleibende Granulatpartikel von dem neu geformten lamellären Knochen umgeben waren und ein noch aktiver Umbau sowohl im apikalen als auch im zentralen Anteil des Augmentates stattfand. Zur lateralen Augmentation in Verbindung mit einer Implantation scheint das ß-TCP einer zu schnellen Degradation zu unterliegen, ohne simultan durch Eigenknochen ersetzt zu werden. Die Beimischung von resorptionsstabilem KEM wie Hydroxylapatit kann der initialen Resorption eventuell besser entgegenwirken (Hallmann und Thor 2008). Welches KEM für laterale Augmentationen tatsächlich am besten geeignet ist, müssen weiterführende Studien belegen.

\subsection{Schlussfolgerungen}

Die anfangs formulierten Ziele und Fragestellungen lassen sich unter Bezugnahme auf die aktuellen Forschungsergebnisse wie folgt beantworten:

a) Die Anwenderkalibrierung zur Validierung der Messmethode mit dem Bildanalyseprogramm ImageJ ergab eine statistisch hohe Interrater-Reliabilität. Eine gute und vom Behandler unabhängige Reproduzierbarkeit der Messwerte nach Einhaltung der vorab bestimmten Messregeln ist somit gewährleistet. In der vorliegenden Studie konnte erstmals das Verfahren zur Bestimmung der 
relativen Knochendichte systematisch so kalibriert werden, dass es bei klinischen Fragestellungen in die Untersuchung integriert werden kann.

b) Die Knochenqualität ist ein breitgefächerter Begriff, der in der Literatur unterschiedlich interpretiert wird und sich aus verschiedenen Struktureigenschaften des Knochens zusammensetzt. Über die Bestimmung der relativen Knochendichte mit der Bildanalysesoftware ImageJ lassen sich Rückschlüsse auf das Degradationsverhalten von ß-TCP, auf den Heilungsverlauf im augmentierten Defektbereich der Kiefer sowie die Knochenregeneration in Referenz zum umliegenden gesunden Knochen ziehen. Die Bewertung der Knochenqualität mit ihrer Mineralstruktur, geometrischen Form und Trabekelanordnung ist mit dem vorgestellten zweidimensionalen Verfahren bisher nicht möglich.

c) Weiterhin konnte gezeigt werden, dass eine relative Knochendichte zwischen $97 \%$ und $102 \%$ in den vier Untersuchungsgruppen (WSR, Osteotomie, Socket Preservation, Zysten) nach fünf bis elf Monaten Nachuntersuchungszeit erzielt wurde. Der umliegende gesunde Knochen diente als Referenzparameter für die Graustufenmessungen und ermöglichte die Vergleichbarkeit der Röntgenaufnahmen eines Patienten, die zu unterschiedlichen Zeitpunkten angefertigt wurden. Das Erreichen der RKD von $100 \%$ wurde als idealer Wert angenommen, bei dem die Mineraldichte im Defekt dem des umliegenden Knochens entsprach und somit als Parameter für die erfolgreiche Knochenregeneration gewertet werden konnte.

d) Die Methode zur Messung der relativen Knochendichte könnte als zusätzliches Monitoringinstrument zur Bestimmung der vollständigen Knochenregeneration nach Defektaugmentationen, unter Einbeziehung klinischer Diagnosen und visueller Beurteilung der Röntgenbilder, in die tägliche Praxis integriert werden. Die Messmethode liefert nach korrekter Durchführung aussagekräftige und objektive Ergebnisse ohne Kostenaufwand und ohne zusätzliche invasive Maßnahmen für den Patienten.

e) Eine gewisse Korrelation zwischen der relativen Knochendichte und den röntgenologischen sowie klinischen Befunden konnte bei der Evaluation hergeleitet werden. Bei einem niedrigen QRKD-Wert (meist $<0,7$ ) war röntgenologisch eine geringere Knochendichte im Defekt als Zeichen einer bindegewebigen Einlagerung erkennbar. In manchen Fällen kam es auch klinisch zu erneuter Beschwerdesymptomatik, überwiegend in der Gruppe der WSR. Die QRKD-Werte sind relative Richtwerte, die aufgrund unterschiedlicher Knochenqualitäten bei jedem Patienten und Untersuchungsregion im Kiefer variieren können. Jeder Fall muss dementsprechend individuell mit seinen röntgenologischen sowie klinischen Befunden betrachtet werden. 
f) Klinische Komplikationen traten in jeder Indikationsgruppe vereinzelt auf. Am häufigsten war die Gruppe der WSR mit einer Komplikationsrate von $21 \%$ und einer Rezidivhäufigkeit von 8,8 \% betroffen. Verlust von ß-TCP-Granulat direkt postoperativ wurde im Gesamtkollektiv nicht beobachtet. Implantationen mit lateraler Knochenaugmentation zeigten die höchste vertikale Knochenverlustrate, was vermutlich auf die Beimischung von autogenen Knochenspänen aus dem Implantatbohrschacht zum ß-TCP zurückzuführen ist. Um eine zu schnelle Resorption des lateralen Augmentates und gegebenenfalls dessen bindegewebige Abkapselung zu umgehen, gilt die Empfehlung das ß-TCP oder besser ein resorptionsstabileres KEM ohne Beimengung von kortikospongiösen Spänen aus dem Knochenkollektor für laterale Augmentationen an der Implantatschulter zu verwenden.

g) Demografische Daten wie Alter, Geschlecht des Patienten, Lokalisation der Defekte hatten weder einen statistisch signifikanten Einfluss auf die Messergebnisse der relativen Knochendichte, auf die Knochenregeneration noch auf die Komplikationsrate.

h) Das phasenreine ß-TCP kann in der Kieferchirurgie für ein breites Indikationsspektrum zum Einsatz kommen. In der vorliegenden Arbeit waren unter den klinischen und röntgenologischen Aspekten gute bis sehr gute Ergebnisse für die Augmentationen von Defekten zur Socket Preservation, nach Osteotomien, Zystektomien, WSR und Sinusliftoperationen erreicht worden. Bei der Augmentation zirkulärer Defekte um die Implantatschulter ist aufgrund der Resorptionskinetik des ß-TCPs eine eingeschränkte Indikation gegeben, hier sollten resorptionsstabilere KEM zum Einsatz kommen. 


\section{$5 \quad$ Zusammenfassung}

Die Röntgendiagnostik stellt eine nicht-invasive und zuverlässige Methode dar, Neubildung von Knochen im klinischen Alltag zu detektieren. Ausgehend von der ursprünglichen Situation, können Verlaufsaufnahmen durch Änderung der Opazität im Kieferknochen Veränderung der Knochendichte anzeigen, die subjektiv vom Behandler befundet werden. Im Fokus der vorliegenden Studie stand die Verwendung einer Bildanalysesoftware (ImageJ) an digitalen Röntgenaufnahmen zur Bestimmung der relativen Knochendichte als Resultat der Knochenregeneration in Defekten unterschiedlicher Indikationsgruppen, die mit ß-TCP augmentiert und mit dem ortsständigen gesunden Knochen verglichen wurden. Das Ziel war es, ein zusätzliches nicht-invasives Hilfsinstrument für die Beurteilung der knöchernen Defektmorphologien nach operativen Eingriffen zu schaffen und dieses auf die Einsetzbarkeit im täglichen Praxisalltag zu testen. Die Messmethode wurde vorab auf ihre Reliabilität untersucht und zur Bestimmung der Reproduzierbarkeit der Messergebnisse kalibriert.

In der durchgeführten Studie mit einem der größten retrospektiv untersuchten Patientenkollektive sind bei 560 Patienten im Zeitraum von 2006 bis 2012984 Kieferdefekte mit ß-TCP versorgt worden. Aufgrund fehlender postoperativer Kontrollaufnahmen konnten lediglich 411 Defektfälle analysiert werden. Das Einsatzspektrum von ß-TCP wurde in den Indikationsgruppen: Wurzelspitzenresektionen $(n=181)$, Auffüllen von Alveolarkammdefekten zur Socket Preservation $(n=47)$, Osteotomien $(n=34)$, Zysten ( $n=14)$ und Augmentationen in Verbindung mit Implantaten $(n=135)$ eruiert. Eine ausgearbeitete Bewertungsskala zur visuellen Beurteilung des Degradationsverhaltens von ß-TCP diente als Zusatzinstrument, Röntgenbefunde in Rückkopplung mit klinischen Komplikationen einordnen zu können.

Der mediane Untersuchungszeitraum betrug 5 bis 17 Monate. Mögliche beeinflussende Faktoren wie das Patientenalter, Geschlecht, Defekte der Maxilla oder Mandibula und postoperative Komplikationen wurden im genannten Zeitraum auf die Knochenheilung evaluiert.

Bei Betrachtung der Ergebnisse war in der Gruppe der WSR die Komplikationsrate mit $21 \%$ am größten ausgefallen. Dies war nicht unbedingt auf die Verwendung von ß-TCP zurückzuführen, sondern stand vielmehr im Einklang mit dem heterogenen Krankheitsbild dieser Gruppe. Anhand der QRKD-Werte der vier Gruppen (WSR, Socket Preservation, Osteotomien, Zysten) konnte eine nahezu ideale Knochendichte der Defekte festgehalten werden. In der Gruppe der Implantationen gestaltete sich die 
Verwendung des Programms zur Bestimmung der RKD als schwierig, weil das verwendete Material entweder resorbiert war oder nicht mehr vom umliegenden Knochen differenziert werden konnte. Insgesamt zeigte sich eine relativ hohe Resorptionsrate von ß-TCP unter Beimischung von autogenen Spongiosaspänen aus dem Implantatbohrschacht.

Die Bestimmung der relativen Knochendichte mittels ImageJ ist unter Einbeziehung der biologischen sowie ökonomischen Gesichtspunkte eine zuverlässige und mithilfe klar definierter Kriterien eine objektivierbare Methode. Es kann als unterstützendes Monitoringinstrument zu klinischen und röntgenologischen Befunden zur Beurteilung der Knochendefektregeneration in die tägliche Praxis integriert werden. Die wichtigsten Voraussetzungen sind der geschulte Umgang der Untersucher mit dem Messverfahren und die Anfertigung der Röntgenaufnahmen in guter Qualität.

Für mögliche weiterführende Untersuchungen im Zusammenhang mit der Bestimmung der relativen Knochendichte ist ein prospektives Studienkonzept mit klar definierten Untersuchungsintervallen zur besseren Vergleichbarkeit zu empfehlen. 


\section{Literaturverzeichnis}

Altonen M, Mattila K (1976): Follow-up study of apicoectomized molars. Int J Oral Surg $\underline{5}$, 3340

Amler MH, Johnson PL, Salaman I (1960): Histological and histochemical investigation of human alveolar socket healing in undisturbed extraction wounds. J Am Dent Assoc 61, 32-44

Anitua E, Orive G, Andia I (2006): Wachstumsfaktorenreiches Plasma (PRGF) zur schnelleren Knochen- und Weichgeweberegeneration in Extraktionsalveolen. Teamwork Interdiszipl J Restaurat Zahnheilkd 2006, 316-324

Araujo M, Lindhe J (2005): Dimensional ridge alterations following tooth extraction. An experimental study in the dog. J Clin Periodontol $\underline{32}, 212-218$

Atwood DA (1971): Reduction of residual ridges: a major oral desease entity. J Prosthet Dent $\underline{26}, 266-279$

Barth A (1893): Über histologische Befunde nach Knochentransplantation. Arch Klin Chir $\underline{46}$, 409

Barth A (1895): Histologische Unteruchungen über Knochenimplantation. Beitr Pathol Anat Allg Pathol 17, 65

Bauer T, Muschler G (2000): Bone graft materials. An overview of the basic science. Clin Orthop Relat Res $\underline{371}, 10-27$

Becker W, Urist M, Tucker L, Becker B, Ochsenbein C (1995): Human demineralized freezedried bone: inadequate induced bone formation in athymic mice. A preliminary report. J Periodontol $\underline{66}, 822-828$

Beyrle B: Die simultane Implantation mit Sinusliftoperation bei reduziertem Knochenangebot eine retrospektive, klinische Studie. Med. Diss. Ulm 2008

Bilk D (2007): Anwendung von Cerasorb $M$ in der Dental-Chirurgie. Ergebnisse einer Anwenderbeobachtung mit 148 Patienten. Z Oral Implant $\underline{3}$, 184-195

Bock JJ: Digitale Radiologie in der Zahnarztpraxis: Zahnfilm, OPG, FRS und DVT. Spitta Verlag, Balingen 2011

Bohner M, Baumgart F (2004): Theoretical model to determine the effects of geometrical factors on the resorption of calcium phosphate bone substitutes. Biomaterials $\underline{25}$, 3569-3582

Brägger U, Pasquali L, Kornman KS (1988): Remodelling of interdental alveolar bone after periodontal flap procedures assessed by means of computer-assisted densitometric image analysis (CADIA). J Clin Periodontol 15, 558-564

Brånemark PI, Zarb G, Albrektsson T: Tissue-integrated protheses. Osseointegration in clinical dentistry. Quintessence Publishing Co., Chicago 1985 
Cann C, Genant H (1980): Precise measurement of vertebral mineral content using computed tomography. J Comput Assist Tomogr $\underline{4}$, 493-500

Cardaropoli G, Araujo M, Lindhe J (2003): Dynamics of bone tissue formation in tooth extraction sites. J Clin Periodontol $\underline{30}$, 809-818

Carlsson GE, Persson G (1967): Morphologic changes of the mandible after extraction and wearing of dentures. A longitudenal, clinical, and X-ray cephalometric study covering 5 years. Odontol Revy $\underline{18}, 27-54$

Chiapasco M, Rossi A, Motta JJ, Crescentini M (2000): Spontaneous bone regeneration after enucleation of large mandibular cysts: A radiographic computed analysis of 27 consecutive cases. J Oral Maxillofac Surg 58, 942-948

Choi EJ: Untersuchung zur mikrochirurgischen Entfernung unterer Weisheitszähne mittels okklusalen Zugangs. Med. Diss. Göttingen 2012

De Groot K (1988): Effect of porosity and physicochemical properties on the stability, resorption, and strength of calcium phosphate ceramics. Ann N Y Acad Sci $\underline{523}$, 227233

Devlin H, Horner K, Ledgerton D (1998): A comparison of maxillary and mandibular bone mineral densities. J Prosthet Dent $\underline{79}, 323-327$

Donovan M, Dickerson N, Hellstein JW, Hanson L (1993): Autologous calvarial and iliac onlay bone grafts in miniature swine. J Oral Maxillofac Surg $\underline{51}$, 898-903

Donovan M, Dickerson N, Hanson L, Gustafson RB (1994): Maxillary and mandibular reconstruction using calvarial bone grafts and Brånemark implants. J Oral Maxillofac Surg $\underline{52}, 588-594$

Eickholz P: Parodontologie von A bis Z: Grundbgriffe für die Praxis. 1. Auflage; Quintessenz Verlag, Berlin 2012

El-Ghannam A, Amin H, Nasr T, Shama A (2004): Enhancement of bone regeneration and graft material resorption using surface-modified bioactive glass in cortical and human maxillary cystic bone defects. Int J Oral Macillofac Implants $\underline{19}$, 184-191

Ettl T, Gosau M, Sader R, Reichert TE (2012): Jaw cysts-filling or no filling after enucleation? A review. J Craniomaxillofac Surg $\underline{40}$, 485-493

Felsenberg D (2001): Struktur und Funktion des Knochens: Stützwerk aus Kollagen und Hydroxylapatit. Pharm Unserer Zeit 30, 488-494

Felsenberg D, Boonen S (2005): The bone quality framework: determinants of bone strength and their interrelationships, and implications for osteoporosis management. Clin Ther 27, 1-11

Fickl S, Kebschull M, Schupbach P, Zuhr O, Schlagenhauf U, Hürzeler MB (2011): Bone loss after full-thikness and partial-thikness flap elevation. J Clin Periodontol $\underline{38}$, 157-162

Friedmann S (2005): The prognosis and expected outcome of apical surgery. Endod Topics $\underline{11}$, 219-262 
Geiger M, Blem G, Ludwig A (2016a): Elaboration and evaluation of a SOP for relative bone density measurements in the jaw using ImageJ. Esthetic Stomatology and Implantology (Естетична Стаматология и Импланталогия) 2, 47-53

Geiger M, Blem G, Ludwig A (2016b): Evaluation of ImageJ for relative bone density measurement and clinical application. J Oral Health Craniofac Sci 1, 12-21

Gelfand M, Sunderman E, Goldman M (1983): Reliability of radiographical interpretations. J Endod $\underline{9}, 71-75$

Gernreich NC, Gerhardus A, Velasco-Garrido M: Knochen- und Knochenersatzmaterialien zur parodontalen Regeneration und zum Knochenaufbau für Implantate: eine systematische Bewertung der medizinischen Wirksamkeit. Asgard-Verlag, Sankt Augustin 2003

Gottlow J, Nyman S, Lindhe J, Karring T, Wennström J (1986): New attachment formation in the human periodontium by guided tissue regeneration. Case reports. J Clin Periodontol $\underline{13}, 604-616$

Götz W (2014): Histologische Untersuchungen zur Einheilung von Knochenersatzmaterialien. Ein wissenschaftliches Projekt. Implantologie Journal $\underline{4}$, 8-17

Güven O, Keskin A, Akal UK (2000): The incidence of cysts and tumors around impacted third molars. Int J Oral Macillofac Surg 29, 131-135

Hallmann M, Thor A (2008): Bone substitutes and growth factors as an alternative/complement to autogenous bone for grafting in implant dentistry. Periodontol 2000 47, 172-192

Harel N, Moses O, Palti A, Ormianer Z (2013): Long-term results of implants immediately placed into extraction sockets grafted with $\beta$-tricalcium phosphate: a retrospective study. J Oral Maxillofac Surg $\underline{71}, 63-68$

Hauschild G, Bader A (2004): Vor- und Nachteile synthetischer versus xenogener Knochenersatzmaterialien. Tierärztliche Praxis Kleintiere 32, 67-70

Hille R (2005): Alveolar Ridge Preservation: Knochenaufbau nach Extraktion. Feldstudie der DGZI. Implantologie Journal $\underline{1}, 12-18$

Hirsch J, Ahlström U, Henrikson P, Heyden G, Peterson L (1979): Periapical surgery. Int J Oral Surg $\underline{8}, 173-185$

Hirsch R, Clarke G (1989): Differential diagnosis of severe periodontal lesions. Aust Dent J $\underline{34}$, 548-558

Horch H-H, Sader R, Pautke C, Neff A, Deppe H, Kolk A (2006): Synthetic, pure-phase betatricalcium phosphate ceramic granules (Cerasorb ${ }^{\circledR}$ ) for bone regeneration in the reconstructive surgery of the jaws. Int J Oral Maxillofac Surg $\underline{35}, 708-713$

Horowitz RA, Mazor Z, Miller RJ, Krauser J, Prasad HS, Rohrer MD (2009a): Clinical evaluation alveolar ridge preservation with a beta-tricalcium phosphate socket graft. Compend Contin Educ Dent $\underline{30}, 588-590$ 
Horowitz RA, Rohrer MD, Prasad HS, Mazor Z (2009b): Enhancing extraction. Socket therapy. JIACD $1,47-58$

Horowitz RA, Mazor Z, Foitzik C, Prasad H, Rohrer M, Palti A (2009c): B-tricalcium phosphate as bone substitute material: properties and clinical applications. Int J Dent Implants Biomater $\underline{2009}, 2-11$

Ihan Hren N, Miljavec M (2008): Spontaneous bone healing of the large bone defects in the mandible. Int J Oral Maxillofac Surg 37, 1111-1116

Jäger M, Westhoff B, Wild A, Krauspe R (2005): Knochenspanentnahme am Becken, Techniken und Probleme. Orthopäde 2005, 1-34

Jensen J, Sindet-Petersen S (1991): Autogenous mandibular bone grafts and osseointegrated implants for reconstruction of the severely atrophied maxilla: a preliminary report. J Oral Maxillofac Surg $\underline{49}, 1277-1287$

Johansson B, Grepe A, Wannfors K (1998): CT-scan in assessing volumes of bone grafts to the heavily resorbed maxilla. J Craniomaxillofac Surg $\underline{26}, 85$

Johansson B, Grepe A, Wabbfors K, Hirsch J (2001): A clinical study of changes in the volume of bone grafts in the atrophic maxilla. Dentomaxillofac Rad 30, 157-161

Kalk WW, Raghoebar GM, Jansma J, Boering G (1996): Morbidity from iliac crest bone harvesting. J Oral Maxillofac Surg 54, 1424-1429

Karring T, Nyman S, Gottlow J, Laurell L (1993): Development of the biological concept of guided tissue regeneration - animal and human studies. Periodontol $2000 \underline{1}, 26-35$

Khoury F, Hanser T: Augmentative Verfahren in der Implantologie. Quintessenz, Berlin 2009

Kim S, Kratchman S (2006): Modern endodontic surgery concepts and practice: a review. J Endod $\underline{32}$, 601-623

Klemetti E, Vainio $P$ (1993): Effect of bone mineral density in skeleton and mandible on extraction of teeth and clinical alveolar height. J Prosthet Dent $\underline{70}, 21-25$

Knabe C, Koch C, Rack A, Stiller M (2008): Effect of ß-tricalcium phosphate particles with varying porosity on osteogenesis after sinus floor augmentation in humans. Biomaterials $\underline{29}$, 2249-2258

Kolk A, Handschel J, Drescher W, Rothamel D, Kloss F, Blessmann M, Heiland M, Wolff KD, Smeets R (2012): Current trends and future perspectives of bone substitute materials from space holders to innovative biomaterials. J Craniomaxillofac Surg $\underline{40}, 706-718$

Kondo N, Ogose A, Tokunaga K, Ito T, Arai K, Kudo N, Inoue H, Irie H, Endo N (2005): Bone formation and resorption of highly purified beta-tricalcium phosphate in the rat femoral condyle. Biomaterials $\underline{26}$, 5600-5608

Lan Levengood SKL, Polak SJ, Wheeler MB, Maki AJ, Clark SG, Jamison RD, Wagoner Jonson AJ (2010): Multiscale osteointegration as a new paradigm for the design of calcium phosphate scaffolds for bone regeneration. Biomaterials $\underline{31}$, 3552-3563 
Laurencin CT, El-Amin SF (2008): Xenotransplantation in orthopaedic surgery. J Am Acad Orthop Surg $\underline{16}$, 4-8

Le Geros RZ (1988): Calcium phosphate materials in restorative dentistry: a review. Adv Dent Res $\underline{2}, 164-180$

Lekholm U, Zarb G: Patient selection and preparation. In: Brånemark PI, Zarb G (Hrsg.): Tissueintegrated prostheses: osseointegration in clinical dentistry. Quintessence Publishing Company, Chicago 1985, 199-209

Lindeboom JAH, van den Akker HP (2003): A prospective placebo-controlled double-blind trial of antibiotic prophylaxis in intraoral bone grafting procedures: a pilot study. Oral Surg Oral Med Oral Pathol Oral Radiol Endod $\underline{96}$, 669-672

Lindh C, Nilsson M, Klinge B, Petersson A (1996): Quantitative computed tomography of trabecular bone in the mandible. Dentomaxillofac Rad $\underline{25}, 146-150$

Lu JX, Flautre B, Anselme K, Hardouin P, Gallur A, Descamps M, Thierry B (1999): Role of interconnection in porous bioceramics on bone recolonization in vitro and vivo. $J$ Mater Sci/Mater Med 10, 111-120

Marx RE, Garg AK (1998): Bone structure, metabolism, and physiology: its impact on dental implantology. Implant Dent 그, 267-276

Maus U, Andereya S, Gravius S, Ohnsorge AK, Siebert CH, Kaufmann MM, Niedhart C (2007): Klinische Erfahrungen mit dem resorbierbaren Knochenersatzstoff Cerasorb ${ }^{\oplus}$. Orth $\operatorname{Prax} \underline{43}, 258-261$

Merten H, Hönig J, Wiltfang J, Ficker J, Luhr H (1994): Verschluß von Trepanationsdefekten mit porösen HA-Blöcken beim Minipig. Bedeutung des Critical-size-defect (CSD) für die Evaluierung osteokonduktiver Eigenschaften von Knochenersatzmaterialien. Z Zahnärztl Implantol 10, 199-211

Merten HA, Gruber RM, Nitsch A, Ludwig A, Schliephake H (2003): Evaluation oralchirurgischer Augmentationsmaterialien - Ein tierexperimentell-histomorphologischer Vergleich. Implantologie 11, 215-236

Mikkonen M, Kullaa-Mikkonen A, Kotilainen R (1983): Clinical and radiologic re-examination of apicoectomized teeth. Oral Surg Oral Med Oral Pathol $\underline{55}, 302-306$

Misch C (1990): Density of bone: effect on treatment plans, surgical approach, healing and progressive loading. Int J Oral Implantol $\underline{6}, 23-31$

Misch C, Judy K (1987): Classification of partially edentollous arches for implant dentistry. Int J Oral Implantol $\underline{4}, 7-13$

Misch C, Dietsch F (1993): Bone-grafting materials in implant dentistry. Implant Dent $\underline{2}, 158-$ 167

Molven O, Halse A, Fristad I (2002): Long-term reliability and observer comparisons in the radiographic diagnosis of periapical disease. Int Endod J 35, 142-147

Mulliken J, Glowacki J (1980): Induced osteogenesis for repair and construction in the craniofacial region. Plast Reconstr Surg $\underline{65}, 553-560$ 
Nair PN, Luder HU, Maspero FA, Fischer JH, Schug J (2006): Biocompatibility of beta-tricalcium phosphate root replicas in porcine tooth extraction sockets - a correlative histological, ultrastructural, and X-ray microanalytical pilot study. J Biomater Appl $\underline{20}$, 307-324

Nentwig GH: Wurzelspitzenresektion. In: Horch H-H, Becker J, Haunfelder D, Diedrich P (Hrsg.): Zahnärztliche Chirurgie. Urban \& Fischer Verlag, München 2003, 178-200

Nevins M, Mellonig JT: Implantattherapie. Erfolgreiche klinische Methoden. Band 2; Quintessence Verlag, Berlin 1999

Nevins M, Camelo M, De Paoli S, Friedland B, Schenk RK, Parma-Benfenati S, Simion M, Tinti C, Wagenberg B (2006): A study on the fate of the buccal wall of extraction sockets of the teeth with prominent roots. Int J Periodontics Restorativ Dent 26, 19-29

Niedhart C, Pingsmann A, Jurgens C, Marr A, Blatt R, Niethard FU (2003): Complications after harvesting of autologous bone from the ventral and dorsal iliac crest - a prospective, controlled study. Z Orthop $\underline{141}, 481-486$

Norton MR, Gamble C (2001): Bone classification: an objective scale of bone density using the computerized tomography scan. Clin Oral Implants Res $\underline{12}, 79-84$

Palm F, Hilscher C, Kind M (2006): Einsatz einer neuen synthetischen, phasenreinen ß-TCP Keramik in der Mund- Kiefer- und Gesichtschirurgie - Eine offene Studie mit $n=121$ Patienten. Implantologie Journal $\underline{4}, 6-11$

Palti A, Hoch T (2002a): A concept for the treatment of various dental bone defects. Implant Dent $11,73-78$

Palti A, Hoch T (2002b): Membranen in der chirurgischen Zahnarztpraxis. Eine Bestandsaufnahme. Implantologie Journal $\underline{4}, 8-14$

Peters F, Reif $D$ (2004): Functional materials for bone regeneration from beta-tricalcium phosphate. Mater Werkst 35, 203-207

Plenk H, Lederer J (2008): Cerasorb ${ }^{\circledR}$ : Materialkundliche Grundlagen und klinischhistomorphologische Erfahrungen. Zahn Krone $\underline{5}$, 16-20

Quayle AA (1990): Atraumatic removal of teeth and root fragments in dental implantology. J Oral Maxillofac Implants $\underline{5}$, 293-296

Reinert S, König S, Bremerich A, Eufinger H, Krimmel M (2003): Stability of bone grafting and placement of implants in the severely atrophic maxilla. Br J Oral and Maxillofac Surg $\underline{41}, 249-255$

Reit C, Gröndahl HG (1983): Application of statistical decision theory to radiographic diagnosis of endodontically treated teeth. Scand J Dent Res $\underline{91}, 213-218$

Reit C, Hollender L (1983): Radiographic evaluation of endodontic therapy and the influence of observer variation. Scand J Dent Res $\underline{91}$, 205-212

Ruffieux K, Köhli M: Knochenaufbau Werkstofftechnologie und klinisches Handbuch EasyGraft/Easy-Graft Crystal. 1. Aufl; Eigenverlag DS Dental, Schlieren 2010 
Saldanha JB, Casati MZ, Neto FH, Sallum EA, Nociti FH (2006): Smoking may affect the alveolar process dimensions and radiographic bone density in maxillary extraction sites: a prospective study in humans. J Oral Maxillofac Surg 64, 1359-1365

Sandhu HS, Grewal HS, Parvataneni H (1999): Bone grafting for spinal fusion. Orthop Clin North Am 30, 685-698

Saunders MB, Gulabivala K, Holt R, Kahan RS (2000): Reliability of radiographic observations recorded on a proforma measured using inter- and intra-observer variation: a preliminary study. Int Endod J 33, 272-278

Schenk RK (1991): Zur Problematik der Knochenersatzstoffe: Histophysiologie des Knochenumbaus und der Substitution von Knochenersatzstoffen. Hefte Unfallheilkd $\underline{216}, 23-35$

Schermer SW (2006): Defektrekonstruktion mit alloplastischen Knochenersatzmaterialien. Implantation bei reduziertem und stark reduziertem Knochenangebot. Oralchir J 2006, 22-26

Schlegel AK, Donath K (1998): Bio-Oss ${ }^{\circledR}$ - A resorbable bone substitute? J Long Term Eff Med Implants $\underline{8}, 201-209$

Schmitz J, Hollinger O (1986): The critical size defect as an experimental model for craniomandibulofacial nonunion. Clin Orthop 205, 299-308

Schulte W (1960): Die Eigenblutfüllung: Eine neue Methode zur Versorgung größerer Knochendefekte nach intraoralen Eingriffen. Dtsch ZahnarztI Z 15, 910-914

Schulte W (1965): Die Knochenregeneration nach der Ausschälung großer Kieferzysten und ihre Konsequenzen für die Operationstechnik. Dtsch Zahn Mund Kieferheilkd $\underline{45}$, 177206

Schwartz Z, Weesner T, van Dijk S, Cochran DL, Mellonig JT, Lohmann CH, Carnes DL, Goldstein $M$, Dean DD, Boyan BD (2000): Ability of deproteinized cancellous bovine bone to induce new bone formation. J Periodontol $\underline{71}, 1258-1268$

Schwenzer N, Ehrenfeld M: Zahnärztliche Chirurgie. 3. Auflage; Thieme, Stuttgart 2000

Schwenzer N, Ehrenfeld M: Chirurgische Grundlagen. 4. Auflage; Thieme, Stuttgart 2008

Schwenzer N, Ehrenfeld M: Zahnärztliche Chirurgie. 4. Auflage; Thieme, Stuttgart 2009

Sclar AG (1999): Preserving alveolar ridge anatomy following tooth removal in conjunction with immediate implant placement. The biocol technique. Atlas Oral Maxillofac Surg Clin North Am $\underline{7}, 39-59$

Shapurian T, Reiser G, Griffin T, Rand W (2006): Quantitative evaluation of bone density using the Houndsfield index. Int J Oral Macillofac Implants 21, 290-297

Shokier HM, Khalifa GA (2009): Assessment of bone healing in large bony defects after enucleation of jaw cysts without using any graft material using direct digital radiographie and c. t. scan (clinical study). Cairo Dent J $\underline{25}, 35-42$ 
Smeets R, Hanken H, Jung O, Rothamel D, Handschel J, Al-Dam A, Blessmann M, Heiland M, Kolk A (2014a): Knochenersatzmaterialien. Aktueller Stand und ein Ausblick in die Zukunft. MKG-Chirurg $\underline{7}, 53-67$

Smeets R, Jung O, Hanken H, Hartjen P, Al-Dam A, Gröbe A, Heiland M, Gosau M, Rothamel D, Schlee $M$ (2014b): Was können regenerative Materialien in der Zahnmedizin leisten und wo sind die Grenzen? Dtsch Zahnärztl Z 69, 708-721

Smolka W, Eggensperger N, Carollo V, Ozdoba C, lizuka T (2006): Changes in the volume and density of calvarial split bone grafts after alveolar ridge augmentation. Clin Oral Implants Res 17, 149-155

Spiekermann H, Donath K, Hassell TM, Jovanovic S, Richter EJ: Implantology. Georg Thieme Verlag, Stuttgart 1995

Swart JG, Allard RH (1985): Subperiosteal onlay augmentation of the mandible: a clinical and radiographic survey. J Oral Maxillofac Surg $\underline{43}, 183-187$

Szabo G, Barabas J, Nemeth Z, Hrabak K, Suba Z (2005): Vergleich von autologem Knochen mit $ß$-Tricalciumphosphat bei bilateralem Sinuslift. Eine prospektive, randomisierte klinische Studie mit histologischer und histomorphometrischer Auswertung. Implantologie Journal $\underline{6}, 50-53$

Tadic D, Epple M (2004): A thorough physicochemical characterisation of 14 calcium phosphate based bone substitution materials in comparison to natural bone. Biomaterials $\underline{25}$, 987-994

Tatum H (1986): Maxillary and sinus implant reconstructions. Dent Clin North Am 30, 207-229

Trombelli L, Farina R, Marzola A, Bozzi L, Liljenberg B, Lindhe J (2008): Modeling and remodeling of human extraction sockets. J Clin Periodontol 35, 630-639

Truhlar R, Ohrenstein I, Morris H, Ochi S (1997): Distribution of bone quality in patients receiving endosseous dental implants. J Oral Maxillofac Surg $\underline{55}, 38-45$

Van der Weijden F, Dell'Acqua F, Slot DE (2009): Alveolar bone dimensional changes of postextraction sockets in humans: a systematic review. J Clin Periodontol $\underline{36}, 1048-1058$

Verhoeven J, Cune MS, Terlou M, Zoon MA, de Putter C (1997): The combined use of endosteal implants and iliac crest onlay grafts in the severely atrophic mandible: a longitudinal study. Int J Oral Macillofac Surg 26, 351-357

Verhoeven J, Ruijter J, Cune MS, Terlou M, Zoon M (2000): Onlay grafts in combination with endosseous implants in severe mandibular atrophy: one year results of a prospective, quantitative radiological study. Clin Oral Implants Res $\underline{11}, 583-594$

Vermeeren JI, Wismeijer D, van Waas MA (1996): One-step reconstruction of the severely resorbed mandible with onlay bone grafts and endosteal implants. A 5-year follow-up. Int J Oral Macillofac Surg 25, 112-115

Wagner W, Al Nawas B: Implantatmaterialien und Konstruktionsprinzipien der Implantate aus chirurgischer Sicht. In: Koeck B, Wagner W u. a. (Hrsg.): Implantologie. Urban \& Fischer Verlag, München 2004, 62-68 
Weiß C: Basiswissen medizinische Statistik. 5. Auflage; Springer Verlag, Heidelberg 2010

Whiteman DH, Berry RL, Green DM (1997): Platelet gel: an autologous alternative to fibrin glue with applications in oral and maxillofacial surgery. J Oral Maxillofac Surg 55, 12941299

Wiltfang J, Schulze-Mosgau S, Schlegel KA (2001): Einfluss von Implantatbett und Implantatlager auf die Osseointegration. ZM 23, 44

Zakariasen K, Scott D, Jensen J (1984): Endodontic recall radiographs: how reliable is our interpretation of endodontic success or failure and what factors affect our reliability? Oral Surg Oral Med Oral Pathol 57, 343-347

Zerbo IR, Bronckers ALJJ, de Lange G, van Beek GJ, Burger EH (2001): Histology of human alveolar bone regeneration with a porous tricalcium phosphate. A report of two cases. Clin Oral Implants Res 12, 379-384

Zerbo IR, Zijderveld SA, de Boer A, Bronckers ALJ, de Lange G, ten Bruggenkate CM, Burger EH (2004): Histomorphometry of human sinus floor augmentation using a porous betatricalcium phosphate: a prospective study. Clin Oral Implants Res $\underline{15}, 724-732$

Zerbo IR, Bronckers ALJJ, de Lange G, Burger EH (2005): Localisation of osteogenic and osteoclastic cells in porous beta-tricalcium phosphate particles used for human maxillary sinus floor elevation. Biomaterials $\underline{26}, 1445-1451$

Zhang M, Powers RMJ, Wolfinbarger LJ (1997): Effect(s) of the demineralization process on the osteoinductivity of demineralized bone matrix. J Periodontol $68,1085-1092$

Zhao Y, Liu B, Wang SP, Wang YN (2010): Computed densitometry of panoramic radiographs in evaluation of bone healing after enucleation of mandibular odontogenic keratocysts. Chin J Dent Res $\underline{13}, 123-126$

Zijderveld SA, Zerbo IR, van den Bergh JP, Schulten EA, ten Bruggenkate CM (2005): Maxillary sinus floor augmentation using a ß-tricalcium phosphate (Cerasorb) alone compared to autogenous bone grafts. Int J Oral Macillofac Implants 20, 432-440

Zijderveld SA, Schulten EAJM, Aartman IHA, ten Bruggenkate, CM (2009): Long-term changes in graft height after maxillary sinus floor elevation with different grafting materials: radiographic evaluation with a minimum follow-up of 4.5 years. Clin Oral Implants Res $\underline{20}, 691-700$ 


\section{Danksagung}

Mein besonderer Dank gilt Herrn PD Dr. Dr. Arwed Ludwig für die Vergabe des interessanten Dissertationsthemas, seine fachliche Beratung und Unterstützung.

Herrn Dr. rer. nat. Klaus Jung und Frau Xenia Schulz aus der Abteilung für Medizinische Statistik danke ich herzlich für die kompetente Betreuung bei der statistischen Auswertung. 